CENTRO UNIVERSITÁRIO FEI

LUIGI GUARINO NETO

\title{
DETERMINAÇÃO DA INFLUÊNCIA DO COMPORTAMENTO DA DEMANDA NA CADEIA DE SUPRIMENTOS DE UMA INDÚSTRIA CIMENTEIRA
}

São Bernardo do Campo

2016 


\section{DETERMINAÇÃO DA INFLUÊNCIA DO COMPORTAMENTO DA DEMANDA NA CADEIA DE SUPRIMENTOS DE UMA INDÚSTRIA CIMENTEIRA}

Dissertação de Mestrado apresentada ao Centro Universitário da FEI, para a obtenção do título de Mestre em Engenharia Mecânica com ênfase em Produção, orientado pelo Prof. Dr. Alexandre Augusto Massote.

São Bernardo do Campo 2016 
Guarino Neto, Luigi.

Determinação da influência do comportamento da demanda na cadeia de suprimentos de uma indústria cimenteira. / Luigi Guarino Neto. São Bernardo do Campo, 2016.

100 f. : il.

Dissertação - Centro Universitário da FEI.

Orientador: Prof. Dr. Alexandre Augusto Massote

1. Simulação de Eventos Discretos. 2. Logística. 3. Cimentos. I. Massote, Alexandre Augusto, orient. II. Título.

CDU 658.5 
Aluno: Luigi Guarino Neto

Título do Trabalho: Determinação da influência do comportamento da demanda na cadeia de suprimentos de uma indústria cimenteira

Área de Concentração: Produção

Orientador: Prof. Dr. Alexandre Augusto Massote

Data da realização da defesa: 03/02/2016

ORIGINAL ASSINADA

\section{Avaliação da Banca Examinadora:}

São Bernardo do Campo,

\section{MEMBROS DA BANCA EXAMINADORA}

Prof. Dr. Alexandre Augusto Massote

Ass. :

Prof. Dr. Wilson de Castro Hilsdorf

Ass.:

Prof. Dr. José Arnaldo Barra Montevech

Ass. :

A Banca Julgadora acima-assinada atribuiu ao aluno o seguinte resultado:

APROVADO \ REPROVADO

\section{VERSÃO FINAL DA DISSERTAČ̃̃O}

APROVO A VERSÃO FINAL DA DISSERTAÇÃO EM QUE FORAM INCLUÍDAS AS RECOMENDAÇÕES DA BANCA

EXAMINADORA
Aprovação do Coordenador do Programa de Pós-graduação

Prof. Dr. Rodrigo Magnabosco 
Dedico este trabalho a Deus e a minha esposa e filha, pela paciência e compreensão. 


\section{RESUMO}

O mercado de cimentos tem como característica uma forte concorrência entre as empresas produtoras que buscam constantemente otimizar seus processos internos para ganhar competitividade e atender o nível de exigências dos consumidores. A gestão da cadeia de suprimentos é um processo extremamente relevante para o negócio, sua configuração precisa estar adequada para garantir o nível de serviço esperado ao mínimo custo, contribuindo para garantir um retorno satisfatório para o capital investido pelos acionistas e mantendo a sua permanência no negócio. Este trabalho tem como proposta realizar uma pesquisa experimental para analisar a cadeia de distribuição de cimento de maneira integrada e avaliar se podem existir benefícios alterando a estratégia logística de distribuição atual no modelo "empurrado" para "puxado", buscando principalmente a redução de custos logísticos. Será apresentada uma proposta de melhoria com objetivo de elevar o desempenho da cadeia de suprimentos bem como da competitividade no mercado. Frente a complexidade dos processos logísticos e variáveis envolvidas nas análises, foi adotado como solução a aplicação de um modelo de simulação por computador utilizando o software Promodel ${ }^{\circledR}$ que se mostra uma ferramenta eficaz e confiável para apoio nas análises e decisões de melhorias de processos e investimentos. Foi possível através do estudo compreender que desde que a demanda possua baixa variabilidade, o fluxo logístico ideal é o empurrado para garantir ganho de escala. Com a elevação do nível de variação da demanda, a ruptura dos estoques se eleva causando perda de vendas e, consequentemente, reduzindo o faturamento e a lucratividade da empresa. A partir de determinado nível de variabilidade na demanda, o fluxo logístico adotado deve ser o puxado. Conclui-se que o comportamento da demanda exerce influência na cadeia de suprimentos da indústria analisada e pode determinar a maneira de se controlar o fluxo de distribuição (puxado ou empurrado) dependendo do nível de variabilidade que possua.

Palavras chave: Cimentos. Logística. Simulação de Eventos Discretos. 


\begin{abstract}
The cement market is characterized by strong competition among companies seeking to constantly optimize its internal processes to increase competitiveness and meet the level of consumer demand. The management of the supply chain is an extremely important process for the business; its configuration must be adequate to ensure the service level expected at a minimum cost, helping to ensure a satisfactory return on the capital invested by shareholders. This paper aims to carry out a case study to analyze the cement distribution chain in an integrated manner and to assess whether there may be benefits by changing the current distribution logistics strategy "pushed" to "pulled", mainly focusing on the reduction of logistics costs. A proposal for improvement in order to raise the performance of the supply chain and market competitiveness will be demonstrated. Faced with the complexity of logistics processes and variables involved in the analysis, we adopted as a solution the utilization of a computer simulation model using Promodel ${ }^{\circledR}$ software that shows to be an effective and reliable tool to support the analysis and processes improvements and investments decisions. It was possible to understand by studying that since the demand has low variability, the ideal logistic flow is pushed to ensure economies of scale. With the rise of demand variation level, the breakdown of stocks rises causing loss of sales and, consequently, reducing the revenues and profitability of the company. From a certain level of variability in demand, the logistics flow adopted should be pulled. It is concluded that the demand behavior has an influence on the analyzed industry supply chain and can determine how to control the flow distribution (pulled or pushed) depending on the level of variability that has.
\end{abstract}

Keywords: Cement. Logistics. Discrete Event Simulation. 


\section{LISTA DE ABREVIATURAS}

ABCP - Associação Brasileira de Cimento Portland

ABNT - Associação Brasileira de Normas Técnicas

CD - Centro de Distribuição

DRE - Demonstração do Resultados do Exercício

EBITDA - Earnings Before Interest, Taxes, Depreciation and Amortization, ou "Lucros antes de juros, impostos, depreciação e amortização", em português

JIT - Just in time, que significa literalmente "na hora certa" ou "momento certo" em português NBR - Denominação de Norma da Associação Brasileira de Normas Técnicas

SCM - Supply Chain Management ou "gestão da cadeia de suprimentos" em português

SMDP - Simulation Model Development Process ou Processo de Desenvolvimento de um Modelo de Simulação em português

SNIC - Sindicato Nacional da Indústria do Cimento 


\section{LISTA DE ILUSTRAÇÕES}

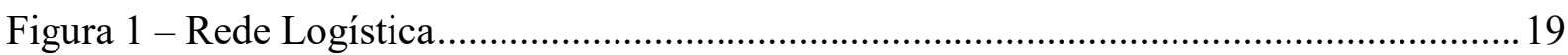

Figura 2 - Estrutura da Cadeia de Suprimentos Integrada .......................................................20

Figura 3 - Vantagem competitiva e os "três C's" ................................................................21

Figura 4 - Curva de Experiência ……………………………………………………...22

Figura 5 - Logística e Vantagem Competitiva ....................................................................23

Figura 7 - Fluxo de Produção Puxado...................................................................................25

Figura 8 - Fluxo de Produção Híbrido ..............................................................................26

Figura 9 - Relação entre estratégias para a cadeia de suprimentos e produtos.........................27

Figura 10 - A relação entre estratégias para a cadeia de suprimentos e produtos. ....................29

Quadro 1 - Características dos trechos empurrados e puxados da cadeia de abastecimento ...30

Figura 11- Evolução dos estados na simulação contínua e discreta ..........................................32

Figura 12 - Modelo como ferramentas para pensar ...................................................................33

Figura 13 - Processo de Desenvolvimento de um Modelo de Simulação ...................................37

Quadro 2 - Elementos e simbologia do IDEF-SIM ................................................................40

Figura 14 - Tela inicial do Promodel $₫$ …………………………………………………...4

Figura 15 - Fábricas de Cimento no Brasil........................................................................50

Quadro 3 - Fábricas de cimento no Brasil ...............................................................................51

Figura 16 - Fluxo de Produção de Cimento …………………………………………….....53

Quadro 4 - Tipos de Cimento no Mercado …………………………………………….......54

Figura 17 - Consumo Aparente de Cimentos......................................................................55

Figura 18 - Distribuição diária média de Cimentos da Fábrica para os CDs e Clientes..........56

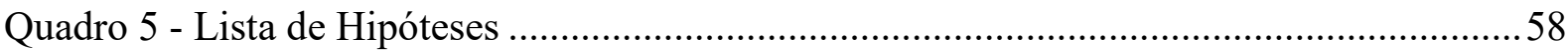

Figura 19 - Cadeia de Suprimento Simulada..........................................................................59

Quadro 6 - Variáveis Dependentes do Modelo de Simulação....................................................61

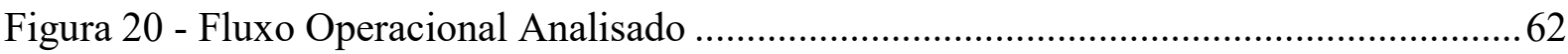




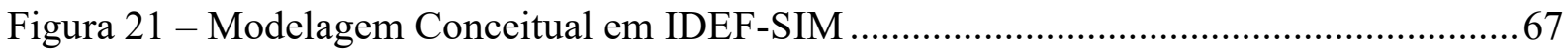

Figura 22 - Modelo Computacional em Promodel ${ }^{\circledR}$. .............................................................. 71

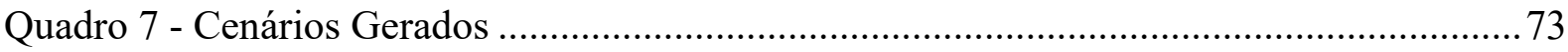

Gráfico 1 - Estoques nos CDs para o fluxo puxado - Cenário I.......................................... 76

Gráfico 2 - Estoques nos CDs para o fluxo empurrado - Cenário II......................................78

Gráfico 3 - Estoques nos CDs para o fluxo puxado - Cenário III ..........................................8 80

Gráfico 4 - Estoques nos CDs para o fluxo empurrado - Cenário IV ................................... 82

Gráfico 5 - Estoques nos CDs para o fluxo puxado - Cenário V ….........................................84

Gráfico 6 - Estoques nos CDs para o fluxo empurrado - Cenário VI ..................................... 86

Gráfico 7 - Estoques nos CDs para o fluxo puxado - Cenário VII …...................................... 88

Gráfico 8 - Estoques nos CDs para o fluxo empurrado - Cenário VIII ...................................90

Gráfico 9 - Comparativo entre cenários - Ruptura (mil tons/ano) .......................................91

Gráfico 10 - Comparativo entre cenários - Lucro Líquido (MM R\$/ano) ..............................91

Gráfico 11 - Fluxo Puxado - Comparativo de Risco de Fornecimento ...................................93

Gráfico 12 - Fluxo Puxado - Comparativo de Risco de Demanda..........................................94

Gráfico 13 - Fluxo Empurrado - Comparativo de Risco de Fornecimento .............................95

Gráfico 14 - Fluxo Empurrado - Comparativo de Risco de Demanda ...................................95 


\section{LISTA DE TABELAS}

Tabela 1 - Variáveis Independentes do Modelo de Simulação 61

Tabela 2 - Tempos de Transporte 66

Tabela 3 - Demandas do Sistema 69

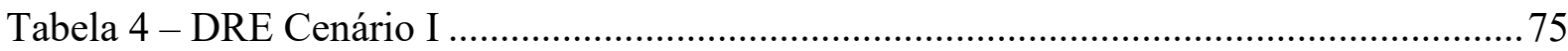

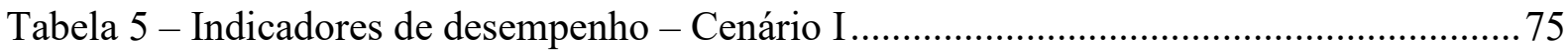

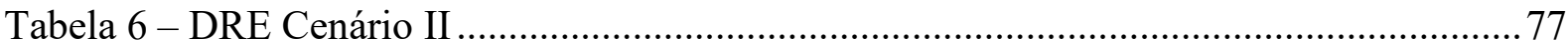

Tabela 7 - Indicadores de desempenho - Cenário II............................................................... 77

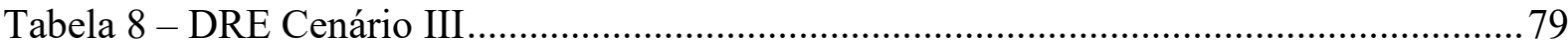

Tabela 9 - Indicadores de desempenho - Cenário III ...................................................... 79

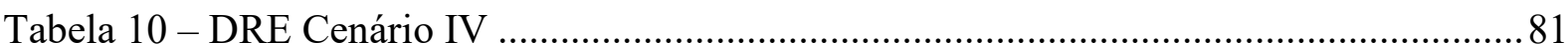

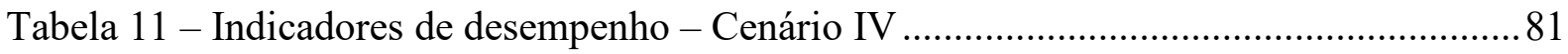

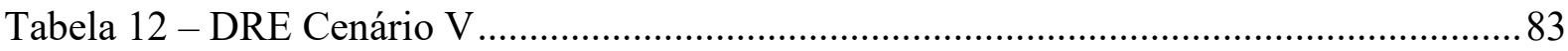

Tabela 13 - Indicadores de desempenho - Cenário V .................................................... 83

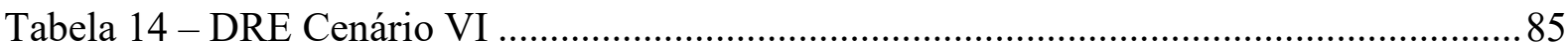

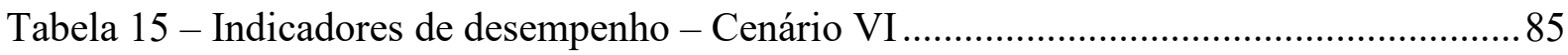

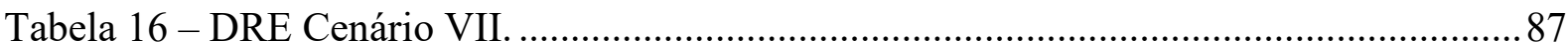

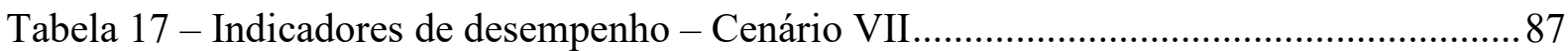

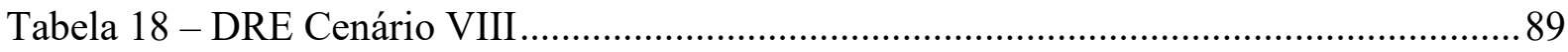

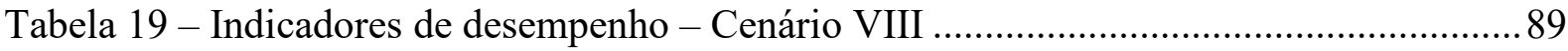

Tabela 20 - Resultados obtidos com a simulação ....................................................................91

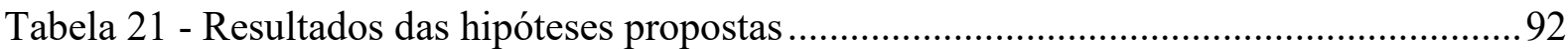




\section{SUMÁRIO}

1 INTRODUÇÃO

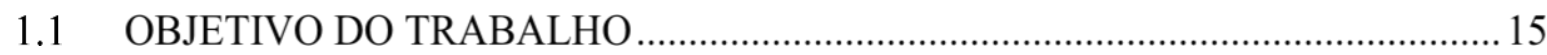

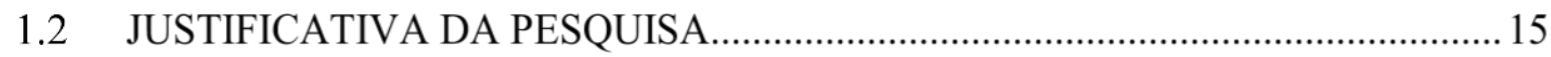

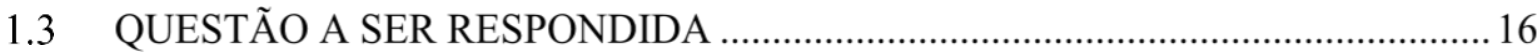

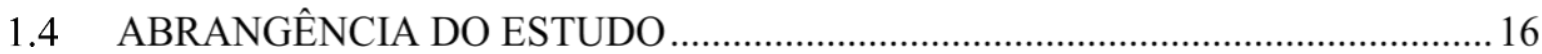

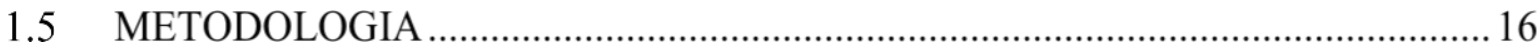

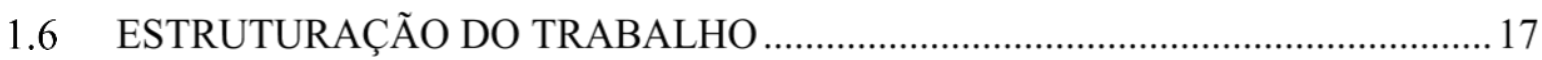

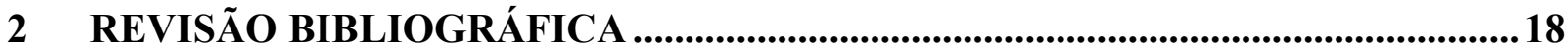

2.1 GESTÃO DA CADEIA DE SUPRIMENTOS ...................................................... 18

2.2 FLUXO DE MATERIAIS: PUXADO X EMPURRADO X HÍBRIDO .....................23

2.2.1 A implementação de uma estratégia empurrada - puxada ...........................29

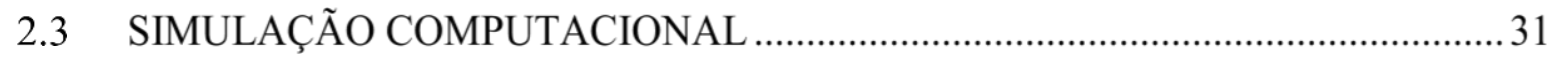

3 DESENVOLVIMENTO DA PESQUISA ........................................................................4

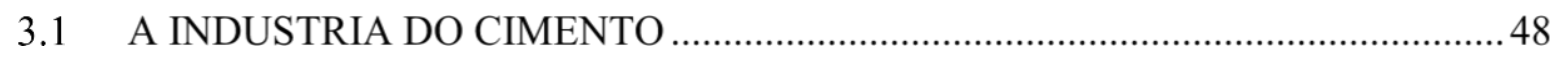

3.1.1 Uma breve história sobre o cimento …………………….......................................48

3.1.2 A indústria do cimento no cenário brasileiro....................................................49

3.1.3 Cadeia Produtiva ....................................................................................................52

3.1.4 Fluxo de Produção do Cimento ………..............................................................52

3.1.5 Tipo de Cimentos .................................................................................................53

3.1.6 Demanda para os próximos anos ...................................................................54

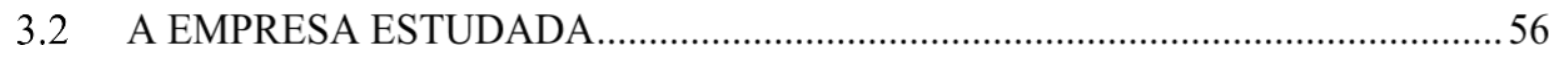

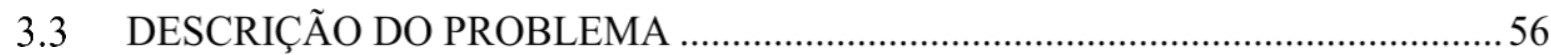

3.4 DESENVOLVIMENTO DA SIMULAÇÃO COMPUTACIONAL ...........................57

3.4.1 Passo 1 - Formulação do problema ....................................................................58

3.4.2 Passo 2 - Especificação dos critérios de desempenho e parâmetros do sistema 
3.4.3 Passo 3 - Desenvolvimento e validação do modelo conceitual ....................... 61

3.4.4 Passo 4 - Coleta de dados ......................................................................... 68

3.4.5 Passo 5 - Desenvolvimento e verificação do modelo computacional .............. 69

3.4.6 Passo 6 - Validação do modelo................................................................... 72

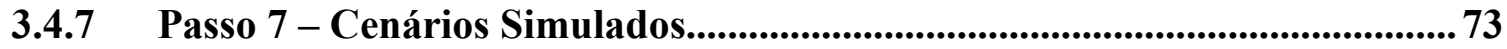

4 PASSO 8 - ANALISE DOS RESULTADOS OBTIDOS........................................... 74

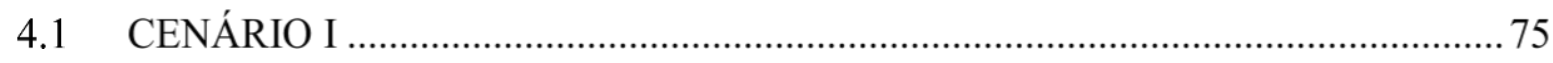

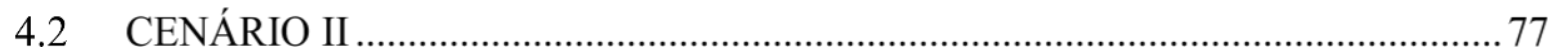

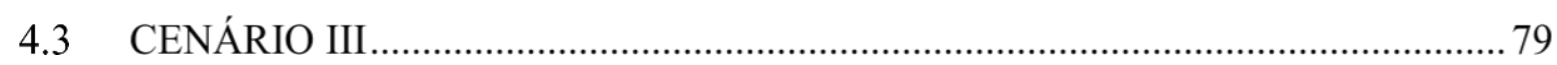

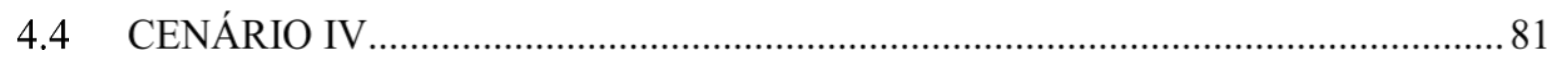

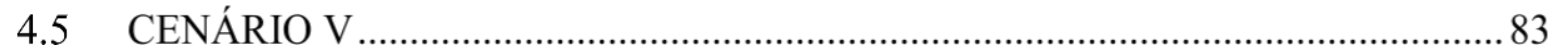

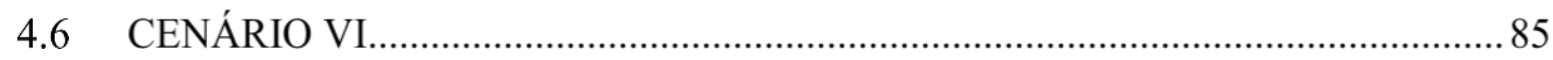

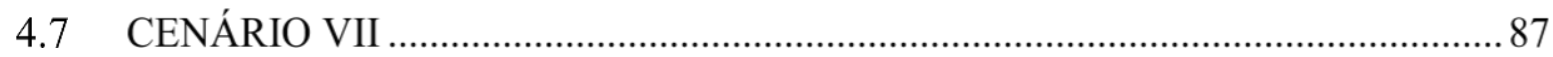

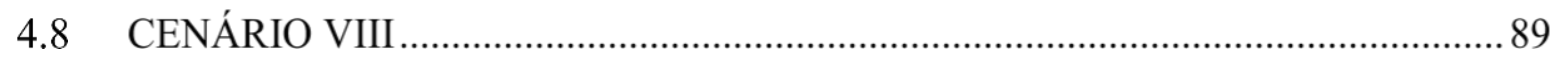

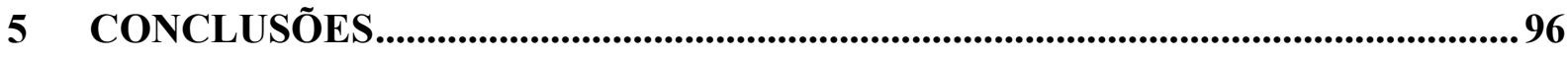

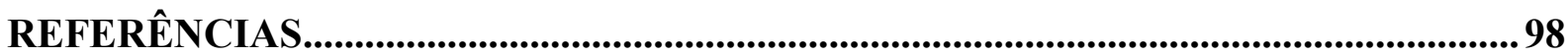




\section{INTRODUÇÃO}

A crescente demanda do país por um produto fundamental na construção civil, o cimento, motiva as empresas produtoras a prepararem suas estruturas para atenderem este mercado competitivo. Um ponto constante de atenção se refere as suas estruturas logísticas, que precisam estar corretamente dimensionadas para não causarem restrições a produção e para não elevarem os custos do produto.

Este trabalho tem como proposta realizar uma simulação computacional para analisar a influência do comportamento da demanda na cadeia de suprimentos de uma indústria cimenteira e avaliar se podem existir benefícios alterando a estratégia logística de distribuição atual no modelo "empurrado" para "puxado", buscando principalmente a redução de custos

logísticos. É apresentada uma proposta de melhoria com objetivo de elevar o desempenho da cadeia de suprimentos bem como da competitividade no mercado.

Frente à complexidade dos processos logísticos e variáveis envolvidas nas análises, adotou-se como solução a aplicação de um modelo de simulação por computador utilizando o software Promodel® que se mostra uma ferramenta eficaz e confiável para apoio as análises e decisões de melhorias de processos e investimentos.

Identifica-se que não é possível de maneira trivial, devido as inúmeras variáveis envolvidas nos processos de distribuição do cimento, avaliar de forma sistêmica e segura os impactos resultantes em alterações significativas nos processos logísticos, o que reforça a necessidade de realizar um estudo que avalie todas as interações da cadeia de distribuição levando em consideração as interdependências entre cada processo logístico.

A intervenção em uma operação real para avaliar mudanças não é uma tarefa fácil de ser realizada e pode trazer grandes impactos financeiros ao negócio se não conduzidas de maneira adequada. A simulação computacional pode realizar a tarefa virtualmente a um custo e riscos muito baixos, por este motivo este tipo de análise é conduzido para que se tenha segurança na tomada de decisão.

Estima-se, a partir de informações obtidas com a empresa analisada, que os custos logísticos envolvidos na produção de cimentos correspondam a cerca de $35 \%$ da receita líquida, sendo assim a compreensão dos processos logísticos e sua racionalização são importantes fatores para a melhoria do sistema e para rentabilidade deste negócio.

A simulação computacional é uma poderosa ferramenta na análise de processos e sistemas complexos, tornando possível o estudo, a análise e a avaliação de situações sem intervenção na vida 
real. Desta maneira, a simulação computacional poderá dar o suporte necessário a tomada de decisões de trade-off ou alternativas de investimentos simulando virtualmente as operações futuras sem que que se façam investimentos prévios.

Este trabalho utiliza o ProModel ${ }^{\circledR}$ para realizar a modelagens propostas. A razão de sua utilização está no fato de ser o software disponível na FEI para a realização de estudos de simulação.

O modelo desenvolvido foi premiado no evento "Simula Brasil 2014", recebendo a primeira colocação na categoria competência, durante o $34^{\circ}$ Encontro Nacional de Engenharia de Produção (ENEGEP).

Análises econômicas foram conduzidas para avaliar a competitividade dos diversos cenários propostos.

\subsection{OBJETIVO DO TRABALHO}

O objetivo deste trabalho é analisar a influência do comportamento da demanda na cadeia de suprimentos de uma indústria cimenteira e avaliar se podem existir ganhos financeiros alterando a estratégia logística de distribuição do modelo "empurrado" para "puxado".

\subsection{JUSTIFICATIVA DA PESQUISA}

A acirrada competição entre as indústrias cimenteiras no país e as maiores expectativas dos clientes por produtos e serviços de maior qualidade e disponibilidade forçam as empresas do segmento a aperfeiçoarem seus processos produtivos buscando redução de custos operacionais.

Historicamente, sabe-se que a demanda pelo cimento obedece certa regularidade, portanto conceitualmente espera-se que o fluxo logístico de distribuição do produto adotado seja empurrado da fábrica para os Centros de Distribuição para que exista ganho de escala no transporte e a garantia de nível de serviço devido a maior proximidade dos clientes. Nota-se, porém, que em determinadas situações de mercado onde exista oscilação na demanda são registrados maiores níveis de ruptura de estoque, afetando a rentabilidade do negócio. É importante analisar a se existem benefícios em se implantar o modelo de distribuição puxado para minimizar perdas financeiras devido a este fator. 
Os custos logísticos na produção de cimento são representativos, estima-se a partir de informações obtidas com a empresa analisada que correspondam a cerca de $35 \%$ de sua receita líquida. Os processos logísticos envolvidos são responsáveis por garantir o nível de serviço ao cliente, sendo assim é importante aplicar esforços para compreender e propor novos processos que possam elevar o patamar das empresas seja em custo ou em nível de serviço.

\subsection{QUESTÃO A SER RESPONDIDA}

A partir dos resultados obtidos pretende-se responder à questão:

a) A distribuição puxada pode trazer valor para a cadeia de distribuição da indústria de cimentos?

\subsection{ABRANGÊNCIA DO ESTUDO}

O presente trabalho restringiu sua pesquisa às operações logísticas de uma indústria do setor cimenteiro, localizada no estado do Rio de Janeiro. Optou-se em analisar a cadeia de distribuição de seu produto de maior representatividade (90\% da produção) que é o cimento ensacado CPIII AF. Os insumos para produção não serão analisados neste momento, o seu recebimento é regular e não causam interferência no processo, sendo considerados como sempre disponíveis. O estudo tem início no CD (Centro de Distribuição) Central da fábrica até a distribuição de cimento ensacado no cliente final.

\subsection{METODOLOGIA}

Segundo Lakatos e Marconi (1991), "método de pesquisa é um conjunto de atividades sistemáticas e racionais que orientam a geração de conhecimentos válidos, indicando um caminho a ser seguido".

De acordo com Gil (2002), pode-se definir pesquisa como o procedimento racional e sistemático que tem como objetivo proporcionar respostas aos problemas que são propostos. A pesquisa é requerida quando não se dispõe de informação suficiente para responder ao problema, ou então quando a informação disponível se encontra em tal estado de desordem que não possa ser adequadamente relacionada ao problema. A pesquisa é desenvolvida mediante o concurso dos conhecimentos disponíveis e a utilização cuidadosa de métodos, técnicas e outros procedimentos. 
Para Miguel (2010) as pesquisas mais utilizadas na engenharia de produção são: Estudo de caso, Survey; Modelagem e simulação, Pesquisa-ação, pesquisa bibliográfica e pesquisa experimental. $\mathrm{O}$ estudo de caso tem como objetivo estudar um determinado fenômeno. Segundo Yin (2005) o estudo de caso destaca-se como melhor estratégia quando são postas questões do tipo "como" e "por que", ou quando o pesquisador tem pouco controle de seus conhecimentos ou quando existe um fenômeno que se encontra na vida real.

A pesquisa do tipo survey, também chamada de pesquisa de avaliação, trata da avaliação de uma amostra significativa de um determinado problema, com a finalidade de extrair conclusões desta amostra (MIGUEL, 2010).

A modelagem e a simulação de acordo com Miguel (2010) é a metodologia que está focada na pesquisa quantitativa e tem como finalidade explicar problemas utilizando equações matemáticas ou modelos de simulação computacional.

A pesquisa bibliográfica tem o objetivo de aprofundar e desenvolver o assunto da pesquisa.

Ainda para Miguel (2010), pesquisas experimentais tratam do estudo de relações causais entre duas ou mais variáveis de um sistema sob condições controladas pelo pesquisador, geralmente em laboratório. As variáveis são manipuladas e controladas pelo pesquisador, que observa os efeitos que estas manipulações produzem no sistema estudado.

O presente trabalho é caracterizado por uma pesquisa quantitativa, e o método utilizado é a simulação computacional de eventos discretos.

\subsection{ESTRUTURAÇÃO DO TRABALHO}

O presente estudo é composto por cinco capítulos.

O primeiro capítulo aborda a visão geral do trabalho e também os objetivos, a justificativa, as questões a serem respondidas, a abrangência do estudo, a metodologia adotada e finalmente a estruturação da dissertação.

O segundo capítulo apresenta uma revisão bibliográfica. O conteúdo da revisão está dividido em três etapas, envolvendo os conceitos sobre Supply Chain, as estratégias para o controle de Fluxo de Materiais e conceitos sobre Simulação Computacional.

O terceiro capítulo apresenta a indústria do cimento, o desenvolvimento do modelo matemático, a simulação das operações em todos os cenários pertinentes.

O quarto capítulo apresenta e analisa os resultados dos cenários simulados. 
A conclusão do trabalho é apresentada no quinto capitulo. Este foca a conclusão do trabalho, resumindo os resultados que são apresentados no item anterior, bem como a resposta à pergunta formulada no item 1.3. Finalmente, neste mesmo capitulo são descritas as sugestões e recomendações para pesquisas futuras, baseadas nesta pesquisa.

\section{REVISÃO BIBLIOGRÁFICA}

Neste capítulo é feita uma revisão da literatura necessária para o desenvolvimento deste trabalho onde são abordados três tópicos:
a) Gestão da Cadeia de Suprimentos
b) Sistemas de Gestão - Puxado x Empurrado x Híbrido
c) Simulação Computacional

\subsection{GESTÃO DA CADEIA DE SUPRIMENTOS}

A acirrada competição nos mercados globais, o aparecimento de produtos com ciclos de vida curtos e as maiores expectativas dos clientes forçam as empresas dos diversos setores a investirem e concentrarem esforços nas suas cadeias de suprimentos. Este cenário, ao lado dos constantes progressos das tecnologias de comunicação e transporte (por exemplo, comunicação móvel, rastreamento, internet e entrega noturna), motivam a constante evolução da cadeia de suprimentos e de diferentes técnicas para sua gestão eficiente.

Simchi Levi, Kaminsky e Simchi Levi (2010) descrevem em sua obra que em uma cadeia de suprimentos típica, matérias-primas são compradas, produtos são manufaturados em uma ou mais fábricas, transportados para depósitos a fim de armazenamento temporário e então transportados para varejistas e clientes. Desta forma, para reduzir custos e melhorar os níveis de serviço, as estratégias eficazes de gestão da cadeia de suprimentos precisam contemplar as interações entre seus diferentes níveis. A cadeia de suprimentos, também chamada de rede logística, consiste em fornecedores, centros de produção, depósitos, centros de distribuição, varejistas, além das matérias-primas, estoques de produtos em processo e produtos acabados que se deslocam entre as instalações (Figura 1), considerando-se também todos os custos envolvidos em cada processo. 
Figura 1 - Rede Logística

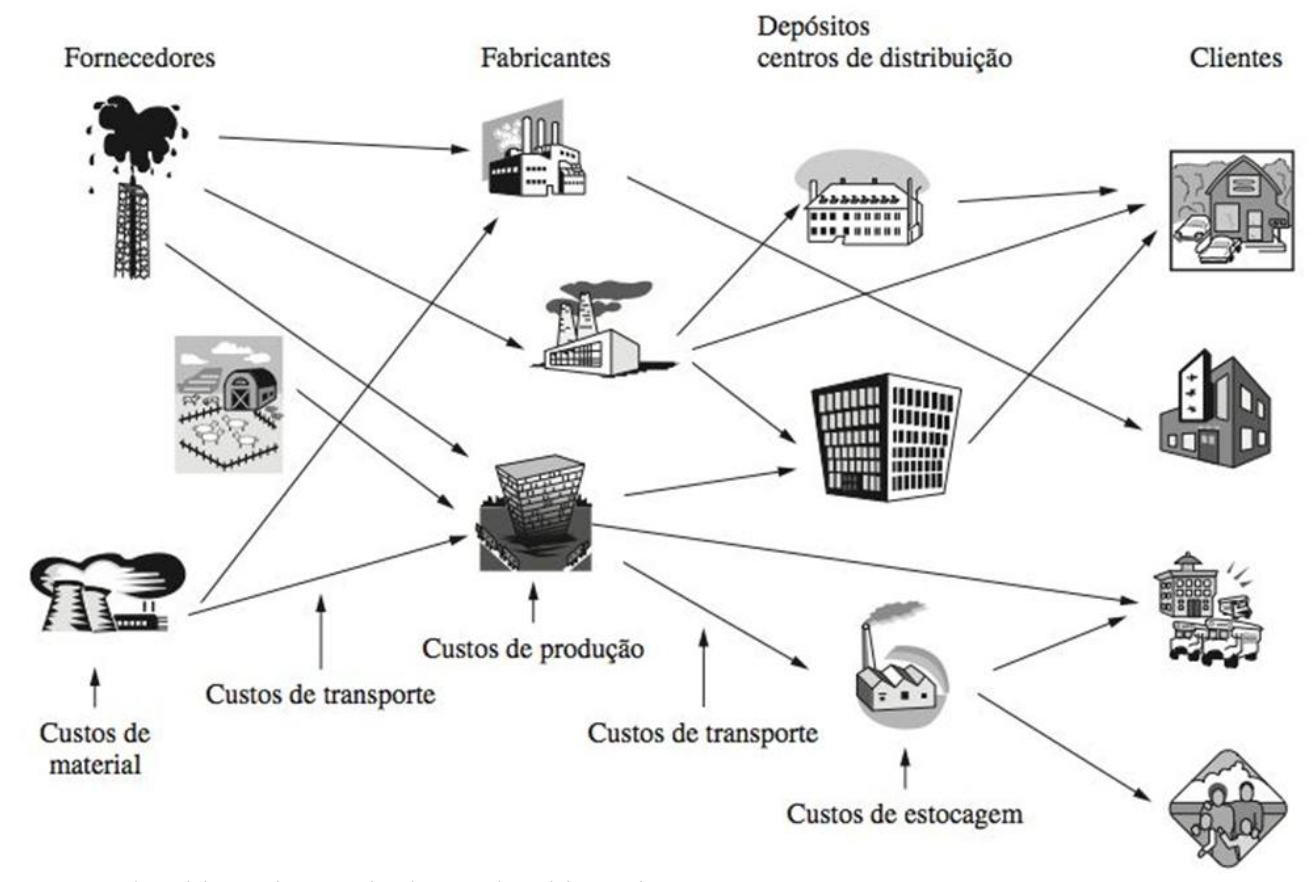

Fonte: Simchi Levi, Kaminsky e Simchi Levi, 2010

Simchi Levi, Kaminsky e Simchi Levi (2010) definem a gestão da cadeia de suprimentos como sendo um conjunto de abordagens que integram, com eficiência, fornecedores, fabricantes, depósitos e pontos comerciais, de forma que a mercadoria é produzida e distribuída nas quantidades corretas, aos pontos de entrega e nos prazos corretos, com o objetivo de minimizar os custos totais do sistema sem deixar de atender as exigências em termos de nível de serviço.

Christopher (2011) define a gestão da cadeia de suprimentos como a gestão de relações a montante e a jusante com fornecedores e clientes, a fim de entregar ao cliente valor superior ao menor custo para toda a cadeia de suprimentos.

Segundo Chopra e Meindl (2003) a gestão da cadeia de suprimentos engloba todos os estágios envolvidos, direta ou indiretamente no atendimento de um pedido de um cliente. Dentro de cada organização, como por exemplo, de uma fábrica, a cadeia de suprimentos inclui todas as funções envolvidas no pedido do cliente, como desenvolvimento de novos produtos, marketing, operação, distribuição, finanças e o serviço de atendimento ao cliente, entre outras.

Cooper, Bowersox e Closs (2007) vão além dessa definição. De acordo com os autores, 
a gestão da cadeia de suprimento implica em uma gestão de relacionamento multi-empresas, inserida numa estrutura caracterizada por limitações de capacidade, de informações, competências essenciais, capital e restrição de recursos humanos. Portanto, a estrutura e a estratégia da cadeia de suprimentos resultam de esforços para conectar operacionalmente uma empresa aos clientes, assim como as redes de apoio à distribuição e aos fornecedores a fim de ganhar vantagens competitivas (Figura 2), atuando de forma integrada.

Figura 2 - Estrutura da Cadeia de Suprimentos Integrada

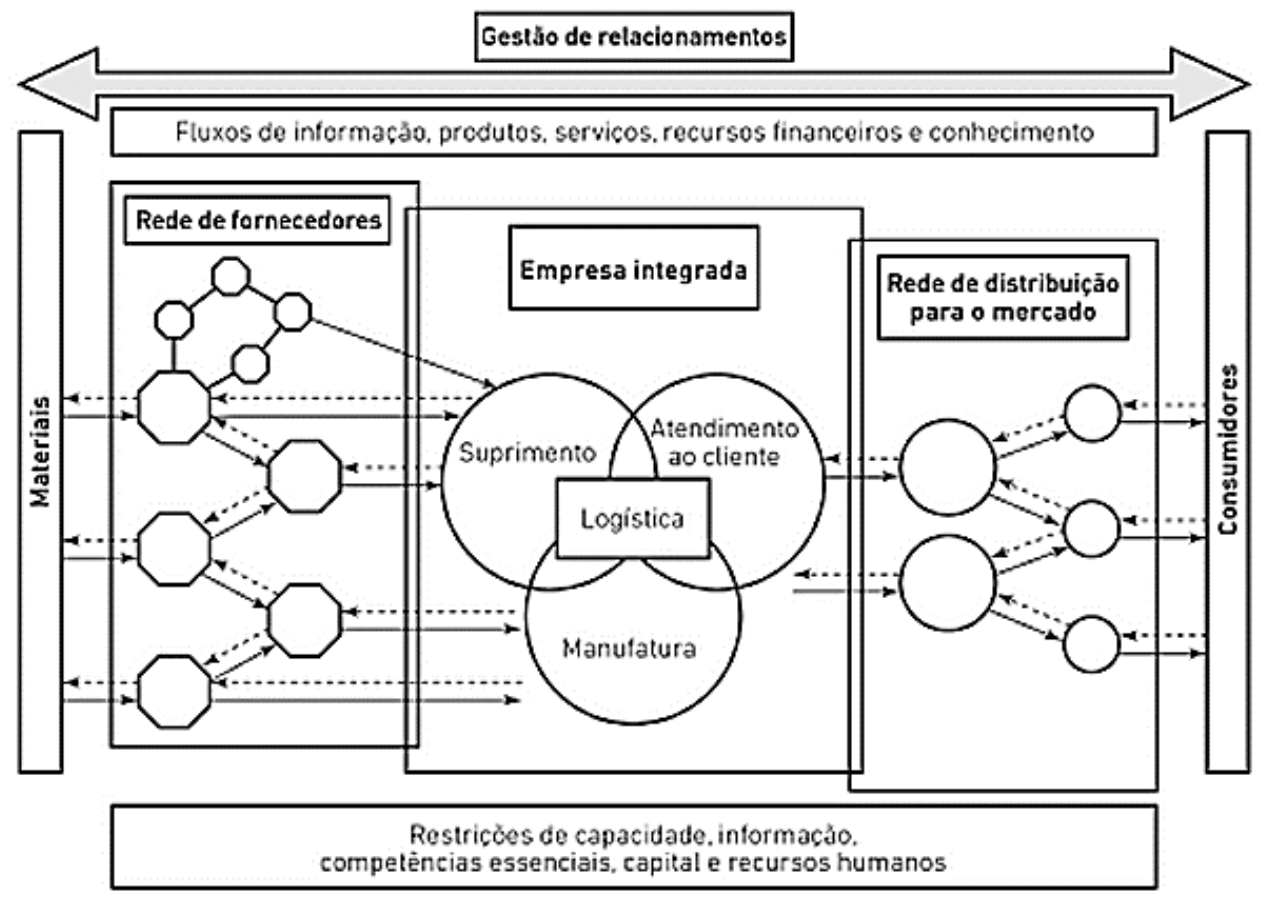

Fonte: Cooper, Bowersox e Closs, 2007

O motivo para a existência de qualquer cadeia de suprimentos é satisfazer as necessidades do cliente, em um processo gerador de lucros. As atividades da cadeia de suprimento iniciam-se com o pedido de um cliente e terminam quando um cliente satisfeito paga pela compra. O termo cadeia de suprimentos representa produtos ou suprimentos que se deslocam ao longo da seguinte cadeia: fornecedores, fabricantes, distribuidores, lojistas e clientes. É importante visualizar os fluxos de informações, monetário e de produtos em ambos os sentidos da cadeia.

O contexto de uma cadeia de suprimentos integrada é a colaboração entre muitas empresas dentro de uma estrutura dos principais fluxos e restrições de recursos, a estrutura e a estratégia da cadeia de suprimentos resultam de esforços para alinhar operacionalmente as 
empresas aos clientes, bem como as redes de apoio de distribuição e abastecimento para obter vantagem competitiva.

A gestão integrada de processos busca identificar e alcançar o menor custo total equilibrando as compensações (trade-off) que existem entre as funções. Portanto, a gestão integrada tem como objetivo alcançar o menor custo total do processo, que não necessariamente significa atingir o menor custo para cada função incluída no processo.

Christopher (2011), reforça que a gestão eficaz da cadeia de suprimentos proporciona importante fonte de vantagem competitiva, em outras palavres, a posição de superioridade duradoura sobre outros concorrentes em termos de preferência dos clientes pode ser alcançada por meio de uma melhor gestão da cadeia de suprimentos.

Christopher (2011) apresenta um modelo simples que representa o enlace triangular entre a empresa, seus concorrentes e os clientes, e a sua relação de três vias (Figura 3).

Figura 3 - Vantagem competitiva e os "três C's"

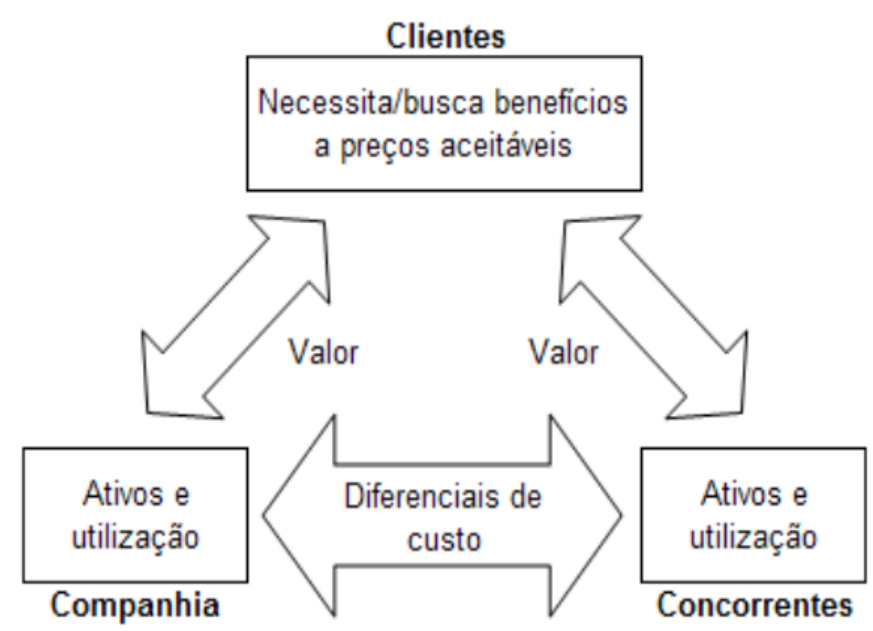

Fonte: Christopher, 2011

Christopher (2011) relata que as vantagens de custo podem ser atribuídas ao ganho de escala das operações, por distribuírem os custos fixos por um valor maior de produção, mas sugere que a principal via de redução de custo é decorrente da "curva de aprendizado". Foi identificado que os trabalhadores se tornam mais habilidosos em tarefas que estão dedicados e é possível prever melhorias nas taxas de produção. A curva descreve a relação entre os custos unitários reais e o volume cumulativo (Figura 4). 
Figura 4 - Curva de Experiência

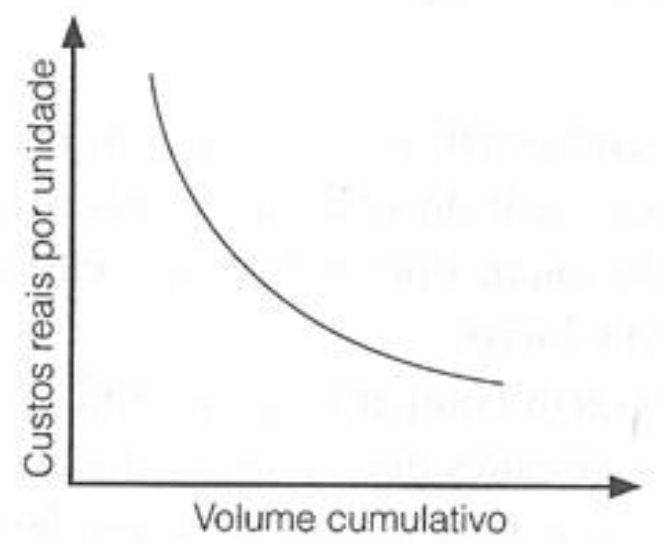

Fonte: Christopher, 2011

Pode -se argumentar que a eficiência e produtividade podem ser alcançadas com melhor gestão da logística e da cadeia de suprimentos, levando a custos unitários do produto bem reduzidos.

$\mathrm{O}$ autor relata que vantagens de valor podem ser intangíveis, ou seja não estão relacionadas com o produto em si, mas a coisas como imagem ou serviços agregados. A menos que o produto possa ser diferenciado dos concorrentes de alguma forma, há forte probabilidade do mercado considera-lo uma "mercadoria" e passar a decidir pela compra do produto do fornecedor mais barato. Daí a necessidade de se buscar agregar vantagens de valor aos produtos para eliminar a concorrência. São diversas as maneiras de agregar valor ao produto como por exemplo o serviço de pós-venda, pacotes financeiros, suporte técnico e assim por diante.

$\mathrm{Na}$ prática as empresas bem-sucedidas são as que buscam atingir em uma posição favorável tanto em custo quanto em valor. Uma maneira de analisar as empresas é utilizar a matriz desenvolvida por Christopher (2011) na Figura 5. 
Figura 5 - Logística e Vantagem Competitiva

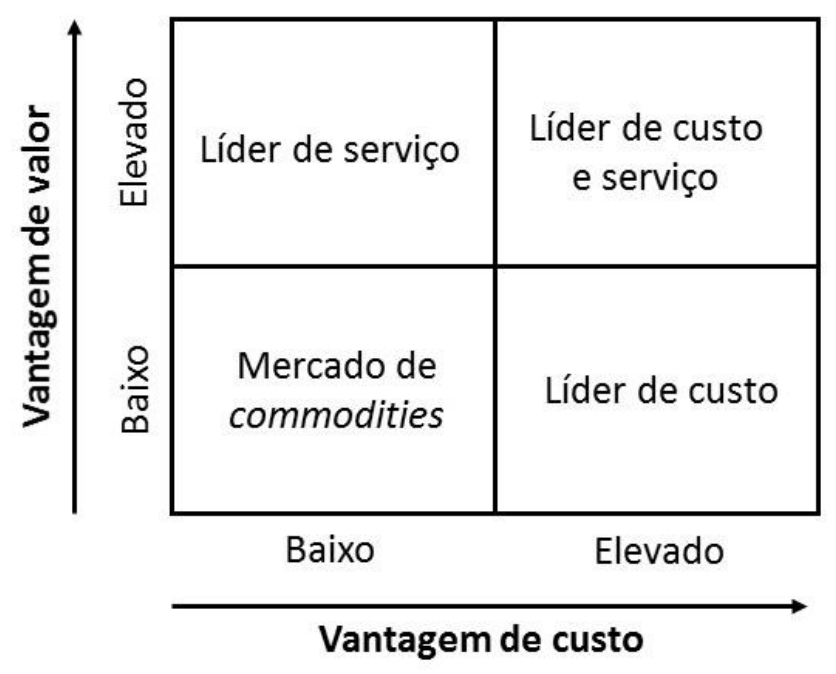

Fonte: Christopher, 2011

Para empresas que se encontram no quadrante inferior esquerdo, pode-se afirmar que seu produto não tem diferenciação alguma de custo ou de valor, são produtos típicos de commodities. As empresas devem buscar estratégias de diferenciação para saírem do quadrante "Mercado de commodities", seja em serviços como por exemplo reduzindo o lead-time, realizando entregas JIT (Just in time), e serviços para melhor atenderem os clientes fazendo com que ela passe para o quadrante superior esquerdo ou seja em custos, através de ganhos obtidos com a reengenharia dos processos logísticos fazendo com que ela passe a atuar no quadrante inferior direito.

Em resumo, Christopher (2011) afirma que as organizações líderes de mercado serão aquelas que buscarem e conquistarem os picos gêmeos da excelência: elas ganharão tanto a liderança de custo quanto a liderança de serviços.

\subsection{FLUXO DE MATERIAIS: PUXADO X EMPURRADO X HÍBRIDO}

Simchi Levi, Kaminsky e Simchi Levi (2010) relatam que a gestão da cadeia de suprimentos gira em torno da integração eficiente entre fornecedores, fabricantes, depósitos e o varejo. Portanto, o desafio para a integração da cadeia de suprimentos consiste em coordenar as atividades ao longo da cadeia de forma que a empresa possa melhorar seu desempenho com: 
a redução de custos, o aumento no nível de serviço, a melhor utilização de recursos e a reação eficaz diante de mudanças no mercado. As estratégias tradicionais da cadeia de suprimentos são muitas vezes classificadas como estratégias empurradas ou puxadas. provável que estes termos tenham se originado na revolução da produção vista na década de 1980, em que os sistemas de produção foram divididos nestas categorias. interessante observar que diversas empresas adotam uma abordagem híbrida, o paradigma da cadeia de suprimentos empurradapuxada.

Corrêa (2010), seguindo a mesma abordagem de Simchi Levi, Kaminsky e Simchi Levi (2010), diz que na gestão estratégica da cadeia de suprimentos uma importante decisão a tomar refere-se à definição correta dos fluxos de materiais e que segundo a literatura eles podem ser empurrados (push em inglês) ou puxados (pull em inglês) ou híbridos (hybrid em inglês).

Corrêa (2010) descreve as características principais de cada fluxo:

Fluxos Empurrados: São aqueles em que as atividades de produção e/ou movimentação de materiais ocorrem antes de um pedido formal de um usuário que se encontre a jusante na rede de suprimento (Figura 6).

Figura 6 - Fluxo de Produção Empurrado

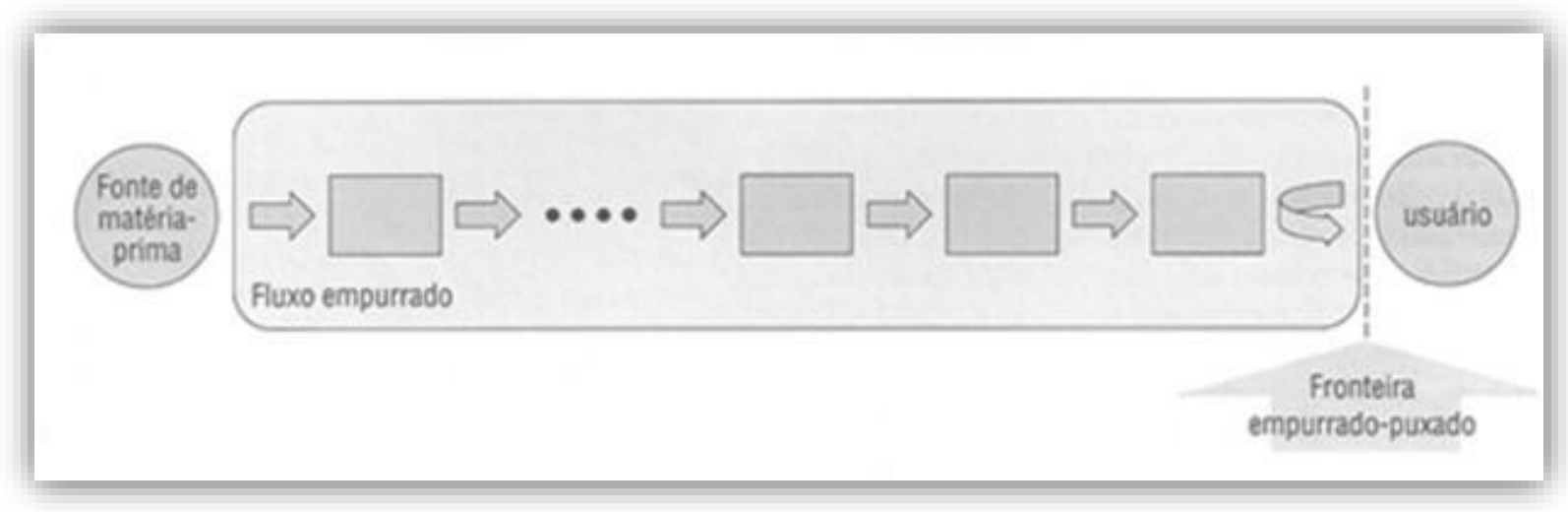

Fonte: Corrêa, 2010

Nesta modalidade as atividades de produção e/ou de movimentação são feitas com base em uma previsão de demanda dos clientes que se encontram a jusante. Com base nesta previsão, os produtos são produzidos e "empurrados" para estágios a jusante da cadeia até que esteja disponível na prateleira, esperando para ser comprado. A produção e/ou o transporte nos sistemas "empurrados" de gestão de fluxo de materiais são feitos antes do cliente colocar o seu pedido de compra. 
Fluxos Puxados: São aqueles em que as atividades de produção e/ou movimentação de materiais só ocorrem depois de um pedido formal de um usuário que se encontre a jusante na rede de suprimento (figura 7).

Figura 7 - Fluxo de Produção Puxado

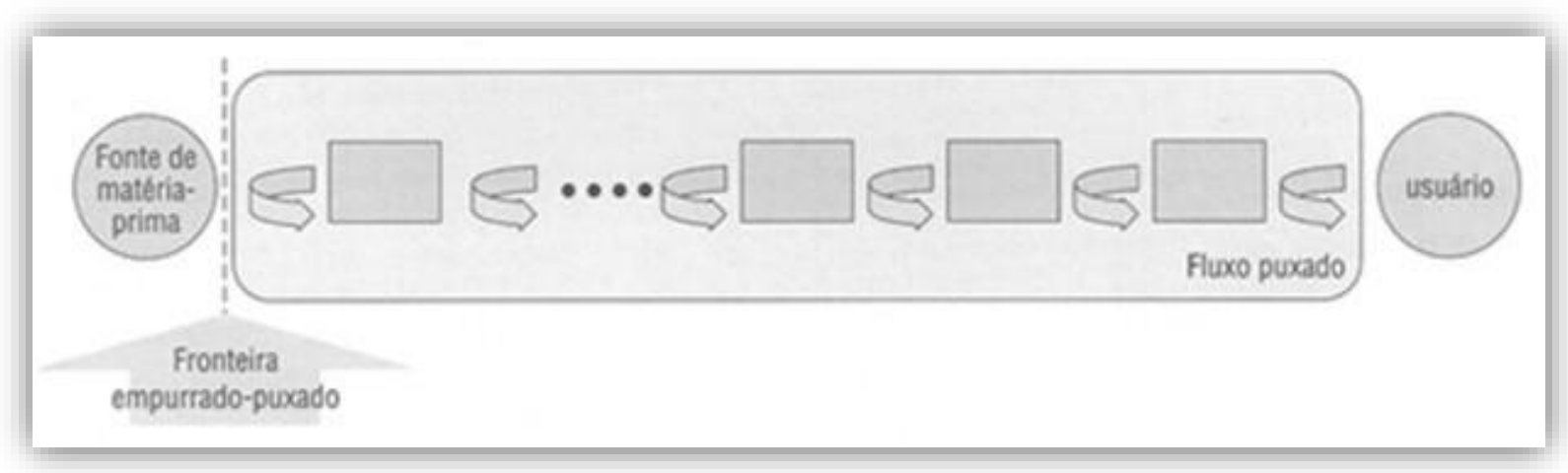

Fonte: Corrêa, 2010

Nesta modalidade as atividades de produção ou de movimentação não são feitas se não houver uma solicitação explicita do cliente. Um exemplo extremo é um produto produzido por encomenda. O fluxo de materiais só ocorre depois da colocação do pedido pelo cliente, ou em outras palavras o fluxo é puxado pela informação dada no pedido do cliente. A produção e/ou o transporte nos sistemas "puxados" de gestão de fluxo de materiais são feitos depois do cliente colocar o seu pedido de compra.

Fluxos Híbridos: Os fluxos híbridos empurrados-puxados ocorrem na maioria das redes de suprimento, nas quais parte dos fluxos (em geral a montante) são empurrados e parte dos fluxos (em geral a jusante) são puxados (Figura 8). 
Figura 8 - Fluxo de Produção Híbrido

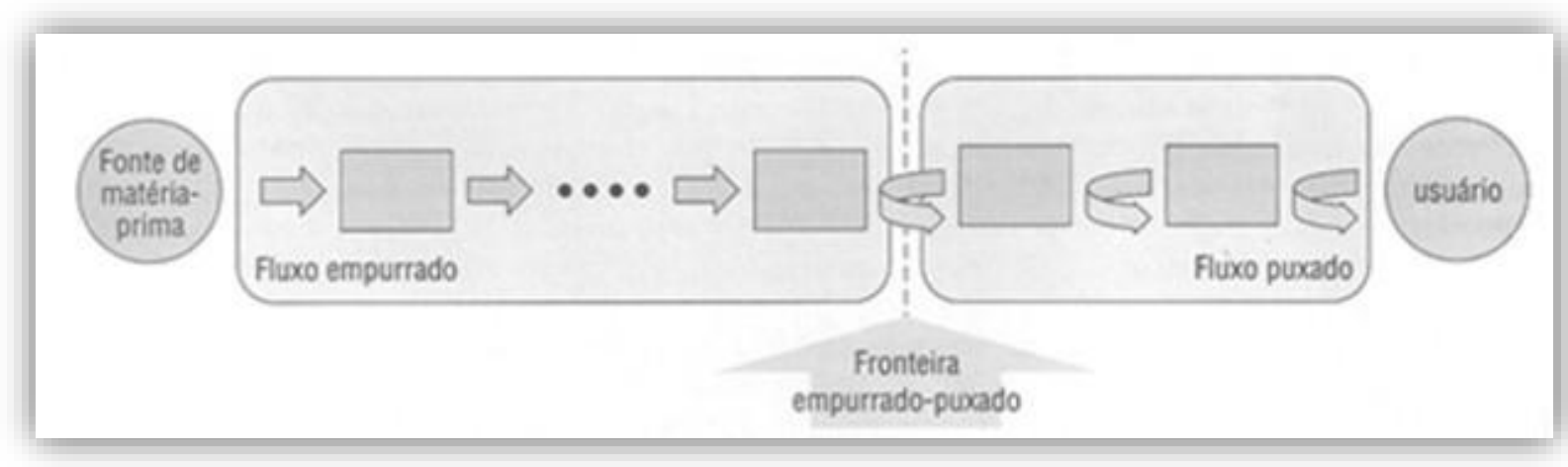

Fonte: Corrêa, 2010

Os fluxos puxados têm como principal vantagem a redução das incertezas, visto que as atividades só são disparadas quando houver um pedido do cliente. As incertezas das previsões e dos processos envolvidos são eliminadas, exigindo-se estoques de segurança menores (eles existem para fazer frente às incertezas) e, portanto, permitindo custos menores. Em compensação os fluxos puxados tendem a ter um tempo lento de resposta já que nada foi feito com antecedência e, portanto, o tempo de espera do cliente, em geral tende a ser longo.

Os fluxos empurrados têm como principal vantagem a velocidade de resposta ao cliente. Como no fluxo empurrado muitas das atividades são realizadas antes do cliente colocar o seu pedido, ele terá que esperar pela realização de relativamente menos atividades depois que coloca seu pedido. Entretanto esta velocidade de resposta tem um custo, como as atividades disparadas antes do cliente colocar seu pedido são baseadas em previsões, o nível de incerteza delas é maior, exigindo assim maiores níveis de estoque de segurança o que aumenta os custos.

Estas vantagens e desvantagens complementares dos sistemas puxados e empurrados levam as empresas a tentarem utilizar ambos. Nesta modalidade híbrida, o sistema empurradopuxado tem parte de seu fluxo empurrado, baseado em previsão (antes do pedido), para encurtar o tempo de resposta por exemplo e parte puxado (com partes das atividades apenas realizadas depois dos pedidos dos clientes, para reduzir assim as incertezas e consequentemente os custos.

Para responder à pergunta sobre a cadeia de abastecimento mais adequada para um determinado produto, Simchi Levi, Kaminsky e Simchi Levi (2010) fornece um quadro de correspondência entre a estratégia da cadeia de abastecimento estratégias com produtos, conforme mostrado na Figura 9. 
Figura 9 - Relação entre estratégias para a cadeia de suprimentos e produtos.

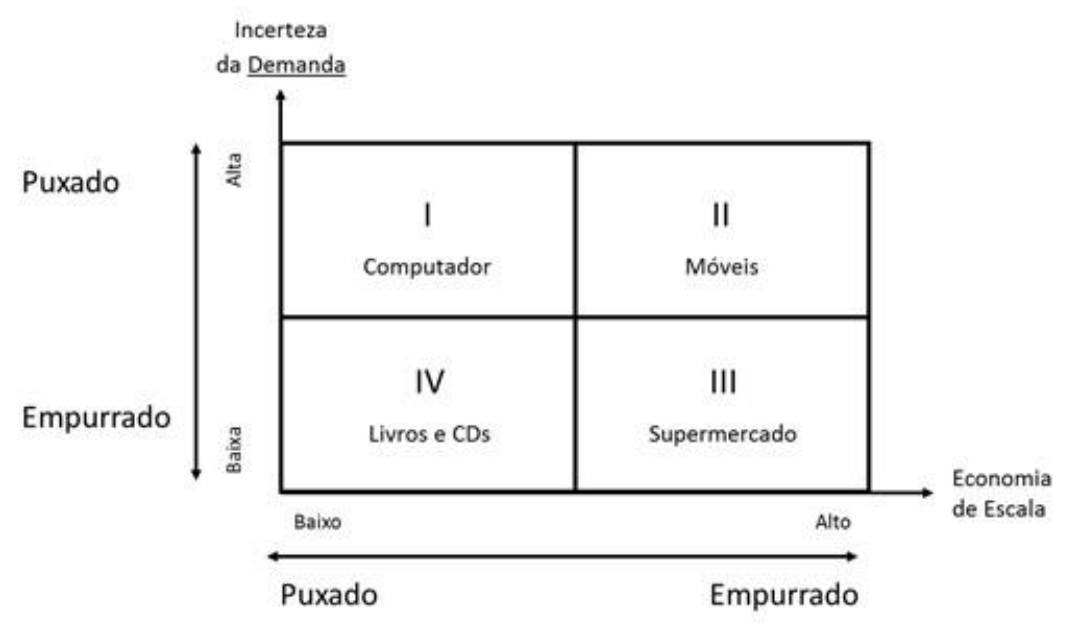

Fonte: Simchi Levi, Kaminsky e Simchi Levi, 2010

Segundo Simchi Levi, Kaminsky e Simchi Levi (2010), o eixo vertical dá informações sobre a incerteza da demanda do produto. O eixo horizontal dá informações sobre a importância da economia de escala na produção ou distribuição.

De acordo com os estudos de Simchi Levi, Kaminsky e Simchi Levi (2010), uma maior incerteza na demanda leva a uma preferência por uma gestão da cadeia de suprimentos com base na demanda realizada: uma estratégia puxada. Em contrapartida, uma menor incerteza na demanda desperta o interesse na administração da cadeia de suprimentos com base em uma previsão de longo prazo: uma estratégia empurrada.

Da mesma forma, mantendo as outras condições inalteradas, quanto maior a importância das economias de escala na redução de custos, maior o valor na agregação da demanda e, assim, maior também a importância de administrar a cadeia de suprimentos com base em uma previsão de longo prazo, isto é, com uma estratégia empurrada. Se as economias de escala não são importantes, então a agregação não reduz custos e a estratégia puxada faz mais sentido.

Na figura 9, o quadrante 1 representa as indústrias (ou, mais precisamente, os produtos) que são caracterizados por elevada incerteza de demanda e situações em que as economias de escala na produção, montagem ou distribuição não são importantes, por exemplo, a indústria de computadores. A estrutura sugere que a estratégia de cadeia de suprimentos puxada é apropriada para estas indústrias e produtos, exatamente o que tem sido aplicado pela Dell Computadores. 
O quadrante III representa produtos que são caracterizados por baixa incerteza de demanda e uma situação em que as economias de escala são muito importantes. Produtos no setor alimentício, como cerveja, massas ou sopa pertencem a essa categoria. A demanda por esses produtos é bastante estável, reduzindo o custo do transporte por fretes de caminhões completos reduzindo os custos na cadeia de suprimento. Portanto, a estratégia tradicional para o varejo é uma estratégia de cadeia de fornecimento empurrada.

Os dois quadrantes representam situações em que é relativamente fácil identificar uma estratégia de cadeia de abastecimento eficiente. O desafio é analisar o restante dos quadrantes.

Evidentemente, nos restantes dois casos há uma incompatibilidade entre as estratégias sugeridas pelos dois atributos, a incerteza e a importância das economias de escala. Por exemplo, o quadrante IV representa produtos caracterizados por baixa incerteza na demanda, indicando uma cadeia de fornecimento empurrada, e situações em que as economias de escala não desempenham um papel importante, o que sugere uma estratégia de cadeia de suprimentos puxada. Como exemplo, muitos livros e CDs caem nesta categoria. Neste caso, uma análise mais cuidadosa é necessária, uma vez que ambos, as estratégias tradicionais de varejo, que é empurrada, e estratégias inovadoras Empurrada-Puxada são apropriadas, dependendo dos custos específicos e incertezas envolvidas.

Finalmente, o quadrante II representa produtos e indústrias para que a incerteza na demanda é alta, enquanto as economias de escala são importantes na redução da produção e/ou despesas de entrega. A indústria moveleira é um excelente exemplo desta situação. Um típico varejista de móveis oferece um grande número de produtos similares que se distinguem pela forma, cor, tecido, etc., e a incerteza da demanda é muito alta. Infelizmente, estes são produtos volumosos e, consequentemente, os custos de entrega também são elevados. Assim, neste caso, não há a necessidade de distinguir entre a produção e a estratégia de distribuição. A estratégia de produção tem que seguir uma estratégia puxada pois é impossível tomar decisões de produção com base em previsões a longo prazo. Por outro lado, a estratégia de distribuição precisa tirar proveito de economias de escala a fim de reduzir o custo de transporte. Esta é exatamente a estratégia empregada por muitos varejistas que não mantêm qualquer estoque de móveis, quando um cliente coloca uma ordem, ela é enviada para o fabricante que adquire o tecido e produz a ordem. Uma vez que o produto esteja pronto, ele é enviado juntamente com muitos outros produtos para a loja de varejo e de lá para o cliente. Para atingir este objetivo, o fabricante normalmente tem um cronograma de entrega fixa e isto é usado para agregar todos produtos que são entregues às lojas na mesma região, reduzindo assim os custos de transporte. 
Por isso, a estratégia da cadeia de fornecimento seguido por fabricantes de móveis é, em certo sentido, uma estratégia Puxada-Empurrada onde a produção é feita com base na demanda, uma estratégia de puxar, enquanto que a entrega é de acordo com um horário fixo, uma estratégia empurrada.

A figura 10 resume quais são as cadeias de abastecimento mais adequadas para um determinado produto conforme Simchi Levi, Kaminsky e Simchi Levi (2010).

Figura 10 - A relação entre estratégias para a cadeia de suprimentos e produtos.

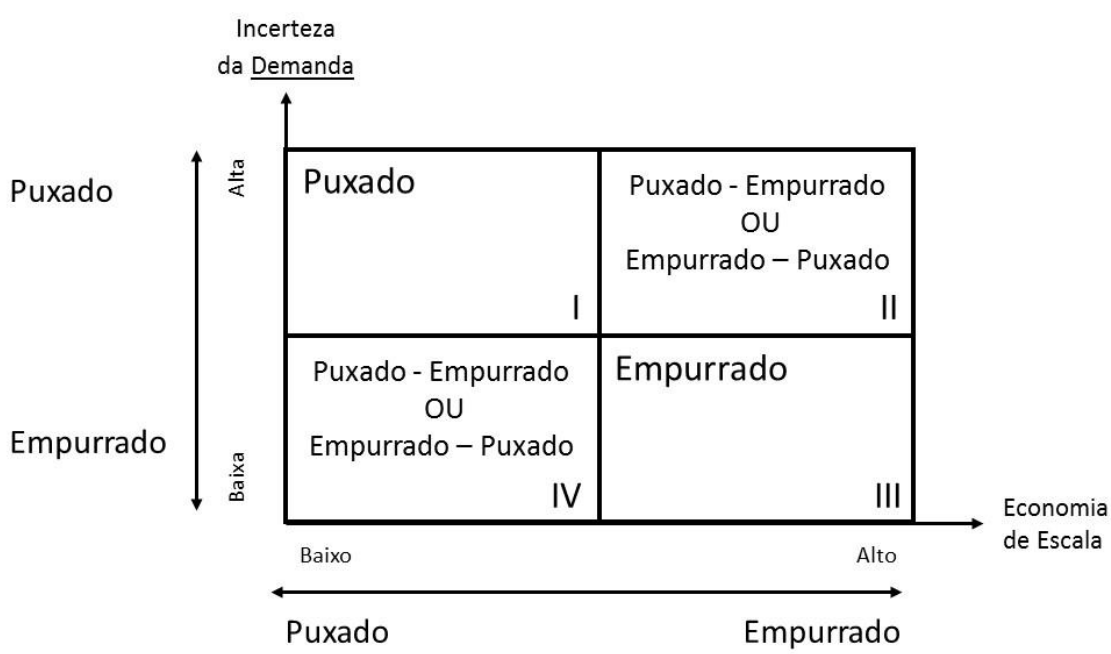

Fonte: Autor “adaptado de” Simchi Levi, Kaminsky e Simchi Levi, 2010

\subsubsection{A implementação de uma estratégia empurrada - puxada}

Segundo Simchi Levi, Kaminsky e Simchi Levi (2010) existem muitas maneiras de implementar uma estratégia de abastecimento empurrada-puxada, dependendo de onde se encontra o limite de empurrar-puxar na cadeia de abastecimento. Por exemplo, a Dell está implementando estratégia empurrada-puxada localizando o limite no ponto de montagem enquanto o fabricante de mobiliário localiza a fronteira no ponto de produção. Existem outros exemplos de indústrias, tais como a automotiva e indústrias de livros, onde o limite está localizado no centro de distribuição do fabricante ou no armazém distribuidor. Evidentemente, o trecho empurrado é aplicado onde a incerteza da demanda é relativamente pequena, assim, 
esta parte com base nas previsões de longo prazo é apropriada. Por outro lado, o trecho puxado é aplicado ao trecho onde a incerteza é alta e, portanto, é importante gerir esta parte da cadeia de fornecimento com base na demanda realizada. Esta distinção entre as duas partes da cadeia de abastecimento tem um impacto importante sobre o objetivo da oferta estratégia de cadeia, bem como sobre as competências organizacionais necessárias em cada caso.

Dado que a incerteza na parte empurrada da cadeia de abastecimento é relativamente pequena, o nível de serviço não é um problema e, portanto, o foco nesta parte da cadeia de fornecimento é na minimização de custo. Além disso, esta parte da cadeia de abastecimento é caracterizada não só pela baixa incerteza da demanda e as economias de escala na produção e/ou transporte, mas também por longos prazos de entrega e estruturas da cadeia de suprimentos complexas. Assim, a redução de custo é conseguida pela melhor utilização dos recursos, tais como as capacidades de produção e de distribuição, minimizando estoques, transporte e custos de produção. Por outro lado, a parte puxada da cadeia de abastecimento é caracterizada pela alta incerteza da demanda, simples estrutura de cadeia de fornecimento e um tempo de ciclo curto. Assim, o foco está no nível de serviço. A análise anterior indica que os diferentes processos necessitam de ser aplicado a diferentes partes da cadeia de suprimentos, conforme mostra o quadro 1.

Quadro 1 - Características dos trechos empurrados e puxados da cadeia de abastecimento

\begin{tabular}{|c|c|c|}
\hline PARCELA & EMPURRADA & PUXADA \\
\hline OBJETIVO & MINIMIZAR CUSTOS & MAXIMIZAR O NÍVEL DE SERVIÇO \\
\hline COMPLEXIDADE & ALTA & BAIXA \\
\hline FOCO & ALOCAÇÃO DE RECURSOS & CAPACIDADE DE REAÇÃO \\
\hline LEAD TIME & LONGO & CURTO \\
\hline Processos & PLANEJAMENTO DA CADEIA DE SUPRIMENTOS & ATENDIMENTO DO PEDIDO \\
\hline
\end{tabular}

Fonte: Simchi Levi, Kaminsky e Simchi Levi (2010)

Como o foco na parte puxada da cadeia de abastecimento está no nível de serviço, processos de atendimento de pedidos são tipicamente aplicados. Da mesma forma, uma vez que o foco da parte de envio da cadeia de fornecimento é no custo e na utilização de recursos, os processos de planejamento tático são usados aqui para desenvolver uma estratégia eficaz de atendimento. Pode-se observar no quadro 1 que a única parte da cadeia de abastecimento onde as duas estratégias interagem está no limite entre os trechos empurrado-puxado. Este é o ponto 
onde é necessário coordenar as duas estratégias da cadeia de suprimentos, normalmente através da gestão de estoques, no entanto, este estoque desempenha um papel diferente em cada porção. Na porção empurrada, o estoque é parte da saída gerada pelo processo de planejamento tático, enquanto na parte Puxada representa a entrada para o cumprimento processo. Assim, a interface entre a porção empurrada da cadeia de abastecimento e a porção puxada é a previsão de demanda. Esta previsão, que é baseada no histórico de dados obtidos a partir da porção puxada, é usada para conduzir o processo de planejamento tático.

\subsection{SIMULAÇÃO COMPUTACIONAL}

Chwif (2010) define a simulação como a representação simplificada das diversas interações entre as partes de um sistema real ou não.

Miguel (2010) define a simulação como uma técnica experimental, executada geralmente em um computador, para analisar o comportamento de todo um sistema no mundo real. A simulação envolve a modelagem de um processo ou de um sistema onde o modelo produz a mesma resposta do sistema real aos eventos que ocorrem nele durante um período dado de tempo. A simulação pode ser usada para prever o comportamento de um sistema complexo de fabricação ou de serviço, através dos movimentos e da interação dos componentes do sistema. O programa de simulação gera relatórios e estatísticas detalhadas que descrevem o comportamento do sistema sob estudo. Baseado nestes relatórios, as disposições físicas, a seleção do equipamento, os procedimentos de funcionamento, os recursos alocados e a sua utilização, o estoque e outras características do sistema importantes podem ser avaliados.

De acordo com Chwif (2010), os modelos de simulação podem ser classificados em três categorias básicas: Simulação de Monte Carlo, Simulação contínua e Simulação de eventos discretos. A simulação de Monte Carlo utiliza-se de geradores de números aleatórios para simular sistemas físicos ou matemáticos, nos quais não se considera o tempo explicitamente como uma variável, é útil para solução de problemas complexos que surgem no Cálculo Integral, por exemplo. Modelos de simulação dinâmica representam sistemas conforme eles mudam ao longo do tempo.

A simulação contínua e a de eventos discretos levam em consideração as mudanças de estado do sistema ao longo do tempo. A simulação contínua é utilizada para modelar sistemas cujo estado varia continuamente no tempo. 
Considerando por exemplo uma xícara de chá colocada a temperatura ambiente (figura 11). O fenômeno de resfriamento do chá é contínuo e pode ser melhor representado por uma simulação contínua, por outro lado a simulação de eventos discretos é utilizada para modelar sistemas que mudam seu estado em momentos discretos no tempo, a partir da ocorrência de eventos. No exemplo da figura 11 a preparação do chá envolve três eventos: (A) Colocação da água quente na xícara, (B) colocação do chá na água quente e (C) disponibilização do chá, note que cada evento ocorre em instantes determinados no tempo (Figura 11).

Figura 11- Evolução dos estados na simulação contínua e discreta

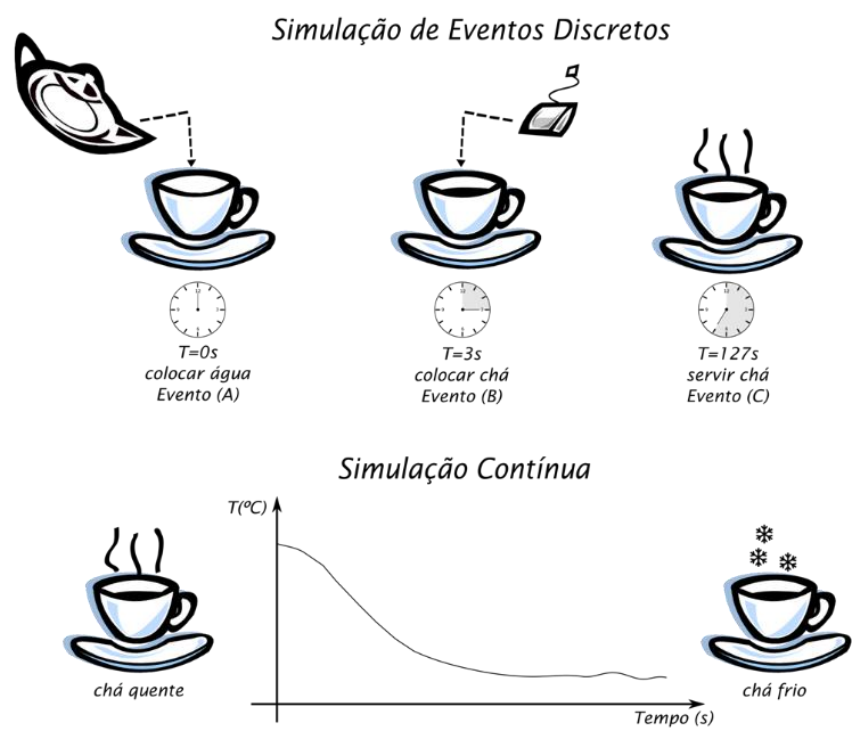

Fonte: Chwif, 2010

Este trabalho utiliza a metodologia de simulação de eventos discretos, segundo Chwif (2010) este é o tipo de modelagem utilizada particularmente como uma ferramenta para se obterem respostas a sentenças do tipo "O que ocorre se", como por exemplo:

a) O que ocorre se adicionarmos um $3^{\circ}$ turno de produção?

b) O que ocorre se houver um "pico de demanda de 30 "?

c) O que ocorre se adquirirmos um novo equipamento?

Segundo Chwif (2010), a lista de alternativas para esse tipo de perguntas pode ser infinita, o que leva a conclusão de que um modelo de simulação pode ser capaz de analisar diversos aspectos do sistema, ou melhor todos os aspectos do sistema de interesse. 
No caso de simulação de eventos discretos, os modelos "são processados" ao invés de serem resolvidos, isto é, uma história artificial do sistema é gerada a partir de os pressupostos do modelo e as observações são coletadas para serem analisadas e estimar o sistema verdadeiro e suas medidas de desempenho.

Os modelos de simulação do mundo real são bastante grandes, e a quantidade de dados armazenados e manipulado é vasta, de modo que esses desenvolvimentos são geralmente realizados com o auxílio de um computador.

Pidd (2004) classifica os modelos como "ferramentas para pensar", como na figura 12.

Figura 12 - Modelo como ferramentas para pensar

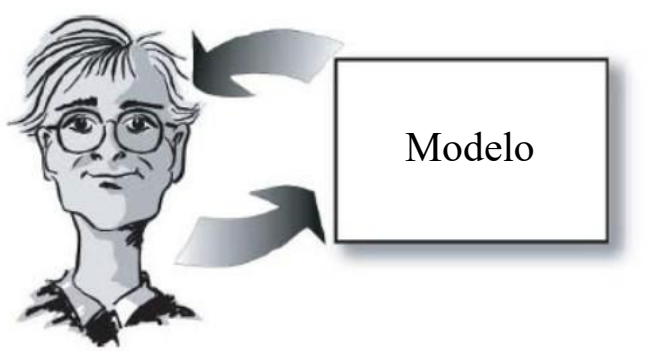

Fonte: Pidd (2004)

Estes modelos são utilizados como parte de uma intervenção que visa a melhoria de um sistema existente ou a criação de um novo. Usado desta forma, estes modelos substituem a ação humana, mas visam apoiá-lo. O mais simples apoio é oferecer ferramentas que usam o computador para executar cálculos com mais precisão e muito mais rápido do que a maioria dos seres humanos.

Chwif (2010) relata em sua obra que o campo de aplicação da simulação é muito amplo, e pode ser dividida em dois grandes setores: manufatura e serviços. Alguns bons exemplos de aplicação são listados abaixo:

\section{a) Exemplos em Serviços:}

- Aeroportos e Portos: Dimensionamentos de postos de check-in necessários, dimensionar um sistema de transporte de bagagens, o tempo de carga e descarga de um navio no porto, etc.

- Bancos: Determinar o número de caixas eletrônicos necessários, estudar problemas de layout, tempos de filas, etc. 
- Cadeias Logísticas: Determinar a melhor política de estocagem, transporte e distribuição, etc.

- Call Centers ou Centrais de Atendimento: Determinar a melhor configuração de uma ilha de atendimento, número ideal de postos de atendimentos necessários em uma determinada hora do dia, etc.

- Escritórios: Determinar o melhor fluxo de processos em um escritório, em uma repartição pública ou em um cartório, etc.

- Hospitais: Comportamento das UTIs, dimensionamento de ambulâncias, testes de políticas de transplante de órgãos, etc.

- Parque de diversões: Verificação do tempo de espera em atrações, distribuição física das atrações no parque, etc.

- Restaurantes e Cadeias de Fast Foods: Verificação de tempos de espera, utilização de mesas, capacidade da cozinha, etc.

- Supermercados: Decisão sobre melhor política de abertura de caixas, tamanho ideal do estacionamento, etc.

\section{b) Exemplos em Manufatura:}

- Sistemas de movimentação e armazenagem de materiais:

- Linhas de Montagem:

- Células automatizadas:

- Problemas de programação de produção:

- Análise de Estoques:

- Logística Interna:

Robinson (2004) apresenta as razões mais fortes para utilização de simulação e os benefícios obtidos pelos gestores:

a) Promover a criatividade: Ideias que podem produzir melhorias substanciais frequentemente nunca foram tentadas por causa do medo ou risco de fracasso. Com uma simulação, no entanto, as ideias podem ser analisadas em um ambiente que é livre de risco. Isso pode ajudar a estimular a criatividade na abordagem de situações-problema. 
b) Criação de conhecimento e compreensão: $O$ desenvolvimento e utilização de um modelo de simulação obriga as pessoas a pensar em problemas que de outra forma não podem ter sido considerados. O modelador busca informações, pede dados e perguntas pressupostos, todos dos quais levam a um melhor conhecimento e compreensão do sistema que está a ser simulado.

c) Visualização e comunicação: Muitas boas ideias foram desconsideradas por não existir a possibilidade de demonstrar os benefícios a um gerente sênior. Simulações visuais provar ser uma ferramenta poderosa para a comunicação.

Embora a simulação tenha muitas vantagens, existem também algumas desvantagens que devem ficar claras para os desenvolvedores, segundo Robinson (2004) são elas:

a) Caro: O Software de simulação não é necessariamente barato e o custo de desenvolvimento do modelo e utilização pode ser considerável, particularmente se consultores tiverem que ser contratados.

b) Demorado: A simulação é uma abordagem demorada. Isso só aumenta o custo de sua utilização e significa que os benefícios não são imediatos. A maioria dos modelos de simulação exige uma quantidade significativa de dados. Isto não está sempre disponível imediatamente e muitas análises podem ser obrigados a colocá-lo em uma forma adequada para a simulação.

c) Requer especialização: A simulação computacional é mais do que o desenvolvimento de um programa de computador ou a utilização de um pacote de software. Ele requer habilidades, entre outras coisas, modelagem conceitual, validação e estatísticas bem como habilidades em trabalhar com pessoas e gerenciamento de projetos.

d) O excesso de confiança: Existe um perigo de que qualquer coisa produzida em um computador seja vista como que esteja certo. Com esta simulação é ainda agravada com o uso de uma animação, dando uma aparência de realidade. Ao interpretar os resultados de uma simulação, deve-se considerar a validade do modelo subjacente e os pressupostos e simplificações que foram feitas. 
Manuj, Mentzer, Bowers (2009) apresenta no fluxograma da figura 13, de forma estruturada, os oito passos necessários para desenvolvimento de uma simulação computacional com rigor para pesquisa em logística e supply chain, chamado de SMDP (Em inglês: Simulation Model Development Process ou em português: Processo de Desenvolvimento de um Modelo de Simulação) 
Figura 13 - Processo de Desenvolvimento de um Modelo de Simulação

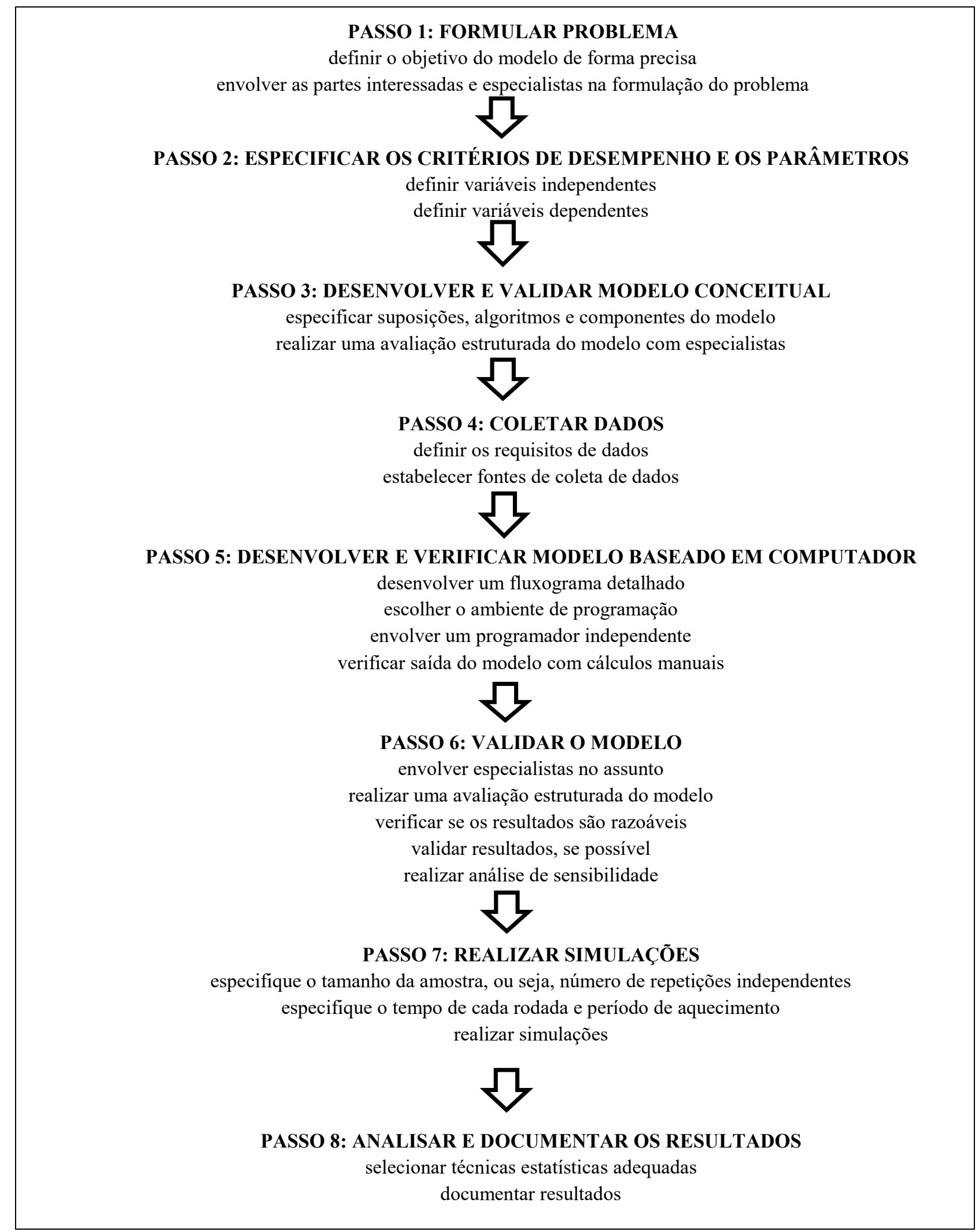

Fonte: Manuj, Mentzer, Bowers, 2009. 
Os oito passos são detalhados a seguir, definidos na pesquisa de Manuj, Mentzer, Bowers (2009):

a) Formular o problema

O objetivo da formulação do problema é definir os objetivos gerais e específicos e perguntas a serem respondidas com o modelo de simulação. Muitas vezes é necessário um processo iterativo para facilitar a formulação do problema.

b) Especificar as variáveis independentes e dependentes

As variáveis dependentes refletem os critérios de desempenho e variáveis independentes incluem os parâmetros do sistema. Em um modelo de simulação, variáveis independentes são manipulados e o seu efeito sobre as variáveis dependentes são registadas e analisadas. As análises de valores da variável dependente darão as respostas ao problema formulado na etapa 1.

c) Desenvolver e validar o modelo conceitual

Um modelo conceitual é uma abstração do mundo real sob investigação usando relações matemáticas e lógicas sobre os componentes e estrutura do sistema. Declarações explícitas de pressupostos e detalhamento das descrições das relações incluídas no modelo conceitual asseguram que o modelo é desenvolvido de acordo com a declaração do problema. O processo de modelagem conceitual adotado se fundamenta na metodologia IDEF-SIM que, em conformidade com os estudos realizados por Leal, Almeida e Montevechi (2008), possibilitam a melhoria na elaboração do modelo e, consequentemente, propiciam sua implementação e documentação.

Segundo o Federal Information Processing Standards Publications, durante os anos 70, o Program for Integrated Computer Aided Manufacturing (ICAM), da Força Aérea Norte Americana, buscou aumentar a produtividade da manufatura através de aplicação sistemática de tecnologia de computação. O ICAM identificou a necessidade de uma melhor análise e técnicas de comunicação para as pessoas envolvidas em programas de melhoria de produtividade em manufatura. Como resultado, o ICAM desenvolveu uma série de técnicas conhecidas como IDEF (Integrated Definition Methods). Existem 16 métodos (do IDEF0 ao IDEF14 - incluindo IDEF1X) sendo que cada um destes foi projetado para capturar um tipo de informação particular através da modelagem do processo. Maiores detalhes sobre a aplicação do IDEF podem ser encontrados no site mantido pela Knowledge Based Systems, Inc. 
(www.idef.com).

A técnica proposta por Montevechi et al (2010), chamada de IDEF-SIM (Integrated Definition Methods - Simulation), tem como foco projetos de simulação, porém são compatíveis para outros fins, como projetos de melhoria em geral. Observa-se que os elementos IDEF0 e IDEF3 foram utilizados, além de um símbolo do fluxograma de processo. De forma geral os métodos utilizados podem ser descritos como:

a) IDEF0: utilizada para produzir um modelo funcional. Um modelo funcional é uma representação estruturada de funções, atividades ou processos dentro de um sistema modelado ou de área definida;

b) IDEF3: A técnica permite a captura e representação com elementos gráficos, tanto para a transição de estados em um sistema de eventos discretos, como para a representação das atividades associadas com cada estado de transição.

O quadro 2 apresenta os elementos e a simbologia utilizada. 
Quadro 2 - Elementos e simbologia do IDEF-SIM

\begin{tabular}{|c|c|c|c|}
\hline Elementos & & logia & Técnica de origem \\
\hline Entidade & & & IDEF3 \\
\hline Funções & & & IDEFØ \\
\hline Fluxo da entidade & & & IDEFØ e IDEF3 \\
\hline Recursos & & & IDEFØ \\
\hline Controles & & & IDEFØ \\
\hline \multirow{3}{*}{$\begin{array}{l}\text { Regras para fluxos paralelos } \\
\text { e/ou alternativos }\end{array}$} & $\&$ & Regra 'E' & \multirow{3}{*}{ IDEF3 } \\
\hline & $x$ & Regra 'OU' & \\
\hline & $\mathrm{O}$ & Regra 'E/OU' & \\
\hline Movimentação & \multicolumn{2}{|c|}{ 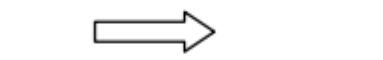 } & Fluxograma \\
\hline Informação explicativa & \multicolumn{2}{|c|}{$\cdots \rightarrow$} & IDEFØ e IDEF3 \\
\hline $\begin{array}{l}\text { Fluxo de entrada no sistema } \\
\text { modelado }\end{array}$ & \multicolumn{2}{|c|}{$\stackrel{H}{\longrightarrow}$} & - \\
\hline Ponto final do sistema & \multicolumn{2}{|c|}{ () } & - \\
\hline Conexão com outra figura & \multicolumn{2}{|c|}{$\triangle$} & - \\
\hline
\end{tabular}

Fonte: Montevechi et al (2010).

Simbologia utilizada na técnica proposta IDEF-SIM:

a) Entidade: são os itens a serem processados pelo sistema, representando matéria prima, produtos, pessoas, documentos, entre outros. Elas podem ser agrupadas ou divididas ao longo do processo produtivo e são movimentadas por meios próprios ou por meio de recursos. Uma vez representada, o símbolo somente aparecerá no momento em que uma nova entidade for criada. Desta forma, torna-se claro o número de entidades a ser utilizada e em que pontos do modelo a entidade sofrerá uma transformação;

b) Funções: representam os locais onde a entidade sofrerá alguma ação. Entende-se como funções postos de trabalho, esteiras de movimentação, filas e estoques, postos de atendimento. 
Estas funções podem modificar uma entidade, como no caso de postos desf trabalho, ou mesmo alterar o ritmo de tempo desta entidade no fluxo, como uma espera (fila, estoque);

c) Fluxo da entidade: direcionamento da entidade dentro do modelo, caracterizando os momentos de entrada e saída da entidade nas funções;

d) Recursos: representam elementos utilizados para movimentar as entidades e executar funções. Os recursos podem representar pessoas ou equipamentos. Em um sistema pode haver recursos estáticos ou dinâmicos. Os recursos estáticos não são dotados de movimento. Os recursos dinâmicos, por sua vez, podem se mover sobre um caminho definido;

e) Controles: regras utilizadas nas funções, como seqüenciamento, regras de filas, programações, entre outros;

f) Regras para fluxos paralelos e/ou alternativos: estas regras são chamadas de junções, na técnica IDEF3. Dois ou mais caminhos, após uma função, podem ser executados juntos (junção E), ou de forma alternativa (junção OU), ou permitindo ambas as regras (junção E/OU);

g) Movimentação: representa um deslocamento de entidade, no qual o modelador acredita possuir efeito importante sobre o modelo. Ao representar este elemento, espera-se encontrar no modelo computacional uma programação específica para este movimento, como tempo gasto e recurso utilizado;

h) Informação explicativa: utilizado para inserir no modelo uma explicação, com o objetivo de facilitar o entendimento do modelo;

i) Fluxo de entrada no sistema modelado: define a entrada ou criação das entidades dentro do modelo;

j) Ponto final do sistema: defini o final de um caminho dentro do fluxo modelado;

k) Conexão com outra figura: utilizado para dividir o modelo em figuras diferentes.

Através da utilização e adaptação de elementos lógicos já utilizados nas técnicas de modelagem IDEF0 e IDEF3, além da criação de novos elementos, esta técnica proposta permite a elaboração de modelos conceituais com informações que facilitam a elaboração dos modelos computacionais em projetos de simulação. Além desta utilização, a técnica permite uma documentação de modelos computacionais, facilitando o entendimento do projeto.

A validação dos resultados de um sistema depende do que está incluído na sua descrição. Portanto, é importante a construção de um modelo conceitual de modo que o modelo possa ser verificado antes de investir recursos no desenvolvimento de um modelo de simulação. 
Para Chwif e Medina (2010) a verificação de modelos de simulação pode ser entendida como a retirada de bugs (elementos que estão causando mau funcionamento) do modelo computacional e existem algumas técnicas ou procedimentos que podem ser utilizados para facilitar este processo, como por exemplo:

a) Implementação modular/verificação modular: construir o modelo em partes, a cada parte implementada deve-se verificar o modelo. Somente se esta parte estiver aparentemente correta é que se deve passar para a construção da próxima parte, e assim sucessivamente.

b) Valores constantes ou simplificados versus cálculos manuais: em um modelo de simulação utiliza-se uma ampla gama de distribuições e probabilidades. Para o uso desta técnica tomam-se os valores médios de cada distribuição e consideram-se estes valores como constantes determinísticos e então se comparam os resultados do modelo com os resultados de uma planilha de cálculo e observa-se se eles coincidem.

c) Utilização do debugger, trace ou depurador: softwares de simulação possuem um depurador que faz com a que a simulação ocorra passo a passo e assim é possível visualizar os eventos que estão correndo e eventos futuros, bem como os valores das variáveis do modelo. Este depurador funciona como uma lente de aumento que auxilia na descoberta de erros presentes no modelo.

d) Simulação manual: realizar uma simulação manual é uma atividade dispendiosa, mas permite que o analista ganhe uma sensibilidade prévia do comportamento do modelo e assim, quando este implementar o modelo no computador, terá uma percepção maior sobre a correspondência entre modelo conceitual e computacional. Esta técnica não se aplica a modelos muito grandes.

e) Animação gráfica: é uma poderosa ferramenta de verificação, pois diagnostica diversos tipos de erros, como por exemplo, entidades que somem do modelo ou seguem a rota errada.

f) Revisão em grupo: esta técnica se resume em implementar o modelo e deixar que uma outra pessoa ou grupo verifique onde o modelo não está funcionado adequadamente.

d) Coletar os dados

A coleta de dados pode ser um desafio, pois os dados podem não estar prontamente disponível nos formatos exigidos ou em um nível apropriado de detalhes. A coleta de dados 
pode seguir simultaneamente com o desenvolvimento do modelo conceitual. Os requisitos de dados devem primeiro ser criados para especificar os parâmetros do modelo, o layout do sistema, procedimentos operacionais e distribuições de probabilidades das variáveis de interesse. Os dados incluem as bases de dados da empresa, entrevistas, pesquisas, livros e / ou outras fontes publicadas. Antes da incorporação no modelo, os dados precisam de ser verificados, limpos e atualizados para evitar discrepâncias e / ou falta de informação.

e) Desenvolver e verificar o modelo baseado em computador

A modelagem deva iniciar de forma simples e a complexidade adicionada passo a passo até a finalização do desenvolvimento. A verificação é a determinação de que a implementação em computador do modelo conceitual está correta. É um processo contínuo e melhor realizado simultaneamente com o desenvolvimento do modelo, codifica-lo totalmente. A verificação inclui o exame das saídas de sub-modelos e modelo de simulação completo para assegurar que os modelos de execução e são comportando corretamente.

f) Validar o Modelo

A validação do modelo é o processo de determinar se uma simulação é uma precisa representação do sistema sob investigação. Um modelo "válido" pode ser usado para tomar decisões similares às que seriam feitas se fosse viável e rentável para realizar com o sistema real. Um modelo inválido pode levar a conclusões e decisões erradas.

A literatura apresenta diversas técnicas de validação, Sargent (2009) destaca as seguintes técnicas:

a) Animação: o modelo operacional do modelo é apresentado mostrando-se graficamente como o modelo se move através do tempo. Por exemplo, os movimentos de peças através de uma fábrica durante uma rodada de simulação são mostrados graficamente.

b) Comparação com outros modelos: diversos resultados gerados pelo modelo computacional podem ser comparados com resultados já conhecidos de modelos analíticos ou ainda com outros modelos computacionais já validados.

c) Testes degenerativos: A degeneração do comportamento do modelo é testada pela seleção adequada dos valores de entrada e parâmetros internos. Por exemplo, o número médio na fila de um único servidor continua a aumentar ao longo do tempo, quando a taxa de chegada é maior do que a taxa de serviço.

d) Validade de eventos: a ocorrência dos eventos de um modelo de simulação é comparada 
com o do sistema real para determinar se estas são similares. Por exemplo, comparar o número de incêndios em uma simulação de um departamento de bombeiros.

e) Teste de Condição Extrema: a estrutura do modelo e saídas devem ser plausíveis para uma extrema e improvável combinação níveis dos fatores no sistema. Por exemplo, se os estoques em processo são iguais a zero, a saída da produção deveria ser igual a zero.

f) Validade de Face: especialistas do sistema são questionados a fim de saber se o modelo e/ou seu comportamento estão razoáveis. Por exemplo, questionar se a lógica do modelo conceitual está correta e se o relacionamento entre entrada e saída do modelo está correto.

g) Validação com Dados Históricos: Se existem dados históricos (por exemplo, os dados coletados em um sistema especificamente para construir e testar um modelo), parte destes dados é utilizada para construir o modelo e os dados restantes são usados para determinar (testar) se o modelo se comporta como o sistema.

h) Métodos Históricos: Os três métodos históricos de validação são o racionalismo, o empirismo, e economia positiva. Racionalismo pressupõe que todos sabem se as hipóteses assumidas em um modelo são verdadeiras. Deduções lógicas são utilizadas a partir destes pressupostos para o desenvolvimento correto (válido) do modelo. Empirismo exige cada pressuposto e resultado para ser empiricamente validado. A economia positiva exige apenas que o modelo seja capaz de prever o futuro e não se preocupa com suposições de um modelo ou estrutura (relações de causalidade ou mecanismos).

i) Validade Interna: Várias repetições (rodadas) de um modelo estocástico são feitas para determinar a quantidade de variabilidade estocástica do modelo. Uma grande quantidade de variabilidade (falta de coerência) do modelo pode causar resultados questionáveis.

j) Gráficos operacionais: Valores de diferentes medidas de desempenho, como por exemplo, o número na fila e percentual de servidores ocupados, são mostrados graficamente. O comportamento dinâmico de indicadores de desempenho é mostrado durante a execução do modelo de simulação para garantir que eles se comportam corretamente.

k) Análise de Sensibilidade: Esta técnica consiste em alterar os valores das entradas e parâmetros internos de um modelo para determinar o efeito sobre o comportamento deste modelo ou dos resultados. As mesmas relações devem ocorrer tanto no modelo 
como no sistema real. Esses parâmetros que são sensíveis, ou seja, provocam mudanças significativas no comportamento do modelo ou resultados, devem ser então suficientemente precisos.

1) Validação preditiva: O modelo é utilizado para prever o comportamento do sistema e, em seguida, são feitas comparações entre a previsão do modelo e o comportamento do sistema para determinar se eles são os mesmos. Os dados do sistema podem ser provenientes de um sistema operacional ou obtidos através da condução de experimentos no próprio sistema.

m) Rastros: Os comportamentos de diferentes tipos de entidades específicas no modelo são rastreados (seguidos) através do modelo para determinar se a lógica do modelo está correta e se a precisão necessária foi obtida.

n) Teste de Turing: apresentam-se aos especialistas do sistema modelado os resultados do modelo e resultados do sistema, sem identificar a origem, se eles não conseguirem discriminar os resultados o modelo pode ser considerado validado.

g) Realizar as simulações

Para cada configuração de sistema de interesse, devem haver as rodadas independentes no modelo. Cada uma destas práticas deve ser analisada contra o custo em tempo e dinheiro para fazer rodadas adicionais.

h) Analisar os resultados

Os estudos em nossa amostra empregam várias técnicas de análise, tais como inspeção visual de saídas gráficas, limites médios, inferior e superior, desvio padrão e percentis de variáveis dependentes, análise de variância e diferentes métodos de comparações múltiplas. Modeladores, revisores, e os especialistas devem estar cientes de pressupostos adotados que pode afetar a adequação de uma determinada técnica estatística para uma dada situação. As escolhas das técnicas de análise variam consideravelmente, dependendo da distribuição de variáveis de entrada e de saída. Portanto, o pesquisador deve explicar a escolha.

Entre os softwares de simulação de eventos discretos encontrados no mercado o escolhido para o desenvolvimento deste trabalho foi o software comercial Promodel ${ }^{\circledR}$. O pacote do software inclui três softwares principais, sendo o Promodel ${ }^{\circledR}$ (para simulação de eventos discretos), SimRunner (para otimização de modelos computacionais) e StatFit (para estudos de 
distribuição de probabilidade). A figura 14 mostra a tela de abertura do Promodel®.

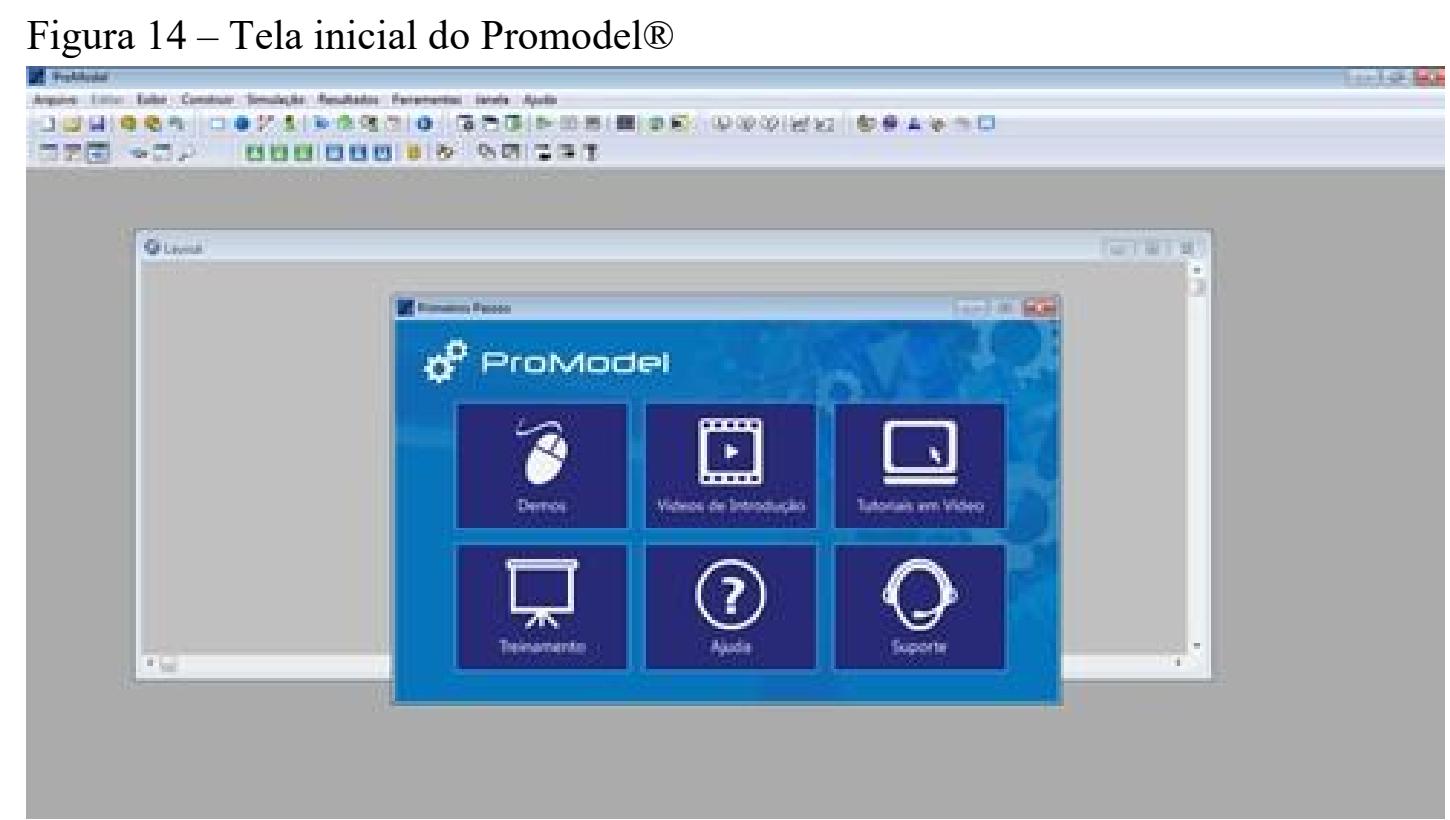

Fonte: O Autor

O software Promodel ${ }^{\circledR}$ fornece os elementos de modelagem em blocos de construção para uma representação física e lógica dos componentes do sistema que está sendo modelado. Os elementos físicos do sistema, tais como peças, máquinas, ou recursos, podem ser referenciados graficamente ou por nome.

A sequência de programação do modelo obedece às definição e programação das seguintes etapas:

a) Locais - São a representação de localização de estoques, máquinas, filas, locais que não se movimentam (permanecem fixos).

b) Entidades - São os solicitantes de serviços que se movimentam no processo.

c) Redes de Caminhos - Define a rede de caminhos a ser utilizada pelos recursos ou entidades para movimentação.

d) Recursos - São os prestadores de serviços / equipamentos que se movimentam pelo sistema.

e) Processos - Descreve a trajetória e operação das entidades pelo sistema. É a lógica do processo.

f) Chegadas - Descreve a regra de chegada das entidades no sistema. 
Depois da programação completa e validada o modelo pode ser processado para simular as operações propostas. O sistema possui um módulo de relatórios chamado de Output Viewer (Visualizador de saídas/resultados) que concentra diversos tipos de relatórios apresentados em forma de tabelas, gráficos, histogramas, gráficos tipo torta, etc e medições de desempenho para análise clara dos resultados.

O software pode trabalhar de forma integrada ao Excel, facilitando a entrada de dados no sistema.

A literatura existente demonstra a aplicabilidade da simulação de eventos discretos em pesquisa, foram encontrados 86 artigos nos últimos 5 anos utilizando a simulação de eventos discretos para analisar os efeitos de sistemas puxados ou empurrados na logística (sciencedirect - termo: "push pull discrete event simulation").

A simulação de eventos discretos se apresenta como a metodologia ideal para analisar os efeitos de controle da cadeia logística de forma puxada ou empurrada, por exemplo Sastry, Saxena e Upadhaya (2012) desenvolvem sua pesquisa com a análise de cadeias de suprimentos puxadas na indústria utilizando simulação computacional, Torga (2007) em sua dissertação de mestrado busca também aplicar a simulação de eventos discretos para analisar os resultados de sistemas puxados de manufatura.

Podemos concluir que a simulação computacional de eventos discretos é a ferramenta correta para tratar do fenômeno estudado neste trabalho.

Os artigos analisados em sua grande maioria estão relacionados a engenharia de produção, especificamente a manufatura de bens não perecíveis, o cimento por se tratar de um produto perecível (3 meses) adiciona um aspecto a pesquisa não tratado anteriormente na literatura.

\section{DESENVOLVIMENTO DA PESQUISA}

Neste capítulo são apresentados a indústria do cimento, o desenvolvimento do modelo matemático e a simulação computacional das operações em todos os cenários pertinentes. 


\subsection{A INDUSTRIA DO CIMENTO}

\subsubsection{Uma breve história sobre o cimento}

Segundo a ABCP (2015), a palavra CIMENTO é originada do latim CAEMENTU, que designava na velha Roma espécie de pedra natural de rochedos e não esquadrejada. A origem do cimento remonta há cerca de 4.500 anos. Os imponentes monumentos do Egito antigo já utilizavam uma liga constituída por uma mistura de gesso calcinado. As grandes obras gregas e romanas, como o Panteão e o Coliseu, foram construídas com o uso de solos de origem vulcânica da ilha grega de Santorino ou das proximidades da cidade italiana de Pozzuoli, que possuíam propriedades de endurecimento sob a ação da água.

O grande passo no desenvolvimento do cimento foi dado em 1756 pelo inglês John Smeaton, que conseguiu obter um produto de alta resistência por meio de calcinação de calcários moles e argilosos. Em 1818, o francês Vicat obteve resultados semelhantes aos de Smeaton, pela mistura de componentes argilosos e calcários. Ele é considerado o inventor do cimento artificial. Em 1824, o construtor inglês Joseph Aspdin queimou conjuntamente pedras calcárias e argila, transformando-as num pó fino. Percebeu que obtinha uma mistura que, após secar, tornava-se tão dura quanto as pedras empregadas nas construções. A mistura não se dissolvia em água e foi patenteada pelo construtor no mesmo ano, com o nome de cimento Portland, que recebeu esse nome por apresentar cor e propriedades de durabilidade e solidez semelhantes às rochas da ilha britânica de Portland.

No Brasil, estudos para aplicar os conhecimentos relativos à fabricação do cimento Portland ocorreram aparentemente em 1888, quando o comendador Antônio Proost Rodovalho se empenhou em instalar uma fábrica na fazenda Santo Antônio, de sua propriedade, situada em Sorocaba-SP. Várias iniciativas esporádicas de fabricação de cimento foram desenvolvidas nessa época. Assim, chegou a funcionar durante apenas três meses, em 1892, uma pequena instalação produtora na ilha de Tiriri, na Paraíba, cuja construção data de 1890, por iniciativa do engenheiro Louis Felipe Alves da Nóbrega, que estudara na França e chegara ao Brasil com novas ideias, tendo inclusive o projeto da fábrica pronto e publicado em livro de sua autoria. Atribui-se o fracasso do empreendimento não à qualidade do produto, mas à distância dos centros consumidores e à pequena escala de produção, que não conseguia competitividade com os cimentos importados da época.

A usina de Rodovalho lançou em 1897 sua primeira produção - o cimento marca Santo 
Antonio - e operou até 1904, quando interrompeu suas atividades. Voltou em 1907, mas experimentou problemas de qualidade e extinguiu-se definitivamente em 1918. Em Cachoeiro do Itapemirim, o governo do Espírito Santo fundou, em 1912, uma fábrica que funcionou até 1924, com precariedade e produção de apenas 8.000 toneladas por ano, sendo então paralisada, voltando a funcionar em 1935, após modernização.

Todas essas etapas não passaram de meras tentativas que culminaram, em 1924, com a implantação pela Companhia Brasileira de Cimento Portland de uma fábrica em Perus, Estado de São Paulo, cuja construção pode ser considerada como o marco da implantação da indústria brasileira de cimento. As primeiras toneladas foram produzidas e colocadas no mercado em 1926. Até então, o consumo de cimento no país dependia exclusivamente do produto importado. A produção nacional foi gradativamente elevada com a implantação de novas fábricas e a participação de produtos importados oscilou durante as décadas seguintes, até praticamente desaparecer nos dias de hoje.

\subsubsection{A indústria do cimento no cenário brasileiro}

No Brasil, seguindo a dinâmica da indústria do cimento no mundo, o setor é concentrado com atuação de grandes empresas nacionais e multinacionais. Os fatores econômicos e de mercado - como as características de ser uma indústria intensiva em capital, a necessidade de grandes escalas de produção e a posse de jazidas minerais próximas aos grandes mercados consumidores - funcionam como barreira à entrada de empresas de médio porte e até mesmo, de certa maneira, de grandes empresas do setor.

Para serem competitivas, as fábricas devem possuir elevadas escalas de produção. De acordo com relatório divulgado à imprensa em 2011 pelo Sindicato Nacional das Industrias de Cimento - SNIC, a escala mínima das unidades industriais é de um milhão de toneladas, que demandam investimentos da ordem de US\$ 200 milhões a US\$ 300 milhões, algo perto de um investimento inicial entre US\$200 a US\$ 300 por tonelada de capacidade. Segundo estimativas do SNIC (2013), o tempo necessário para a implantação de um projeto, dos estudos preliminares até a "posta-em-marcha" de uma fábrica de cimento, é de 2 a 5 anos.

De acordo com o SNIC (2013), o país no final de 2013 contava com 88 fábricas de cimentos instaladas, concentradas fortemente na região nordeste e sudeste conforme figura 15 e quadro 3. 
Figura 15 - Fábricas de Cimento no Brasil

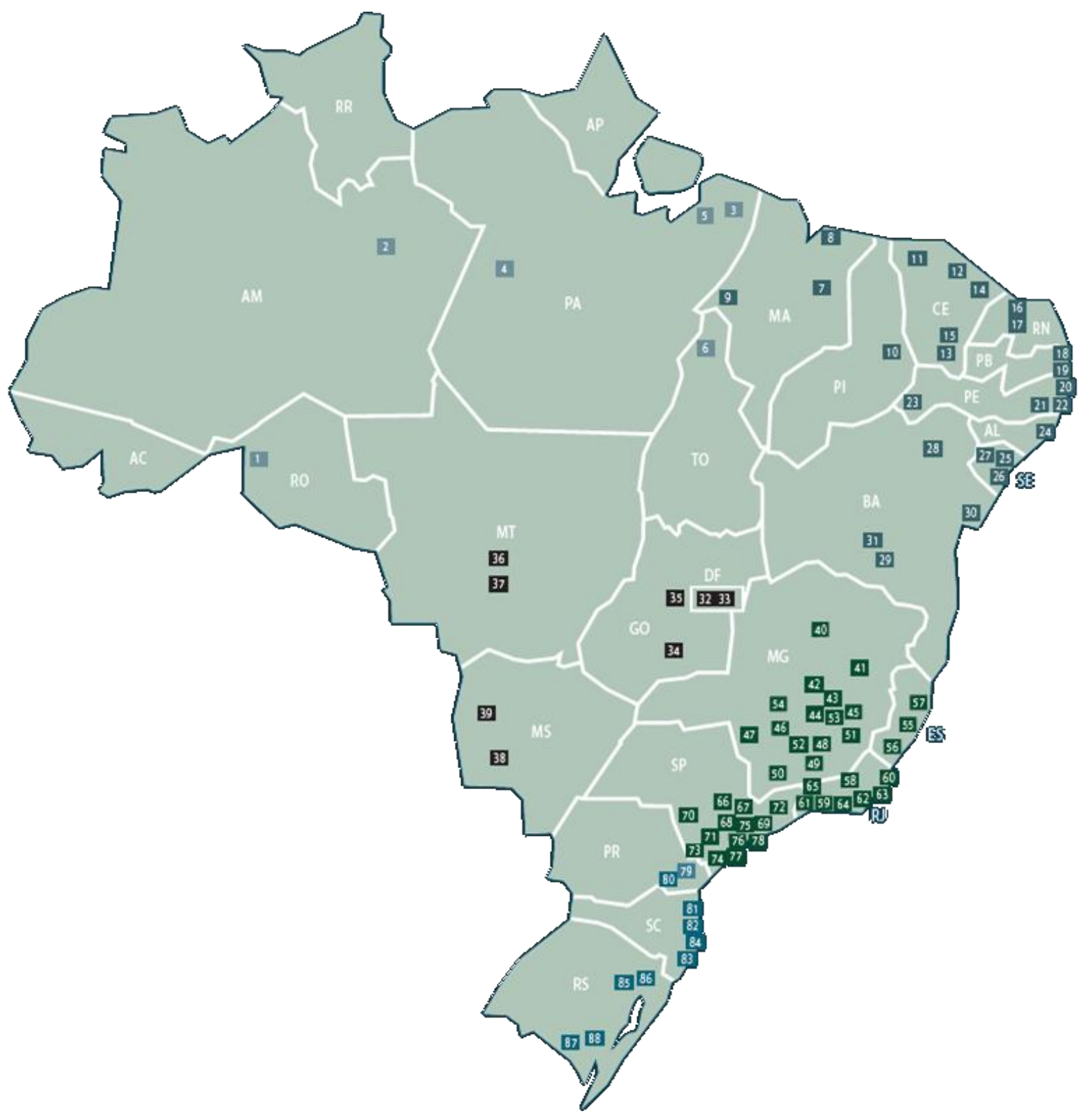

Fonte: SNIC, 2013 
Quadro 3 - Fábricas de cimento no Brasil

\begin{tabular}{|c|c|c|c|c|c|}
\hline REGIÃO & $\mathrm{N}^{0}$ & FABRICA & M UNICÍPIO & UF & GRUPO INDUSTRIAL \\
\hline \multirow{6}{*}{$\begin{array}{l}\text { REGIÃO } \\
\text { NORTE }\end{array}$} & 1 & PORTO VELHO & PORTO VELHO & $\mathrm{RO}$ & VOTORANTIM \\
\hline & 2 & ITAUTINGA & MANAUS & AM & JOÃO SANTOS \\
\hline & 3 & CIBRASA & CAPANEMA & $\mathrm{PA}$ & JOÃOSANTOS \\
\hline & 4 & ITAITUBA & ITAITUBA & PA & JOÃO SANTOS \\
\hline & 5 & BARCARENA & BARCARENA & PA & VOTORANTIM \\
\hline & 6 & XAMBIOÁ & XAMBIOÁ & TO & VOTORANTIM \\
\hline \multirow{25}{*}{$\begin{array}{c}\text { REGIÃO } \\
\text { NORDEST } \\
\text { E }\end{array}$} & 7 & ITAPICURU & CODÓ & $\overline{\mathrm{MA}}$ & JOÃO SANTOS \\
\hline & 8 & SÃOLUIS & SÃOLUÍS & MA & VOTORANTIM \\
\hline & 9 & CIMENTO VERDE DO BRASIL & AÇAILÂNDIA & MA & OUTROS \\
\hline & 10 & ITAPISSUMA & FRONTEIRAS & $\mathrm{PI}$ & JOÃO SANTOS \\
\hline & 11 & SOBRAL & SOBRAL & $\mathrm{CE}$ & VOTORANTIM \\
\hline & 12 & PECÉM & CAUCAIA & CE & VOTORANTIM \\
\hline & 13 & ITAPUII APODI & BARBALHA & $\mathrm{CE}$ & JOÃO SANTOS \\
\hline & 14 & APODI & DIONISIO TORRES & $\mathrm{CE}$ & APODI \\
\hline & 15 & APODI & QUIXERÉ & $\mathrm{CE}$ & APODI \\
\hline & 16 & ITAPETINGA & MOSSORÓ & $\mathrm{RN}$ & JOÃO SANTOS \\
\hline & 17 & MIZU & BARAÚNA & $\mathrm{RN}$ & MIZU \\
\hline & 18 & INTERCEM ENT & JOÃO PESSOA & PB & INTERCEM ENT \\
\hline & 19 & LAFARGE & CAAPORÃ & PB & LAFARGE \\
\hline & 20 & ITAPESSOCA & GOIANA & $\mathrm{PE}$ & JOÃO SANTOS \\
\hline & 21 & INTERCEM ENT & CABO DE STO. AGOSTINHO & $\mathrm{PE}$ & MOAGEM INTERCEM ENT \\
\hline & 22 & POTYPAULISTA & PAULISTA & PE & VOTORANTIM \\
\hline & 23 & PAJEÚ & CARNAÍBA & PE & OUTROS \\
\hline & 24 & INTERCEMENT & SÃOM.DOSCAMPOS & $\mathrm{AL}$ & INTERCEMENT \\
\hline & 25 & LARANJEIRAS & LARANJEIRAS & SE & VOTORANTIM \\
\hline & 26 & ITAGUASSU & N. Sra. do SOCORRO & SE & JOÃOSANTOS \\
\hline & 27 & MIZU & PACATUBA & $\mathrm{SE}$ & MIZU \\
\hline & 28 & INTERCEM ENT & CAMPO FORMOSO & BA & INTERCEM ENT \\
\hline & 29 & INTERCEM ENT & BRUMADO & BA & INTERCEM ENT \\
\hline & 30 & LAFARGE & CANDEIAS & BA & LAFARGE \\
\hline & 31 & ITAGUARANA & ITUAĊU & $\mathrm{BA}$ & JOÃO SANTOS \\
\hline & 32 & CIPLAN & SOBRADINHO & $\mathrm{DF}$ & CIPLAN \\
\hline & 33 & SOBRADINHO & SOBRADINHO & DF & VOTORANTIM \\
\hline & 34 & INTERCEM ENT & CEZARINA & GO & INTERCEM ENT \\
\hline CENTRO. & 35 & LAFARGE & COCALZINHO & GO & LAFARGE \\
\hline OESTE & 36 & NOBRES & NOBRES & MT & VOTORANTIM \\
\hline & 37 & CUIABÁ & CUIABÁ & MT & VOTORANTIM \\
\hline & 38 & INTERCEM ENT & BODOQUENA & MS & INTERCEM ENT \\
\hline & 39 & CORUMBÁ & CORUMBÁ & MS & VOTORANTIM \\
\hline & 40 & LAFARGE & MONTES CLAROS & MG & LAFARGE \\
\hline & 41 & INTERCEMENT & SANTANA DOPARAISO & MG & INTERCEM ENT \\
\hline & 42 & LAFARGE & MATOZINHOS & MG & LAFARGE \\
\hline & 43 & LIZ & VESPASIANO & MG & LIZ \\
\hline & 44 & HOLCIM & PEDRO LEOPOLDO & MG & HOLCIM \\
\hline & 45 & INTERCEM ENT & PEDRO LEOPOLDO & MG & INTERCEM ENT \\
\hline & 46 & LAFARGE & ARCOS & MG & LAFARGE \\
\hline & 47 & ITAÚ DE MINAS & ITAÚ DE MINAS & MG & VOTORANTIM \\
\hline & 48 & TUPI & CARANDAÍ & MG & TUPI \\
\hline & 49 & HOLCIM & BARROSO & MG & HOLCIM \\
\hline & 50 & INTERCEM ENT & IJACI & MG & INTERCEM ENT \\
\hline & 51 & LAFARGE & SANTA LUZIA & MG & LAFARGE \\
\hline & 52 & $\mathrm{CSN}$ & ARCOS & MG & $\mathrm{CSN}$ \\
\hline & 53 & BRENNAND & SETE LAGOAS & MG & BRENNAND \\
\hline & 54 & CARMOCAL & PAINS & MG & OUTROS \\
\hline & 55 & HOLCIM & SERRA & ES & HOLCIM \\
\hline & 56 & ITABIRA & C. de ITAPEM IRIM & ES & JOÃO SANTOS \\
\hline & 57 & MIZU & VITÓRIA & ES & MIZU \\
\hline REGIÃo & 58 & RIO NEGRO & CANTAGALO & RJ & VOTORANTIM \\
\hline SUDESTE & 59 & LAFARGE & CANTAGALO & RJ & LAFARGE \\
\hline & 60 & HOLCIM & CANTAGALO & RJ & HOLCIM \\
\hline & 61 & TUPI & VOLTA REDONDA & RJ & TUPI \\
\hline & 62 & $\operatorname{CSN}$ & VOLTA REDONDA & RJ & $\operatorname{CSN}$ \\
\hline & 63 & MIZU & RIO DE JANEIRO & RJ & MIZU \\
\hline & 64 & SEPETIBA & ITAGUAÍ & RJ & VOTORANTIM \\
\hline & 65 & LAFARGE & RIO DE JANEIRO & RJ & LAFARGE \\
\hline & 66 & HOLCIM & SOROCABA & SP & HOLCIM \\
\hline & 67 & SANTA HELENA & VOTORANTIM & $\mathrm{SP}$ & VOTORANTIM \\
\hline & 68 & SALTO & SALTO DE PIRAPORA & SP & VOTORANTIM \\
\hline & 69 & CUBATÃO & CUBATÃO & SP & VOTORANTIM \\
\hline & 70 & LAFARGE & ITAPEVA & SP & LAFARGE \\
\hline & 71 & RIBEIRÃO GRANDE & RIBEIRÃO GRANDE & SP & VOTORANTIM \\
\hline & 72 & TUPI & MOGI DAS CRUZES & SP & TUPI \\
\hline & 73 & INTERCEM ENT & APIAI & SP & INTERCEM ENT \\
\hline & 74 & INTERCEM ENT & CAJATI & SP & INTERCEM ENT \\
\hline & 75 & INTERCEM ENT & JACAREI & SP & INTERCEM ENT \\
\hline & 76 & MIZU & MOGIDAS CRUZES & SP & MIZU \\
\hline & 77 & SP CIM & SUZANO & SP & OUTROS \\
\hline & 78 & INTERCEMENT & CUBATÃO & $\mathrm{SP}$ & INTERCEMENT \\
\hline & 79 & RIO BRANCO & RIO BRANCODOSUL & $\overline{P R}$ & VOTORANTIM \\
\hline & 80 & ITAMBÉ & BALSA NOVA & $\mathrm{PR}$ & ITAMBÉ \\
\hline & 81 & ITAJAÍ & ITAJAI & SC & VOTORANTIM \\
\hline & 82 & VIDALRAMOS & VIDAL RAMOS & SC & VOTORANTIM \\
\hline REGIÃO & 83 & IMBITUBA & IMBITUBA & SC & VOTORANTIM \\
\hline SUL & 84 & SUPREMO & POMERODE & sc & SECIL/SUPREMO \\
\hline & 85 & INTERCEM ENT & NOVA SANTA RITA & RS & INTERCEMENT \\
\hline & 86 & ESTEIO & ESTEIO & RS & VOTORANTIM \\
\hline & 87 & INTERCEM ENT & CANDIOTA & RS & INTERCEM ENT \\
\hline & 88 & PINHEIRO MACHADO & PINHEIRO MACHADO & RS & VOTORANTIM \\
\hline
\end{tabular}

Fonte: SNIC, 2013 


\subsubsection{Cadeia Produtiva}

O setor cimenteiro caracteriza-se por uma estrutura verticalizada. Seus principais insumos - calcário, gipsita e argila - são obtidos, em sua maioria, junto às minas operadas pelas próprias empresas. Essa "integração para trás", controlando o fornecimento desses insumos, é uma condição importante para os produtores de cimento pelos fatores já mencionados anteriormente. Algumas cimenteiras, em razão de seu alto grau de produtividade e quantidades excedentes, tornam esses depósitos minerais fonte de receitas, obtida por meio de vendas para terceiros.

No caso do calcário, a indústria do cimento é o setor maior demandante do minério, respondendo por $39,60 \%$ do total do consumo, seguida pelo mercado de Extração e Beneficiamento de Minerais, com 14,3\%, e de Corretivos de solos, com 11,33\%, segundo dados do Anuário Mineral Brasileiro 2010, do Departamento Nacional de Produção Mineral (DNPM).

\subsubsection{Fluxo de Produção do Cimento}

O processo de produção inicia-se com a extração de calcário e argila de jazidas localizadas junto às fábricas. O calcário é a principal matéria-prima para a fabricação do cimento e é extraído de jazidas subterrâneas ou a céu aberto, situação mais comum no Brasil.

O calcário extraído é transportado em caminhões até as instalações de britagem, onde o minério é reduzido até dimensões adequadas para ser processado industrialmente. O calcário é empilhado em camadas, possibilitando criar uma mistura na extração para alimentação do moinho (homogeneização) que é realizada sem adição de água, chamada de via seca. Depois, ocorre a mistura entre calcário e argila, numa dosagem básica de 80\% a 95\% de calcário, 5\% a $20 \%$ de argila e pequenas quantidades de minério de ferro e areia para em seguida se dar a moagem conhecida como "moagem de cru". Essa mistura é levada ao forno rotativo que atinge temperaturas superiores a $1.450^{\circ} \mathrm{C}$, gerando o clínquer, produto com aspecto de bolotas escuras. O clínquer, associado ao gesso, calcário, escória de alto-forno ou argila pozolana, é moído na "moagem de cimento" e o produto final destina-se aos silos para estocagem e posterior expedição (cimento ensacado e/ou a granel). A Figura 16 ilustra os processos de fabricação do cimento. 
Figura 16 - Fluxo de Produção de Cimento

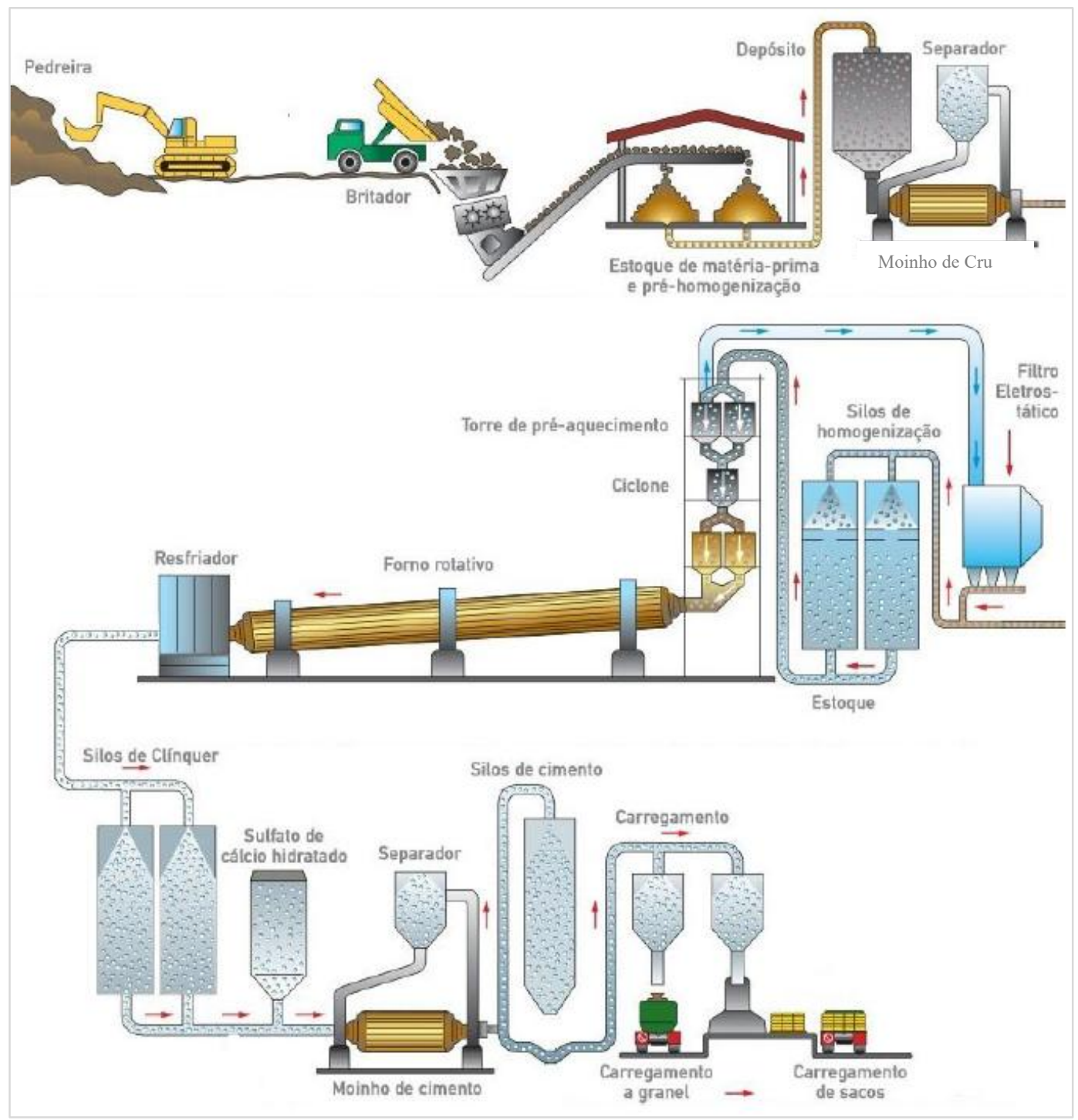

Fonte: Galhardo, 2014.

\subsubsection{Tipo de Cimentos}

O mercado nacional dispõe de 8 opções, que atendem com igual desempenho aos mais variados tipos de obras. O cimento Portland comum (CP I) é referência, por suas características e propriedades. Existem 11 tipos básicos de cimento Portland disponíveis no mercado brasileiro classificados conforme o aditivo utilizado em sua composição. São eles (Quadro 4): 
Quadro 4 - Tipos de Cimento no Mercado

\begin{tabular}{|c|c|c|c|c|c|}
\hline$\#$ & & Tipos de Cimentos & Adição & $\begin{array}{c}\text { Classe } \\
\text { de Resistência } \\
\text { (MPa) }\end{array}$ & $\begin{array}{l}\text { Norma } \\
\text { Brasileira }\end{array}$ \\
\hline \multirow{2}{*}{1} & CPI & Cimento Portland Comum & - & $25,32,40$ & \multirow{2}{*}{ NBR 5732} \\
\hline & CPI - S & Cimento Portland Comum com Adição & Argila $(1-5 \%)$ & 25 ou 40 & \\
\hline \multirow{3}{*}{2} & $\mathrm{CP} \|-\mathrm{E}$ & $\begin{array}{c}\text { Cimento Portland composto com Escória de Alto } \\
\text { Forno }\end{array}$ & Escória $(6-34 \%)$ & $25,32,40$ & \multirow{3}{*}{ NBR 11578} \\
\hline & CP II - Z & Cimento Portland composto com Pozolana & Argila $(6-14 \%)$ & $25,32,40$ & \\
\hline & $\mathrm{CP} \| \mathrm{I}-\mathrm{F}$ & Cimento Portland composto com Filer (Calcário) & Calcário $(6-10 \%)$ & $25,32,40$ & \\
\hline 3 & CP III & Cimento Portland de Alto Forno & Escória (35-70\%) & $25,32,40$ & NBR 5735 \\
\hline 4 & CPIV & Cimento Portland Pozolânico & Argila (15-50\%) & 25 ou 32 & NBR 5736 \\
\hline 5 & CPV ARI & Cimento Portland de Alta Resistência Inicial & - & Variada & NBR 5733 \\
\hline 6 & RS & Cimentos Portland Resistente a Sulfatos & - & Variada & NBR 5737 \\
\hline 7 & $\mathrm{BC}$ & Cimentos Portland de Baixo Calor de Hidratação & - & Variada & NBR 13116 \\
\hline 8 & $\mathrm{CPB}$ & Cimentos Portland Branco & - & $25,32,40$ & NBR 12989 \\
\hline
\end{tabular}

Fonte: ABCP, 2015

\subsubsection{Demanda para os próximos anos}

O desempenho do setor de construção e, consequentemente, do consumo de cimento para um período de cinco anos (2014 a 2018), dependerá de como se comportará a economia brasileira, que é sensível a políticas e planos governamentais. A figura 17 demonstra a evolução e o consumo aparente de cimento (Consumo Aparente = Produção + Importações Exportações) no Brasil e no mundo de 1965 a 2013. 
Figura 17 - Consumo Aparente de Cimentos

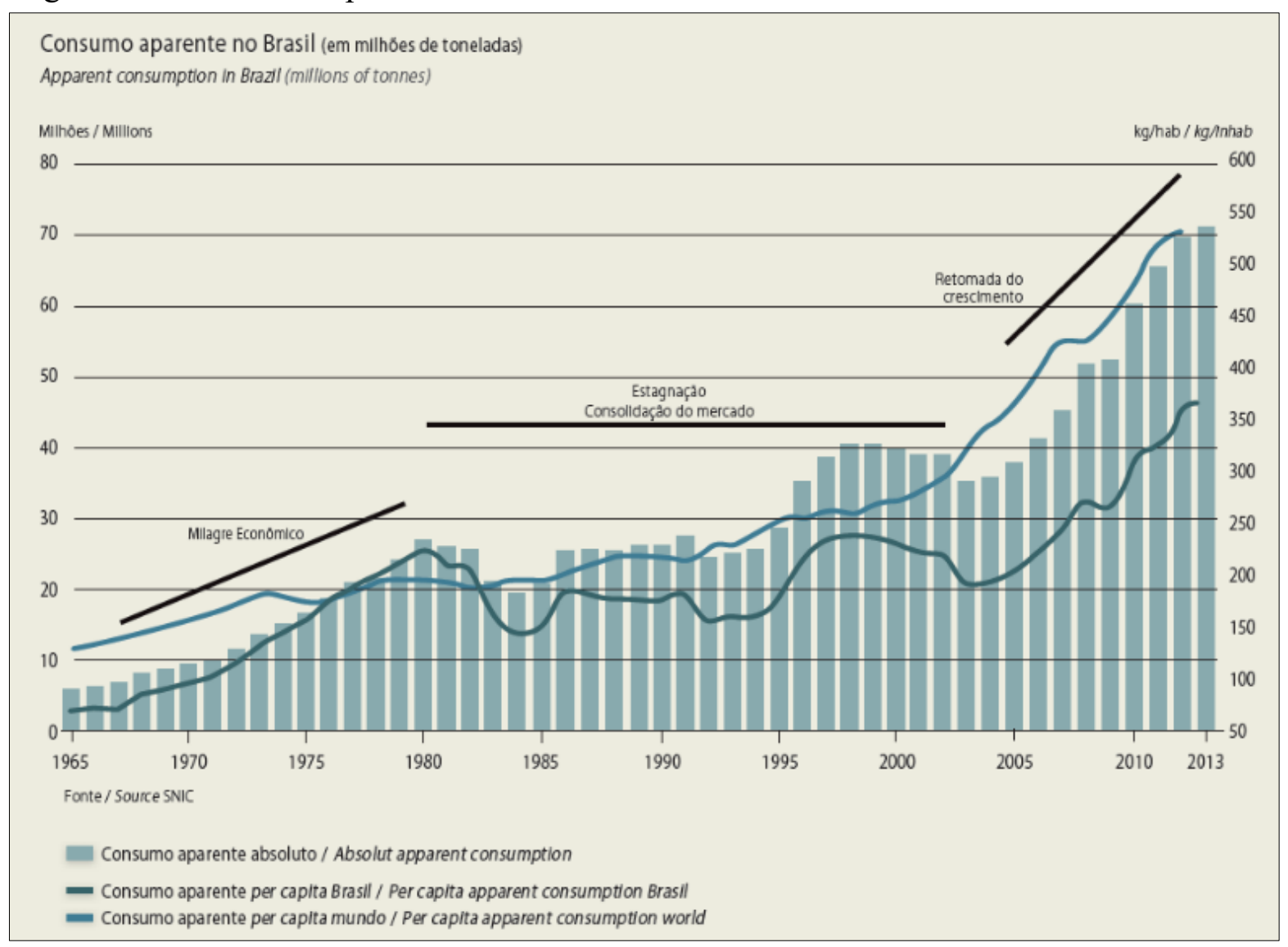

Fonte: SNIC, 2013

De acordo com o SNIC (2013), o consumo per capita de cimento no Brasil é muito pequeno em relação ao de outros países e há muita demanda reprimida nos segmentos de habitação e infra-estrutura.

Alguns fatores políticos podem contribuir para o incremento de consumo de cimentos, como:

a) Políticas do governo para diminuição do déficit habitacional;

b) Políticas de renda do governo federal para aumentar o poder aquisitivo da população;

c) Políticas do governo federal, como o PAC - Programa de Aceleração do Crescimento, para estimular setores de infra-estrutura, habitacional, edificações, pontes, estradas, etc.;

d) Políticas de financiamentos por parte dos bancos oficiais e privados são fatores favoráveis para investimentos na indústria do cimento; 


\subsection{A EMPRESA ESTUDADA}

A pesquisa foi realizada em uma empresa produtora de cimento que iniciou suas operações em 2009 no estado do Rio de Janeiro. A empresa possui uma capacidade de produção de 1,8 milhão de toneladas anuais.

A empresa conta com uma grande vantagem competitiva, é proprietária de uma mina de calcário que garante a disponibilidade de um dos principais insumos para produção do cimento.

A empresa fabrica cimento do tipo CPIII AF, um produto de alta qualidade quando comparado a cimentos da mesma classe e distribui seu produto ensacado ou a granel, atendendo principalmente o mercado da região sudeste do país através de entrega direta a clientes ou por centros de distribuição estrategicamente localizados.

\subsection{DESCRIÇÃO DO PROBLEMA}

A empresa estudada, em condições normais de operação, possui uma capacidade máxima de produção de 150 Mil toneladas de cimento por mês, que são expedidas conforme a estrutura e volumes médios apresentados na figura 18.

Figura 18 - Distribuição diária média de Cimentos da Fábrica para os CDs e Clientes.

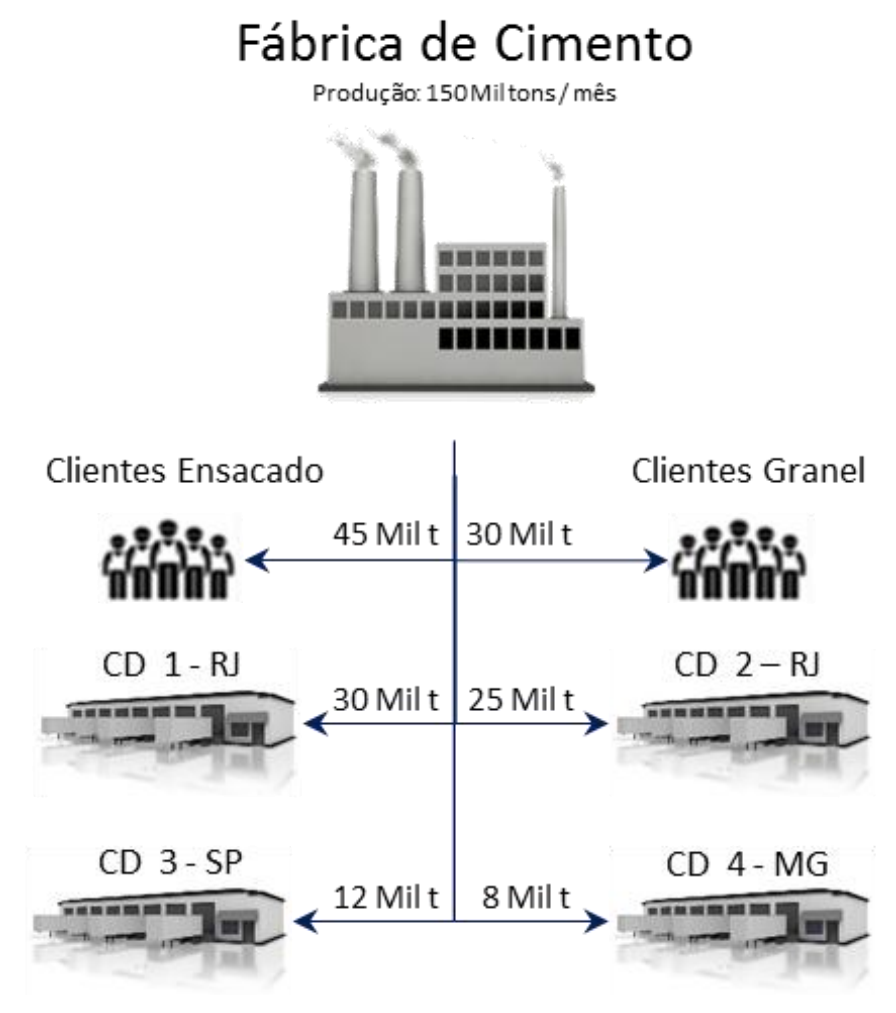

Fonte: O Autor 
Este tipo de distribuição é considerado como "demanda empurrada" pois não leva em consideração a demanda dos clientes no cálculo do volume de transferência para cada CD, os volumes são calculados sobre uma previsão de vendas estimada em base histórica.

Existe uma oscilação natural na demanda dos clientes em cada $\mathrm{CD}$, que fatalmente gera sérios problemas operacionais como os relatados nas situações abaixo:

a) Em Alta Demanda: Acarreta falta de estoque na unidade e consequente perda de vendas, bem como insatisfação do cliente.

b) Em Baixa Demanda: Geração de estoques desnecessários, os CDs atingem sua capacidade máxima de estocagem e caso o produto permaneça armazenado por período maior do que seu prazo de validade ele deve ser destruído. Devemos considerar que apesar da validade do cimento ser de 3 meses o mercado não aceita comprar o produto com prazo de fabricação maior que 1 mês, portanto considera-se que a validade do cimento para venda é de 1 mês.

Buscando atingir maior eficiência operacional e maximização do faturamento com o atendimento de todo o potencial de vendas, houve a necessidade de realizar um estudo que determinasse à luz das teorias de Supply Chain existentes, qual o melhor modelo de distribuição a ser utilizado para o negócio de cimentos.

Frente à complexidade encontrada na realização das análises foi adotada como ferramenta para apoio a decisão o desenvolvimento de uma simulação computacional das operações, que permite avaliar todas os cenários e alterações possíveis nos fluxos atuais e determinar o melhor modelo a ser adotado sem a necessidade de intervenção na operação real e a custos muito baixos.

\subsection{DESENVOLVIMENTO DA SIMULAÇÃO COMPUTACIONAL}

O modelo foi desenvolvido tendo como referência os oito passos sugeridos por Manuj, Mentzer, Bowers (2009) em sua pesquisa. 


\subsubsection{Passo 1 - Formulação do problema}

Em conjunto com especialistas em logística da empresa estudada, foram identificados e incorporados ao modelo de simulação os riscos de fornecimento de cimento ensacado aos centros de distribuição e os riscos da demanda da cadeia de suprimento. Dois tipos de riscos foram identificados: risco de oferta e demanda, operacionalizados em dois níveis específicos: baixo e alto. Duas estratégias foram identificadas durante as duas primeiras fases e incluídas nesta pesquisa: Cadeia de Suprimento Empurrada e Cadeia de Suprimento Puxada. Estas estratégias foram selecionadas porque os envolvidos as identificaram como as mais importantes e mais prováveis de adoção do que outras estratégias. A cadeia de suprimento empurrada consiste em realizar a distribuição do cimento da fábrica aos centros de distribuição por média histórica da demanda, estratégia tradicionalmente adotada pelo mercado. A cadeia de suprimento puxada consiste em realizar a distribuição da fábrica para os centros de distribuição pela quantidade exata já vendida, estratégia não adotada atualmente pela empresa.

Quatro hipóteses foram levantadas para avaliar as estratégias sobre o desempenho da cadeia de suprimento do cimento, apresentadas no quadro 5.

Quadro 5 - Lista de Hipóteses

\begin{tabular}{|c|c|}
\hline Hipótese & Descrição \\
\hline $\mathrm{H} 1$ & $\begin{array}{l}\text { Uma cadeia de suprimento de cimento com baixo risco de demanda e baixo risco de fornecimento vai ter uma melhor } \\
\text { lucratividade com a estratégia de cadeia de suprimento puxada do que com cadeia de suprimento empurrada. }\end{array}$ \\
\hline $\mathrm{H} 2$ & $\begin{array}{l}\text { Uma cadeia de suprimento de cimento com baixo risco de demanda e alto risco de fornecimento vai ter uma melhor } \\
\text { lucratividade com a estratégia de cadeia de suprimento puxada do que com cadeia de suprimento empurrada. }\end{array}$ \\
\hline $\mathrm{H} 3$ & $\begin{array}{l}\text { Uma cadeia de suprimento de cimento com alto risco de demanda e baixo risco de fornecimento vai ter uma melhor } \\
\text { lucratividade com a estratégia de cadeia de suprimento puxada do que com cadeia de suprimento empurrada. }\end{array}$ \\
\hline $\mathrm{H} 4$ & $\begin{array}{l}\text { Uma cadeia de suprimento de cimento com alto risco de demanda e alto risco de fornecimento vai ter uma melhor } \\
\text { lucratividade com a estratégia de cadeia de suprimento puxada do que com cadeia de suprimento empurrada. }\end{array}$ \\
\hline
\end{tabular}

Fonte: O Autor

Entende-se "Risco de Demanda" como o risco de não se conseguir atender os clientes dos CDs Regionais por falta de produto devido a variação da demanda. Entende-se como "Risco de Fornecimento" como sendo o risco envolvido na transferência de produtos entre o Cd Central e os CDs regionais devido a variação no lead time.

Para testar estas hipóteses, foi desenvolvida uma modelagem computacional de uma cadeia de suprimentos de cimentos, representada na Figura 19 e composta por: um fabricante, 
quatro centros de distribuição e os clientes. O Fabricante está baseado no Rio de Janeiro, SP, e os centros de distribuição no rio de Janeiro, São Paulo e Minas Gerais que atendem os clientes em um raio máximo de $100 \mathrm{Km}$. O fabricante vende um único produto: Cimento tipo CPIII32 em granel e ensacado. Para a simulação foi considerado somente o cimento ensacado que é o tipo produto que é distribuído através dos centros de distribuição e comercializado em sacos de $50 \mathrm{Kg}$ cada.

Figura 19 - Cadeia de Suprimento Simulada

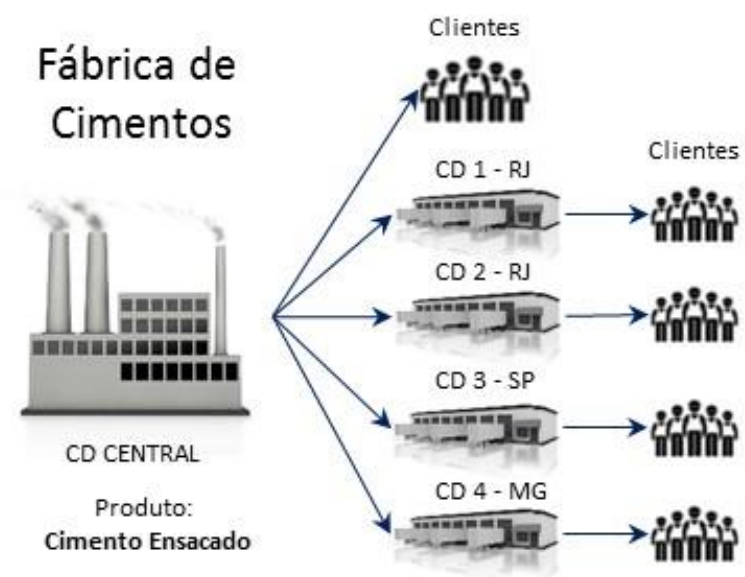

Fonte: O Autor

\subsubsection{Passo 2 - Especificação dos critérios de desempenho e parâmetros do sistema}

Os eventos de risco foram escolhidos como variáveis independentes para o modelo de simulação. Mais de 30 eventos de risco (oferta e demanda) foram identificados na literatura. Alguns exemplos de eventos de risco são: flutuação da demanda, alterações do preço do combustível e atrasos na entrega do CD central para os CD regionais. No entanto, os riscos foram selecionados tendo como base os eventos mais relevantes para a cadeia de suprimento de cimento em análise. Os eventos de risco foram agrupados em duas categorias (oferta e demanda) com base na manifestação do evento e sua relevância para a cadeia de suprimento.

A Tabela 1 fornece as distribuições estatísticas das variáveis independentes, suas definições e valores. Para construção desta tabela foram levantadas informações históricas de 1 ano de operação e analisadas com o software estatístico Stat Fit ${ }^{\circledR}$, pertencente ao pacote do 
simulador Promodel ${ }^{\circledR}$, que definiu as curvas estatísticas adequadas de lead time e demanda de cada fluxo logístico.

Os eventos de risco de fornecimento são divididos em variabilidade de tempo de entrega e de custo de pedido. O risco do lado da demanda é manifestado pela variabilidade da demanda. As fontes de dados das variáveis independentes serão discutidas em detalhe na próxima etapa.

Os valores da Tabela 1 foram utilizados para operacionalizar as estratégias da cadeia de suprimentos de cimento. O baixo risco de fornecimento é operacionalizado como baixa variabilidade do tempo de entrega do $C D$ central e o alto risco de suprimento é operacionalizado como alta variabilidade do tempo de entrega do CD central. O baixo risco da demanda é operacionalizado como baixa variabilidade da demanda e o alto risco da demanda como alta variabilidade demanda ambos representados por sua respectiva curva estatística contendo informações sobre o tipo de distribuição (Distrib.), a Média (Média) e o Desvio Padrão (DP).

A estratégia de cadeia de suprimento empurrada é operacionalizada através da prática do CD central dividir a produção para estoque da fábrica de cimento em lotes de transferência equivalentes a vendas passadas e encaminhá-las aos respectivos $\mathrm{CD}$ regionais que são enviados aos clientes finais por demanda. Na estratégia de cadeia de suprimento puxada, os lotes são montados no CD central em função da demanda real dos clientes do CD regional, ou seja, os lotes de transferência são montados contra pedido e são enviados posteriormente aos clientes pelo CD regional por demanda.

Semelhante as variáveis independentes, as variáveis dependentes foram selecionados com base em revisão de literatura e objetivo da pesquisa. $\mathrm{O}$ teste de hipóteses é baseado no lucro total da cadeia de suprimentos, além deste indicador foi registrado o volume de ruptura para auxiliar na interpretação dos resultados (quadro 6). 
Tabela 1 - Variáveis Independentes do Modelo de Simulação

\begin{tabular}{|c|c|c|c|c|c|c|c|}
\hline Fator de risco & Definição/Distribuição & \multicolumn{3}{|c|}{ Baixo risco } & \multicolumn{3}{|c|}{ Alto risco } \\
\hline \multicolumn{8}{|c|}{ Risco de Fornecimento - Cimento Ensacado } \\
\hline \multicolumn{8}{|c|}{ Tempo de entrega entre o CD central e o CD regional (Horas) } \\
\hline \multirow{6}{*}{ 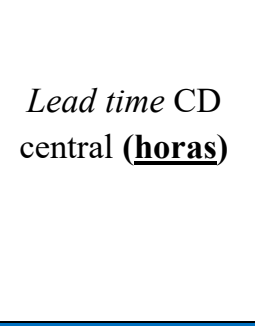 } & Modo de Entrega & Distrib. & Média & DP & Distrib. & Média & DP \\
\hline & Venda Direta & Normal & 4,48 & 0,6 & Normal & 4,48 & 1,8 \\
\hline & $\mathrm{CD} 1$ & Normal & 13,7 & 3,4 & Normal & 13,7 & 10,2 \\
\hline & CD2 & Normal & 13,0 & 3,5 & Normal & 13,0 & 10,5 \\
\hline & CD3 & Normal & 14,4 & 3,5 & Normal & 14,4 & 10,5 \\
\hline & CD4 & Normal & 14,3 & 3,5 & Normal & 14,3 & 10,5 \\
\hline \multicolumn{8}{|c|}{ Risco de Demanda- Cimento Ensacado } \\
\hline \multicolumn{8}{|c|}{ Variação média da demanda diária (Toneladas) } \\
\hline \multirow{6}{*}{$\begin{array}{l}\text { Variabilidade da } \\
\text { demanda } \\
\text { (tons) }\end{array}$} & Modo de Entrega & Distrib. & Média & DP & Distrib. & Média & DP \\
\hline & Venda Direta & Normal & 1.700 & 772 & Normal & 1.700 & 2.316 \\
\hline & $\mathrm{CD} 1$ & Normal & 1.413 & 805 & Normal & 1.413 & 2.415 \\
\hline & CD2 & Normal & 914 & 469 & Normal & 914 & 1.408 \\
\hline & CD3 & Normal & 653 & 446 & Normal & 653 & 1.337 \\
\hline & CD4 & Normal & 482 & 270 & Normal & 482 & 809 \\
\hline
\end{tabular}

Fonte: O Autor

Quadro 6 - Variáveis Dependentes do Modelo de Simulação

\begin{tabular}{|c|c|c|}
\hline Métrica de desempenho & Definição/Operacionalização & Unidade de medida \\
\hline Lucro da cadeia de suprimento & Diferença entre as receitas totais e custos totais & Valor em \$ \\
\hline Ruptura & $\begin{array}{c}\text { Incapacidade de atender à demanda dos clientes devido a } \\
\text { não disponibilidade de produtos. }\end{array}$ & Volume (ton) \\
\hline
\end{tabular}

Fonte: O Autor

\subsubsection{Passo 3 - Desenvolvimento e validação do modelo conceitual}

Especialistas em cada etapa do processo foram consultados e entrevistados para auxiliar no desenvolvimento do modelo conceitual. A equipe primária foi composta por três especialistas. Um especialista em simulação com larga experiência em modelagem, um especialista em logística e um especialista em gestão. A modelagem começou de forma simples e foi-se agregando níveis superiores de complexidade até atingir níveis adequados para representar o sistema real. A equipe acadêmica, em reuniões semanais revisou o processo, 
complementos e mudanças realizadas no modelo em função de revisões da literatura ou maior conhecimento do processo investigado. Depois de uma cobertura aceitável de detalhes pela equipe primária, dois profissionais de empresa investigada revisaram o modelo conceitual separadamente, indicaram oportunidades de melhorias e aprovaram sua adequação do processo final à realidade da cadeia de suprimento investigada.

O sistema analisado no estudo pode ser dividido em seis etapas macro, representadas esquematicamente na figura 20. As operações são detalhadas pela metodologia IDEF-SIM no capítulo 3.4.3.7.

(1) Demanda gerada pelo cliente;

(2) Ordem recebida e processada pelo Centro de Distribuição Central;

(3) Ordem enviada do CD Central para o CD regional;

(4) Ordem recebida e processada pelo Centro de Distribuição Regional;

(5) Ordem enviada do CD regional para os clientes.

(6) Transferência do CD central ao Centro de Distribuição Regional;

Figura 20 - Fluxo Operacional Analisado

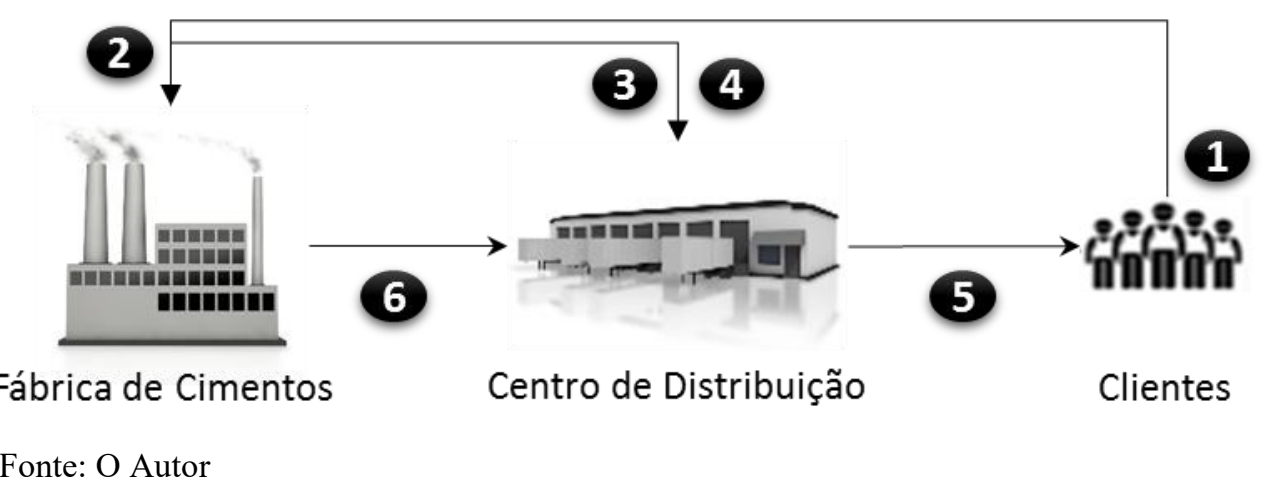

As seções a seguir detalham as seis etapas.

\subsubsection{Etapa 1 - Demanda gerada pelo cliente.}

Cada centro de distribuição atende um conjunto de clientes de sua área de atuação. A demanda é gerada diariamente em cada cliente. A demanda agregada de cada centro de distribuição regional é distribuída normalmente com média e desvio padrão distinta, conforme mostra a tabela 1. A demanda média de cada CD regional é derivada do banco de dados 
secundário de uma grande empresa multinacional fabricante de cimento. O desvio padrão é configurado para $\mathrm{X}$ unidades para o cenário de baixo risco de demanda e $3 \mathrm{X}$ unidades para o cenário de alto risco de demanda. Isto define os coeficientes de variação a 0,1 e 0,3 para os cenários de risco de demanda baixos e altos, respectivamente. Estes coeficientes de variação foram usados em pesquisas anteriores (Mentzer e Gomes, 1991) para operacionalizar cenários de risco de demanda baixa e alta, e foram apoiados durante a validação conceitual com especialistas.

\subsubsection{Etapa 2 - Ordem recebida e processada pelo Centro de Distribuição Central}

A demanda gerada pelo cliente é processada pelo Centro de Distribuição Central que aprova as vendas conforme as políticas de crédito estabelecidas. As ordens são processadas eletronicamente e instantaneamente.

\subsubsection{Etapa 3 - Ordem enviada do CD Central para o CD regional}

As ordens de venda aprovadas no CD Central são transmitidas instantaneamente para os CDs regionais, sem nenhum custo.

\subsubsection{Etapa 4 - Ordem recebida e processada pelo Centro de Distribuição Regional:}

Os pedidos feitos pelos clientes são recebidos instantaneamente no CD Regional e o processamento começa imediatamente. O processamento ocorre vinte e quatro horas por dia, cinco dias por semana e inclui as atividades de separação, embalagem e transporte das mercadorias. A capacidade de atendimento de pedidos é definida em 5 Mil toneladas por dia. O valor do estoque do produto é definido pelo custo médio de produção. A taxa de armazenagem de estoques é fixada em $17 \%$ ao ano (Wilson, 2006).

\subsubsection{Etapa 5 - Ordem enviada do CD regional para os Clientes}

Após o CD Regional processar as ordens, os bens são enviados diariamente para os clientes, o tempo de trânsito é fixado em 3 horas. O custo de transporte é de R $\$ 0,4 /$ ton.km entregues em clientes localizados em um raio médio de $100 \mathrm{Km}$. As mercadorias são enviadas aos clientes de segunda a sexta. Os tempos de trânsito e os custos foram baseados em entrevistas qualitativas e cotações de empresas de transporte. Encomendas não podem ser entregues com atraso aos clientes. Caso os bens solicitados pelo cliente não estejam em estoque, a venda é 
perdida. O preço de venda dos produtos é de $\mathrm{R} \$ 450 /$ ton baseado em dados secundários de um grande fabricante de cimento e que demonstra que o lucro líquido é cerca de $20 \%$ a $25 \%$.

\subsubsection{Etapa 6 - Transferência do CD central ao Centro de Distribuição Regional;}

As encomendas dos CD regionais são processadas baseadas na regra de prioridade: "primeiro a entrar, primeiro a sair". O CD central tem restrição de capacidade máxima de 10 Mil tons de produto acabado, não trabalha com pedidos pendentes e cada ordem é preenchida completamente. O tempo de processamento da ordem no CD central segue uma distribuição normal com uma média de 1 dia e desvio padrão de 0,3 dia.

A fábrica opera à taxa de produção constante de 5 mil toneladas de cimento por dia, o produto é armazenado em silos com capacidade de 15 mil toneladas (3 dias de produção), a produção sofre interrupção caso ocorra algum evento que bloqueie o escoamento do produto acabado e somente quando os silos estiverem cheios. O cimento segue dos silos para duas escadeiras que empacotam o material em unidades de 50 quilos que são posteriormente paletizados automaticamente com 35 sacos por palete, o material é então armazenado e fica aguardando o transporte.

Após as ordens serem processadas, os níveis de estoque de produtos acabados são verificados a cada meia hora. No cenário de cadeia de suprimento puxada, ao final do dia, o nível de estoque é registrado e uma ordem de reposição de quantidade variável (Q) é colocada para o CD central. No cenário de cadeia de suprimento empurrada o próprio CD central determina a quantidade de transferência diária para o CD regional em função de médias históricas, mantendo 2 dias de projeção de vendas como estoque de segurança em cada CD.

O valor para Q é calculado através da seguinte fórmula (Chopra, 2003), que também é uma prática comercial padrão:

$$
\mathrm{Q}=\mathrm{D}(\mathrm{T}+\mathrm{L})+\mathrm{NORM} . \mathrm{INV}(\mathrm{NSC}) * \sigma_{\mathrm{T}+\mathrm{L}}-\mathrm{Q}_{\mathrm{f}}-\mathrm{Q}_{\mathrm{p}}
$$

Onde: $\mathrm{D}=$ Demanda média para o período; $\mathrm{T}=$ Intervalo econômico entre pedidos; $\mathrm{L}=$ Tempo de espera médio para reposição; NORM = Distribuição normal; INV = Inverso; NSC = Nível de serviço de ciclo desejado; $\sigma_{\mathrm{T}+\mathrm{L}}=$ Desvio padrão da demanda durante $\mathrm{T}+\mathrm{L}$ períodos; $\mathrm{Q}_{\mathrm{f}}$ $=$ Saldo atual em estoque, $\mathrm{Q}_{\mathrm{p}}=$ quantidades solicitadas pendentes.

A quantidade de produto a ser pedida é baseada em um nível máximo de estoque estabelecido para cada item do estoque, na quantidade de estoque existente no momento 
(estoque à mão) e na quantidade de produtos já pedida, mas cuja entrega ainda não ocorreu (estoque em transito). Finalmente o valor calculado da $\mathrm{Q}$ foi arredondado para o número inteiro mais próximo que é múltiplo de 28 ton (peso médio do caminhão de carga para o cimento na transferência para os CDs).

O desvio padrão da demanda durante $\mathrm{T}+\mathrm{L}$ períodos $(\sigma \mathrm{T}+\mathrm{L})$ é calculado como:

$$
\sigma_{T+L}=\sqrt{(T+L) * \sigma_{R}^{2}+R^{2} * S_{L}^{2}}
$$

Onde $\sigma_{\mathrm{R}}$ é o desvio padrão do erro da demanda, $\mathrm{R}=$ Demanda prevista para o próximo período e $\mathrm{S}_{\mathrm{L}}$ o o desvio padrão do lead time.

O intervalo econômico ótimo é calculado pela formula:

$$
T^{*}=\sqrt{\frac{2 \times\left(S+C_{e s c}\right)}{h x R_{a} \times C}}
$$

Onde:

$\mathrm{S}=$ Custo do pedido unitário; $\mathrm{C}_{\mathrm{esc}}=$ Custo de falta por ciclo; $\mathrm{h}=$ Taxa de manutenção de estoque; $\mathrm{R}_{\mathrm{a}}=$ Demanda anual $\mathrm{C}=$ Custo do valor do produto.

O custo de falta esperada por ciclo de reposição pode ser avaliada, segundo Chopra (2003) como:

$\mathrm{C}_{\mathrm{esc}}=\left(\mathrm{P}_{\mathrm{V}-\mathrm{C}} \mathrm{C}\right) *\left[-s s\left(1-\mathrm{DIST} . \mathrm{NORM}\left(s s / \sigma_{\mathrm{L}} ; 0 ; 1 ; 1\right)\right)+\sigma_{\mathrm{L}}\right.$ DIST.NORM $\left.\left(s s / \sigma_{\mathrm{L}} ; 0 ; 1 ; 0\right)\right]$

O custo de produção $(\mathrm{C})$ é definido em função do ritmo de produção. O custo de produção é de $\mathrm{R} \$ 150 /$ ton para a cadencia máxima de produção. Normalmente, o custo de produção é 5\% mais caro para cada $5 \%$ de redução da cadência de produção (redução linear).

Os bens são transferidos para os CD's regionais usando o transporte rodoviário em lotes de cargas completas. Os tempos de transporte do CD central e Cd's regionais são apresentados 
na Tabela 2. Os valores de desvio padrão são maiores no cenário de alto risco. Estes valores de desvio padrão são equivalentes aos coeficientes de variação $(\mathrm{CV})$ para 0,1 e 0,3 para os cenários de baixo e alto risco, respectivamente. Estes valores de CV foram usados no passado por Gomes e Mentzer (1991) para operacionalizar variabilidade do tempo de transporte em situações de baixo e de alto risco (Tabela 2).

Tabela 2 - Tempos de Transporte

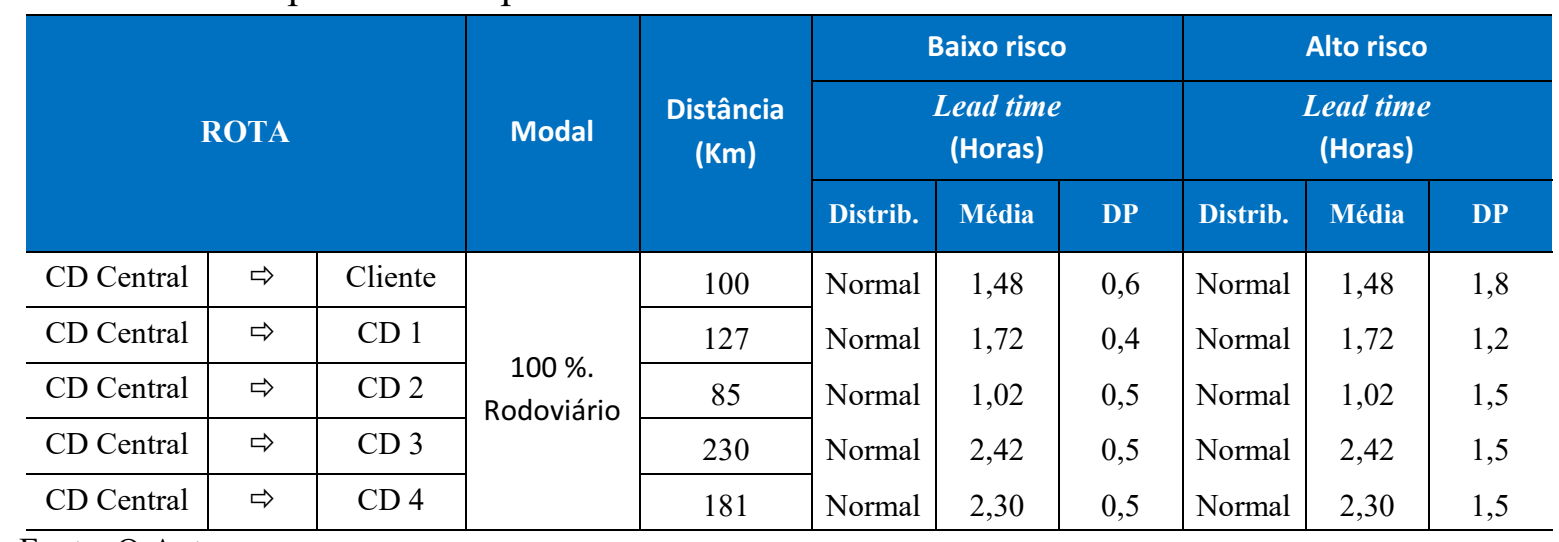

Fonte: O Autor

\subsubsection{Modelo conceitual das operações}

As operações da fábrica foram detalhadas utilizando a metodologia IDEF-SIM que permite a elaboração de modelos conceituais com informações que facilitam o desenvolvimento do modelo computacional, sua validação e documentação (figura 21) 


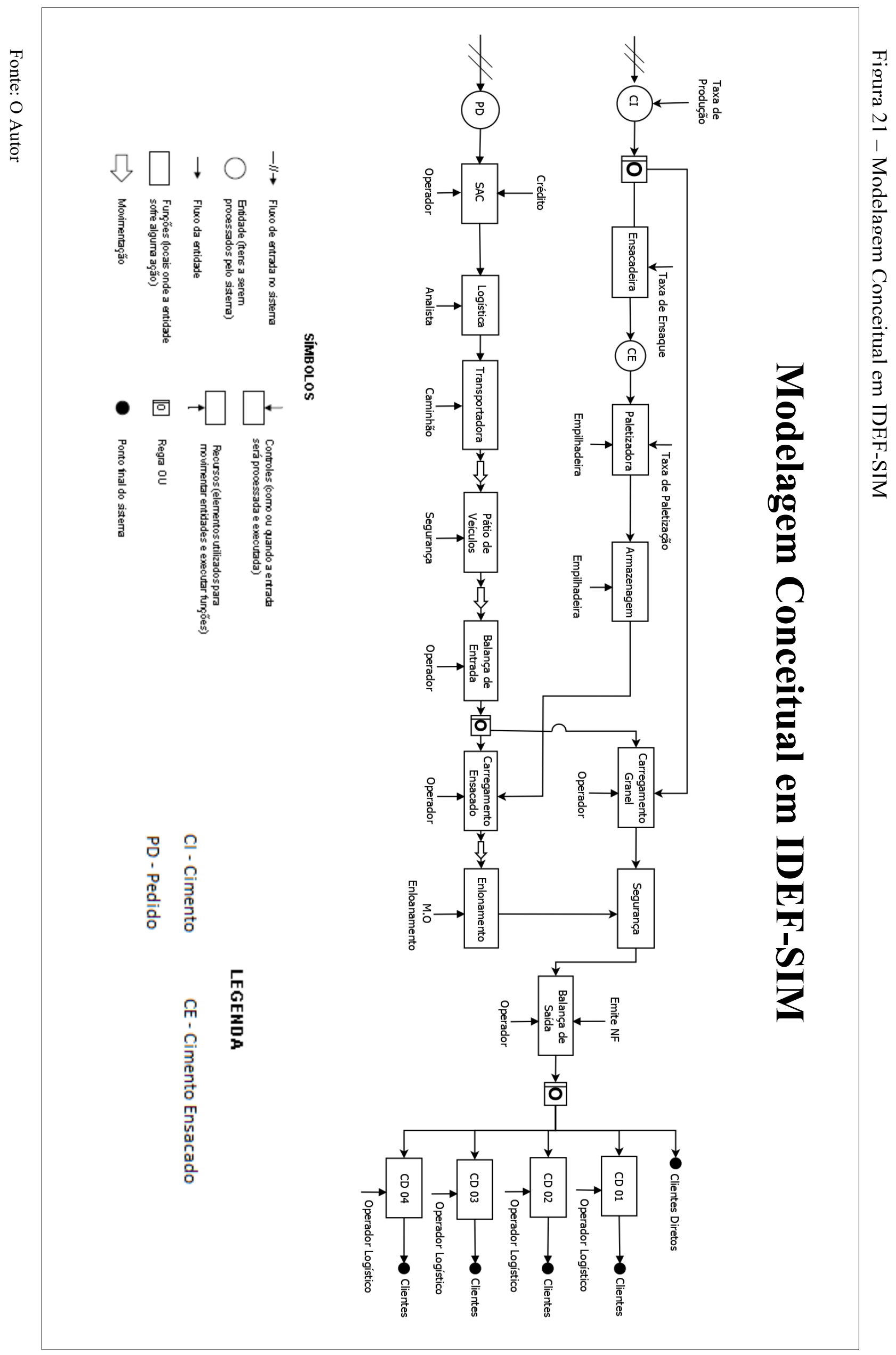


Para que se possa passar para a próxima fase de desenvolvimento, o modelo conceitual precisa ser validado. Esta validação é de grande importância, pois garante que o modelo representa corretamente o funcionamento do sistema analisado, tornando-o assim mais fiel a realidade. Para validação do modelo utilizando a técnica de modelagem IDEF-SIM, realizouse uma nova reunião com todos os envolvidos no projeto que após a familiarização com a metodologia revisaram cada processo detalhadamente e aprovaram a modelagem conceitual.

\subsubsection{Passo 4 - Coleta de dados}

Os dados quantitativos foram obtidos através de mapeamento dos processos e recursos de uma indústria cimenteira o que possibilitou a estruturação de um banco de dados com a descrição das atividades e observações de tempos, movimentos e capacidades. A partir das observações foi possível realizar a cronoanálise dos dados a fim de determinar a variabilidade dos tempos de cada atividade. Essa parte é indispensável para a inserção dos tempos no software de simulação Promodel®. Devido a confidencialidade dos dados da empresa analisada, somente houve aprovação para divulgação neste trabalho das informações que são de conhecimento público.

Os dados qualitativos foram obtidos através de entrevistas com gestores da mesma indústria.

a) Demandas do sistema

Foram adotados para simulação os dados de demanda de vendas de cimentos do ano de 2014, obtidos de bases de dados da empresa (Tabela 3). 
Tabela 3 - Demandas do Sistema

\begin{tabular}{|c|c|c|c|c|c|c|c|}
\hline \multicolumn{8}{|c|}{ Demanda Projetada de Cimentos / Ano (Mil tons) } \\
\hline $\begin{array}{c}\text { Mês } \\
\text { (Ano 2014) }\end{array}$ & $\begin{array}{c}\text { Entrega } \\
\text { Direta Fábrica } \\
\text { Ensacado }\end{array}$ & $\begin{array}{c}\text { Entrega } \\
\text { Direta Fábrica } \\
\text { Granel }\end{array}$ & $\begin{array}{c}\text { Entrega a } \\
\text { partir do } \\
\text { CD_1 }\end{array}$ & $\begin{array}{c}\text { Entrega a } \\
\text { partir do } \\
\text { CD_2 }\end{array}$ & $\begin{array}{c}\text { Entrega a } \\
\text { partir do } \\
\text { CD_3 }\end{array}$ & $\begin{array}{c}\text { Entrega a } \\
\text { partir do } \\
\text { CD_4 }\end{array}$ & $\begin{array}{c}\text { Volume } \\
\text { Total }\end{array}$ \\
\hline Jan & 42 & 31 & 46 & 21 & 13 & 9 & 162 \\
\hline Fev & 39 & 27 & 22 & 8 & 7 & 1 & 104 \\
\hline Mar & 43 & 27 & 25 & 13 & 7 & 3 & 118 \\
\hline Abr & 39 & 31 & 32 & 19 & 10 & 5 & 136 \\
\hline Mai & 47 & 38 & 38 & 34 & 15 & 8 & 180 \\
\hline Jun & 43 & 33 & 36 & 28 & 11 & 12 & 164 \\
\hline Jul & 53 & 36 & 33 & 32 & 14 & 10 & 176 \\
\hline Ago & 54 & 33 & 25 & 21 & 12 & 9 & 154 \\
\hline Set & 48 & 27 & 27 & 31 & 13 & 9 & 155 \\
\hline Out & 49 & 29 & 29 & 35 & 14 & 11 & 166 \\
\hline Nov & 44 & 26 & 23 & 31 & 13 & 9 & 147 \\
\hline Dez & 39 & 22 & 26 & 28 & 13 & 10 & 137 \\
\hline Total Anual & 540 & 360 & 360 & 300 & 144 & 96 & 1.800 \\
\hline Média Mensal & 45 & 30 & 30 & 25 & 12 & 8 & 150 \\
\hline
\end{tabular}

Fonte: O Autor

Devido à alta disponibilidade de veículos na região e a inexistência de ocorrências de falhas de transporte por falta de veículos, adotou-se como premissa para este trabalho que o transporte esteja sempre disponível quando solicitado pelo sistema.

\subsubsection{Passo 5 - Desenvolvimento e verificação do modelo computacional}

O modelo desenvolvido foi implementado utilizando-se o software Promodel ${ }^{\circledR}$ que permite reproduzir a complexidade de processos reais, incorporando a variabilidade e interdependências para realizar análises e mudanças e, assim, aperfeiçoar sistemas e melhorar indicadores.

A construção do modelo da fábrica de cimentos foi realizada seguindo as seguintes etapas, considerando as características do software utilizado.

a) Criação da estrutura do modelo: nesta etapa definiram-se parâmetros como a unidade de tempo e a distância que foram utilizados na simulação, e a escolha do tipo de biblioteca que contém as imagens gráficas necessárias e a adequação da escala da animação compatível com a imagem de fundo construída em CAD (computer aided design) referente a estrutura real da empresa.

b) Locais: os locais são os elementos responsáveis por identificar onde ocorrerão os processos logísticos estudados, representam basicamente todos os estoques da fábrica, Centros de distribuição e Clientes bem como os locais onde as entidades chegam ou 
sofrem algum tipo de transformação e refletem fielmente a operação existente.

c) Entidades: São os objetos que utilizarão serviços do sistema, sofrem movimentação de um local para outro ou algum tipo de transformação, neste caso são os sacos de cimentos. $\mathrm{O}$ software Promodel ${ }^{\circledR}$ permite a configuração das entidades como tamanho, cor, velocidade de movimentação, identificação e outras possibilidades, que tornam o modelo mais parecido com a realidade.

d) Rede de Caminhos: após a definição dos locais e das entidades, o passo seguinte é a definição dos caminhos por onde as entidades transitam, ou seja, em quais os caminhos possíveis os veículos podem se movimentar dentro e fora da fábrica. A estrutura montada permite o transito dos veículos dentro da fábrica e o escoamento da produção para os clientes diretamente ou passando por um centro de distribuição. Um ponto importante é que o desenho está em escala no sistema e todas as distâncias entre os locais são respeitadas o que faz com que os tempos de movimentação das entidades seja realista.

e) Recursos: os recursos são objetos que transportam as entidades de um local para outro. Para esta simulação os recursos considerados são as empilhadeiras, caminhões e operários para enlonamanto dos veículos.

f) Processos: o processo é fundamental para construção do modelo, pois, dá "vida" a ele, ou seja, define-se a ação que cada entidade e recurso sofrem na simulação bem como as lógicas de cada operação.

g) Chegada: nesta etapa é necessário definir os parâmetros de chegada e a quantidade das entidades, isto é, quando e qual a frequência com que as entidades são inseridas no modelo.

h) Variáveis: Foram criadas 102 variáveis, necessárias para controlar todas as etapas e estatísticas dos processos analisados.

Demais configurações foram aplicadas para que o sistema se aproximasse o mais possível da realidade. 
A figura 22 mostra o modelo final construído no software Promodel®, que representa a empresa em estudo. A figura 21 mostra os caminhos onde as entidades podem se movimentar.

Figura 22 - Modelo Computacional em Promodel ${ }^{\circledR}$.

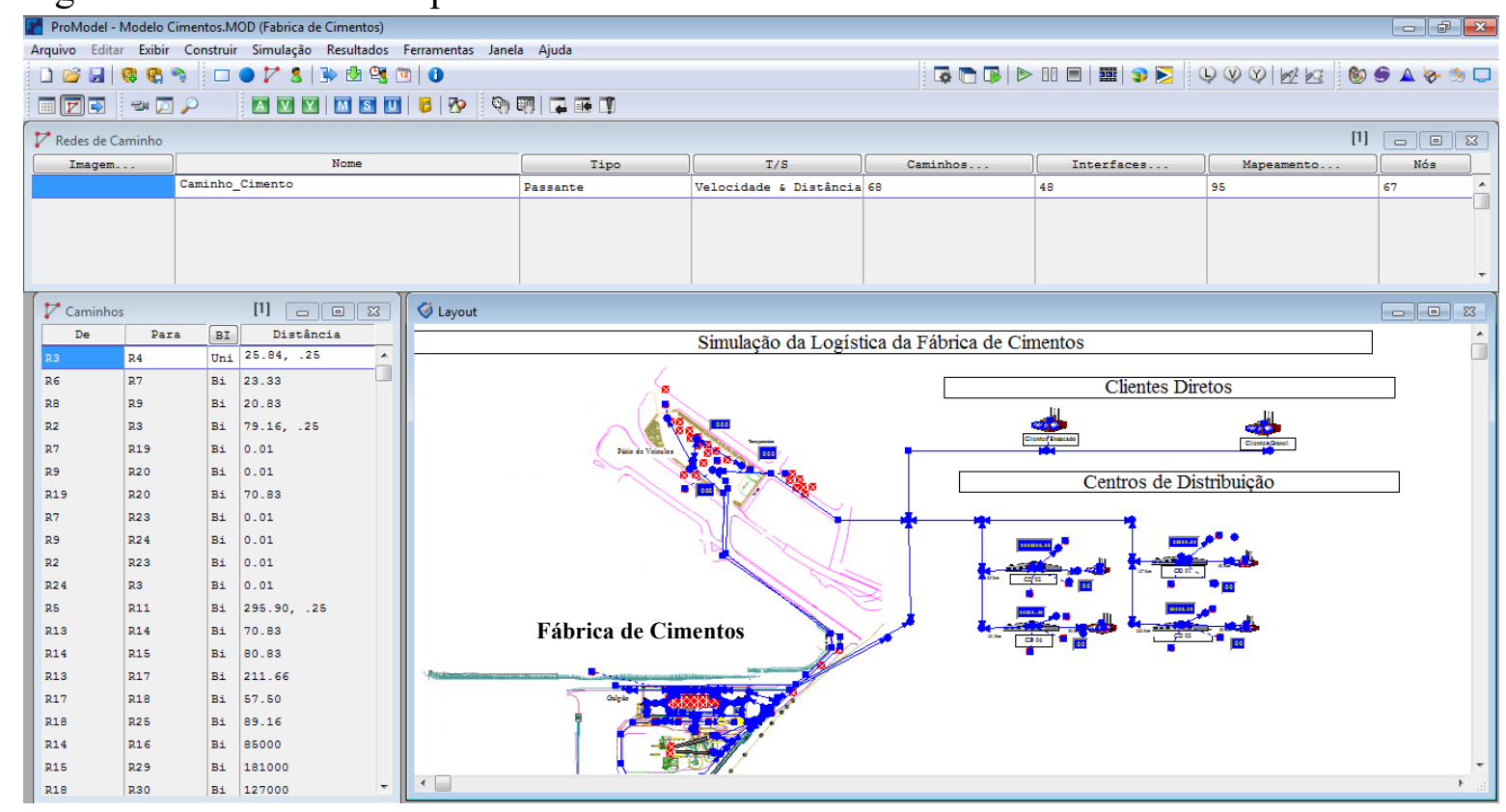

Fonte: O Autor.

Neste estudo o modelo computacional foi validado em quatro fases. Primeiro, foram avaliados os processos e lógicas do modelo, bem como se as entradas de dados do modelo estavam corretas. A lógica para cálculo do modelo puxado contra empurrado é de grande complexidade e foi validada e testada a fim de garantir sua confiabilidade. O envolvimento contínuo dos especialistas também minimizou a possibilidade de erros de modelamento.

Segundo, as soluções de partes do modelo foram comparadas com cálculos manuais para determinar a eficácia dos sub-processos. A validação durante este processo incluiu a verificação do tempo de transporte, das filas de embarques em toda a cadeia de suprimentos e das políticas de inventário, incluindo os custos de produção e transporte, a demanda, os tempos de processamento de pedidos, tempos de transporte e a sua variabilidade e comparação com dados reais de operação. Os sub-processos quando simulados com dados operacionais apresentaram grande aderência aos sub-processos reais sendo aceitos e validados pelos especialistas envolvidos.

Em terceiro, os resultados da simulação com pequenos lotes de produtos foram comparados com os resultados com os cálculos manuais para avaliar o grau de confiabilidade do modelo completo. A validação incluiu a análise dos custos de transporte, dos custos 
produção e processamento e atendimento de pedidos em todos os cenários: baixo e alto risco. Os resultados simulados se mostraram aderentes quando comparados aos da operação real, o modelo simulado respondeu de forma muito próxima ao real, sendo validado para simular os diferentes cenários propostos.

Em quarto, todos os eventos foram verificados manualmente em cada segmento do modelo. O modelo foi construído por etapas, cada etapa substituiu elementos determinísticos por estocásticos até se chegar a um modelo principal completo, integrado e funcional.

\subsubsection{Passo 6 - Validação do modelo}

O processo de validação do modelo é uma fase de extrema importância para garantir que os resultados apresentados representem a realidade das operações de forma precisa e ofereçam confiabilidade para análises futuras.

Conforme visto na revisão de literatura, existem diversas técnicas de validação, como por exemplo, animação, comparação com outros modelos, testes degenerativos e teste de Turing. Para este modelo, utilizou-se das técnicas de validação face a face e animação. Para a validação face a face do modelo computacional e da animação, foi realizada uma reunião com os gestores do projeto e especialistas dos processos logísticos. Primeiramente, apresentou-se novamente o modelo conceitual em IDEF-SIM para representar qual lógica o modelo computacional havia seguido. Através da animação gráfica os especialistas puderam acompanhar o funcionamento das operações e avaliar se existia algum fluxo incorreto, o que não ocorreu.

O modelo foi alimentado com dados reais de operação de um período selecionado e a análise dos resultados gerados comparados com os dados reais. Os resultados apresentados pelo modelo, tais como como utilização dos recursos, tempos e carga e descarga, filas de embarques em toda a cadeia de suprimentos e das políticas de inventário foram inspecionadas e avaliadas por comparação com o sistema real por especialistas nos processos, que validaram os dados estatisticamente através dos resultados de 32 replicações realizadas. Os resultados obtidos com a aplicação do modelo tiveram total aderência com os obtidos em situação real, garantindo a confiabilidade dos cálculos e das análises futuras.

Como todos os presentes na reunião consideraram correta a representação do modelo computacional, o mesmo foi considerado validado pelos especialistas através da validação face a face. 


\subsubsection{Passo 7 - Cenários Simulados}

Foram gerados oito cenários com a combinação de Riscos de Demanda e Riscos de Fornecimento (Tabela 1) de cimentos e estratégias de produção puxada e empurrada (Quadro 7) para validar as hipóteses levantadas. O período da simulação adotado foi de um ano. Para evitar os efeitos iniciais de aquecimento do modelo foram incluídos os valores de estoques iniciais de Matéria Prima e Produto Acabado. Todos os resultados foram registrados para viabilizar os cálculos necessários de cada cenário. O processamento de cada cenário teve uma duração média de 2 horas.

Quadro 7 - Cenários Gerados

\begin{tabular}{|c|c|c|c|c|}
\hline Cenário & $\begin{array}{c}\text { Hipótese } \\
\text { Correspondente }\end{array}$ & $\begin{array}{l}\text { Risco da } \\
\text { Demanda }\end{array}$ & $\begin{array}{c}\text { Risco de } \\
\text { Fornecimento }\end{array}$ & $\begin{array}{l}\text { Estratégia } \\
\text { Logística }\end{array}$ \\
\hline I & \multirow{2}{*}{ H1 } & Baixo & Baixo & Puxada \\
\hline II & & Baixo & Baixo & Empurrada \\
\hline III & \multirow{2}{*}{ H2 } & Baixo & Alto & Puxada \\
\hline IV & & Baixo & Alto & Empurrada \\
\hline $\mathbf{V}$ & \multirow{2}{*}{ H3 } & Alto & Baixo & Puxada \\
\hline VI & & Alto & Baixo & Empurrada \\
\hline VII & \multirow{2}{*}{ H4 } & Alto & Alto & Puxada \\
\hline VIII & & Alto & Alto & Empurrada \\
\hline
\end{tabular}

Fonte: O Autor 


\section{PASSO 8 - ANALISE DOS RESULTADOS OBTIDOS}

A partir dos resultados gerados em cada cenário foram criadas as Demonstrações de Resultados (DRE) para cada período simulado, apresentando os resultados financeiros das operações. Os indicadores EBITDA e margem EBITDA também foram calculados por se tratarem de indicadores relevantes para a indústria estudada.

Foram gerados na sequência os indicadores elencados no trabalho para análise do desempenho de cada cenário analisado.

Foram gerados também os gráficos de evolução dos estoques em cada CD para demostrar o comportamento frente as diversas situações operacionais.

A sazonalidade da demanda causa efeitos diretos nos estoques, que é evidenciada nos gráficos de 1 a 8 entre os meses de Janeiro a Março, a demanda é historicamente menor entre estes meses, resultando em estoques proporcionalmente maiores. 


\subsection{CENÁRIO I}

Este cenário foi simulado considerando um baixo risco da demanda, baixo risco de fornecimento e uma estratégia logística puxada. Os níveis de ruptura de estoques foram de 0,3 mil tons/ano e o lucro líquido atingido com esta operação foi de $\mathrm{R} \$ 111,90$ Milhões/ano. O gráfico 1 mostra a evolução dos estoques no período. A estratégia de operação simulada apresenta ser adequada ao cenário analisado.

Tabela 4 - DRE Cenário I

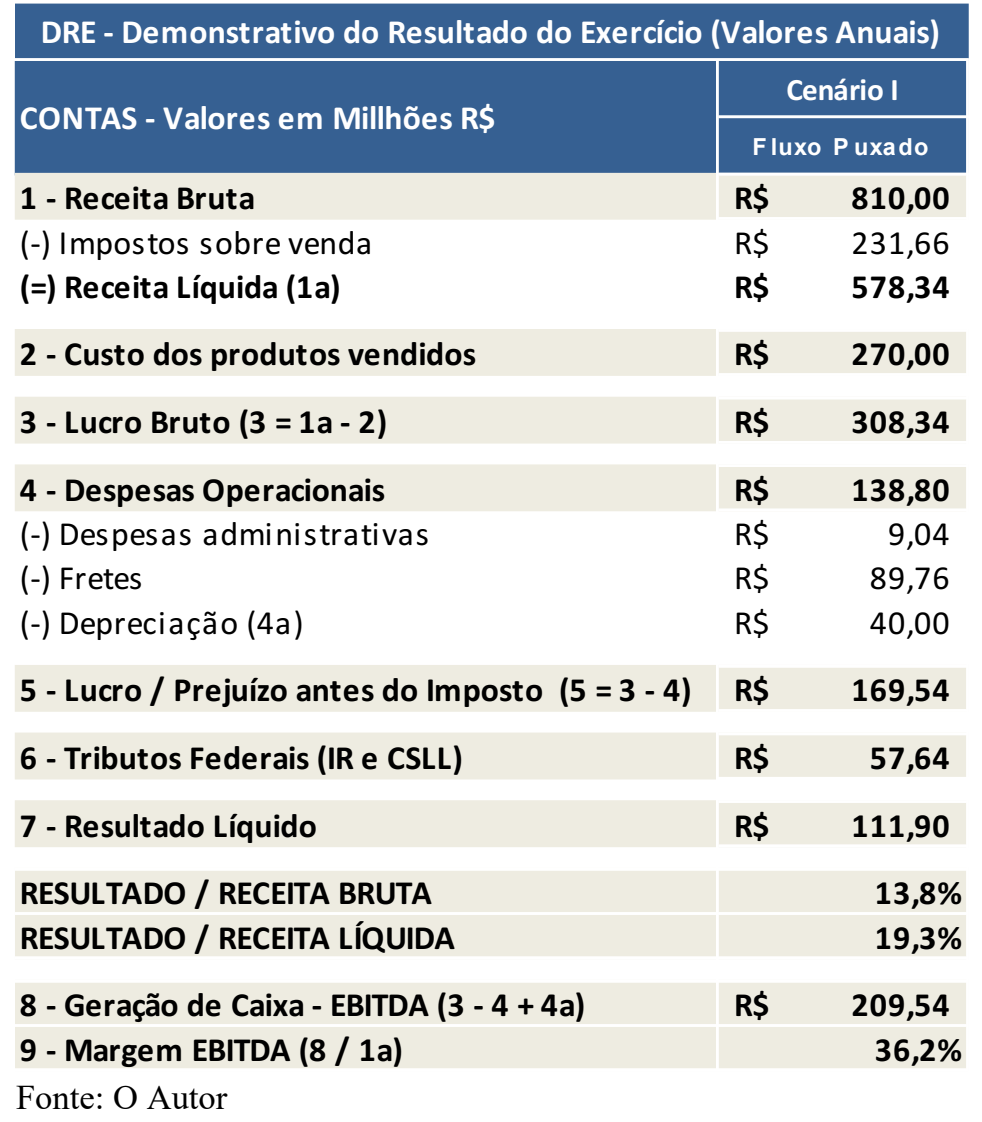

Tabela 5 - Indicadores de desempenho - Cenário I

\begin{tabular}{|c|c|}
\hline \multicolumn{2}{|c|}{ Indicadores de Desempenho (Valores Anuais) } \\
\hline Cenário & Cenário I \\
\hline Fluxo Logístico & Puxado \\
\hline Risco Demanda (Var. Demanda) & Baixo \\
\hline Risco Fornecimento (Var. Lead time) & Baixo \\
\hline Lucro Líquido da cadeia de suprimento (MM R\$) & $\mathbf{R} \mathbf{1 1 1 , 9 0}$ \\
\hline Ruptura (Mil tons) & $\mathbf{0 , 3 0}$ \\
\hline
\end{tabular}

Fonte: O Autor 


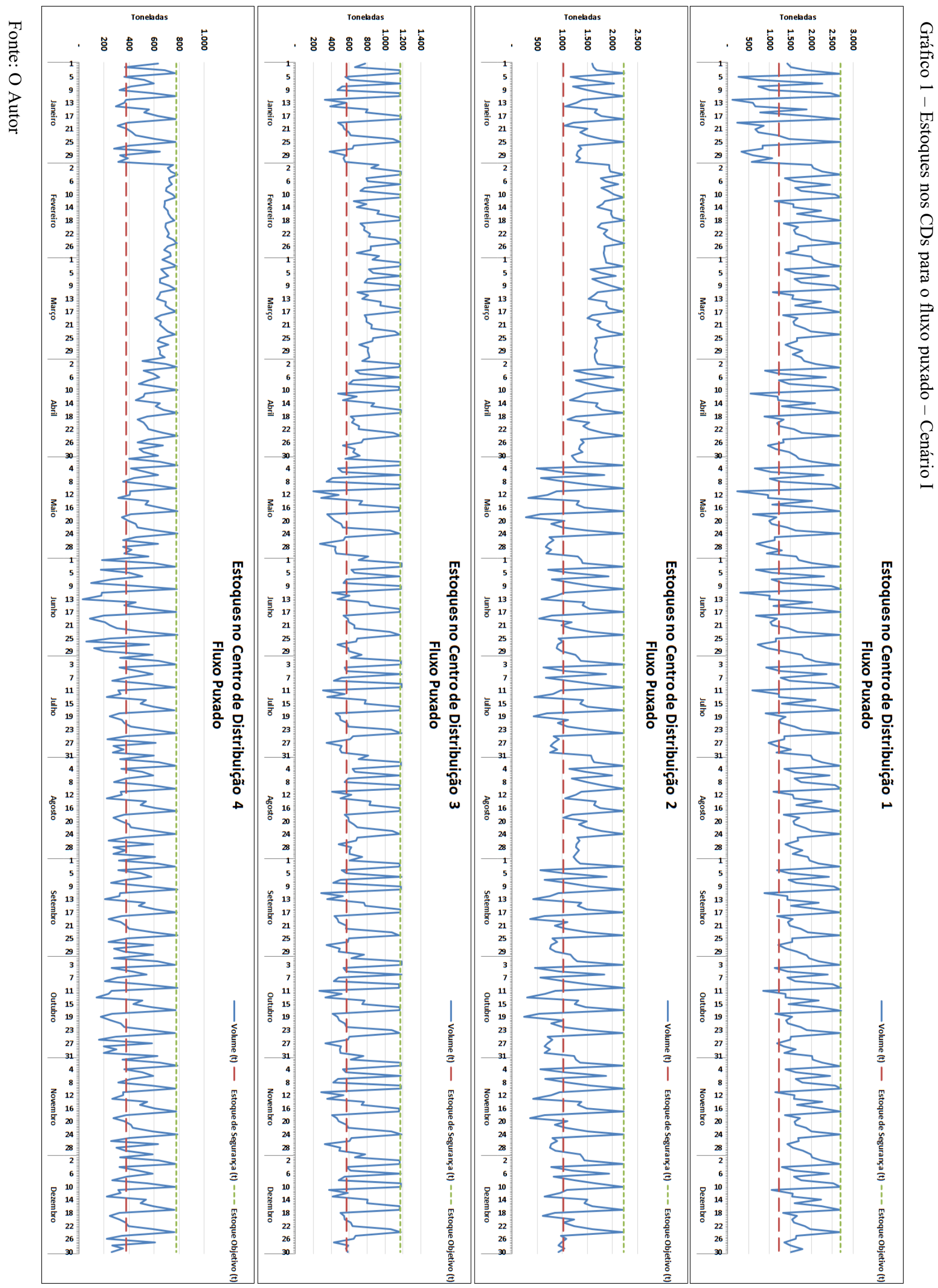




\subsection{CENÁRIO II}

Este cenário foi simulado considerando um baixo risco da demanda, baixo risco de fornecimento e uma estratégia logística empurrada. Os níveis de ruptura de estoques foram de 5 mil tons/ano e o lucro líquido atingido com esta operação foi de R \$102,94 Milhões/ano. O gráfico 2 mostra a evolução dos estoques no período. A estratégia de operação simulada apresenta ser adequada ao cenário analisado apesar de perdas por ruptura de estoques em alguns períodos do ano.

Tabela 6 - DRE Cenário II

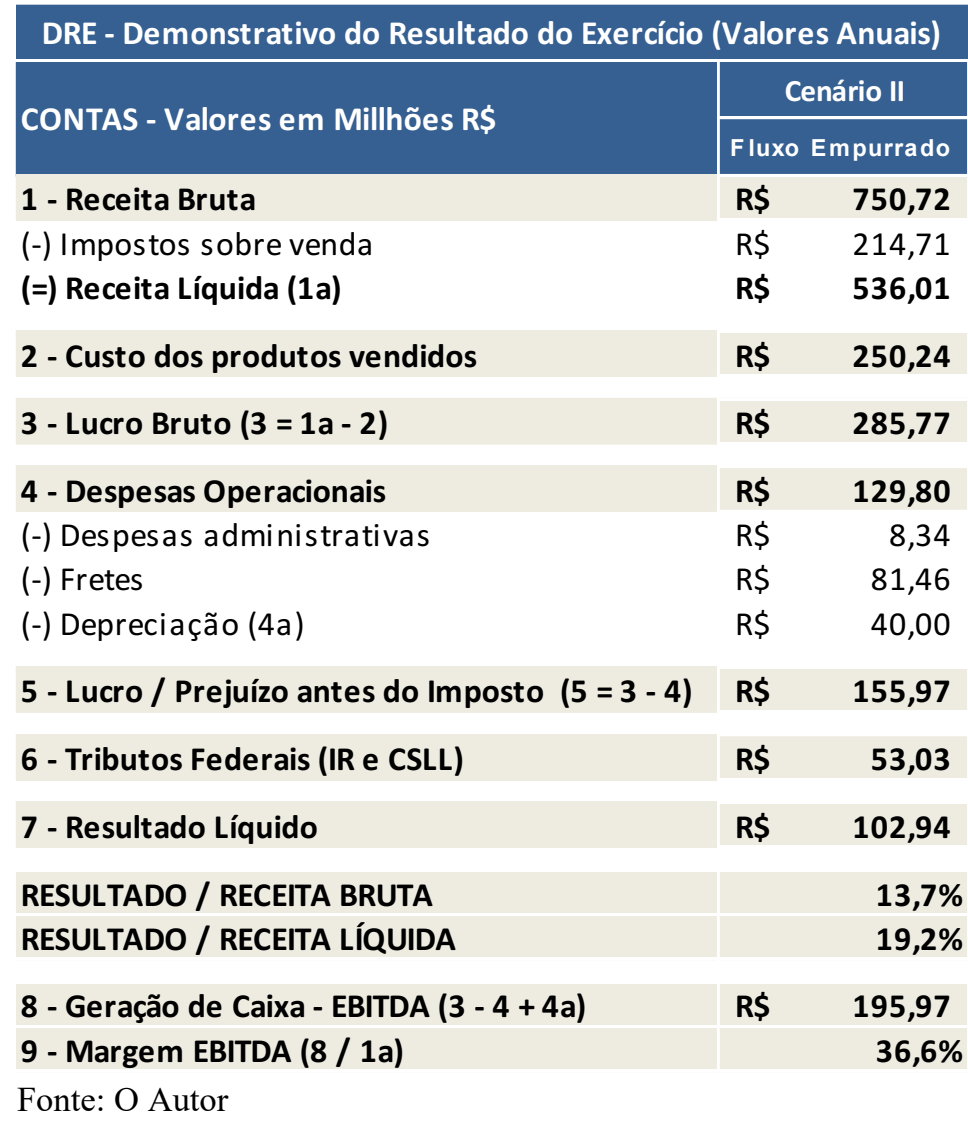

Tabela 7 - Indicadores de desempenho - Cenário II

\begin{tabular}{|c|c|}
\hline \multicolumn{2}{|c|}{ Indicadores de Desempenho (Valores Anuais) } \\
\hline \multicolumn{1}{|c|}{ Cenário } & Cenário II \\
\hline Fluxo Logístico & Empurrado \\
\hline Risco Demanda (Var. Demanda) & Baixo \\
\hline Risco Fornecimento (Var. Lead time) & Baixo \\
\hline Lucro Líquido da cadeia de suprimento (MM R\$̣) & R\$ $\mathbf{1 0 2 , 9 4}$ \\
\hline Ruptura (Mil tons) & 5,00 \\
\hline
\end{tabular}

Fonte: O Autor 


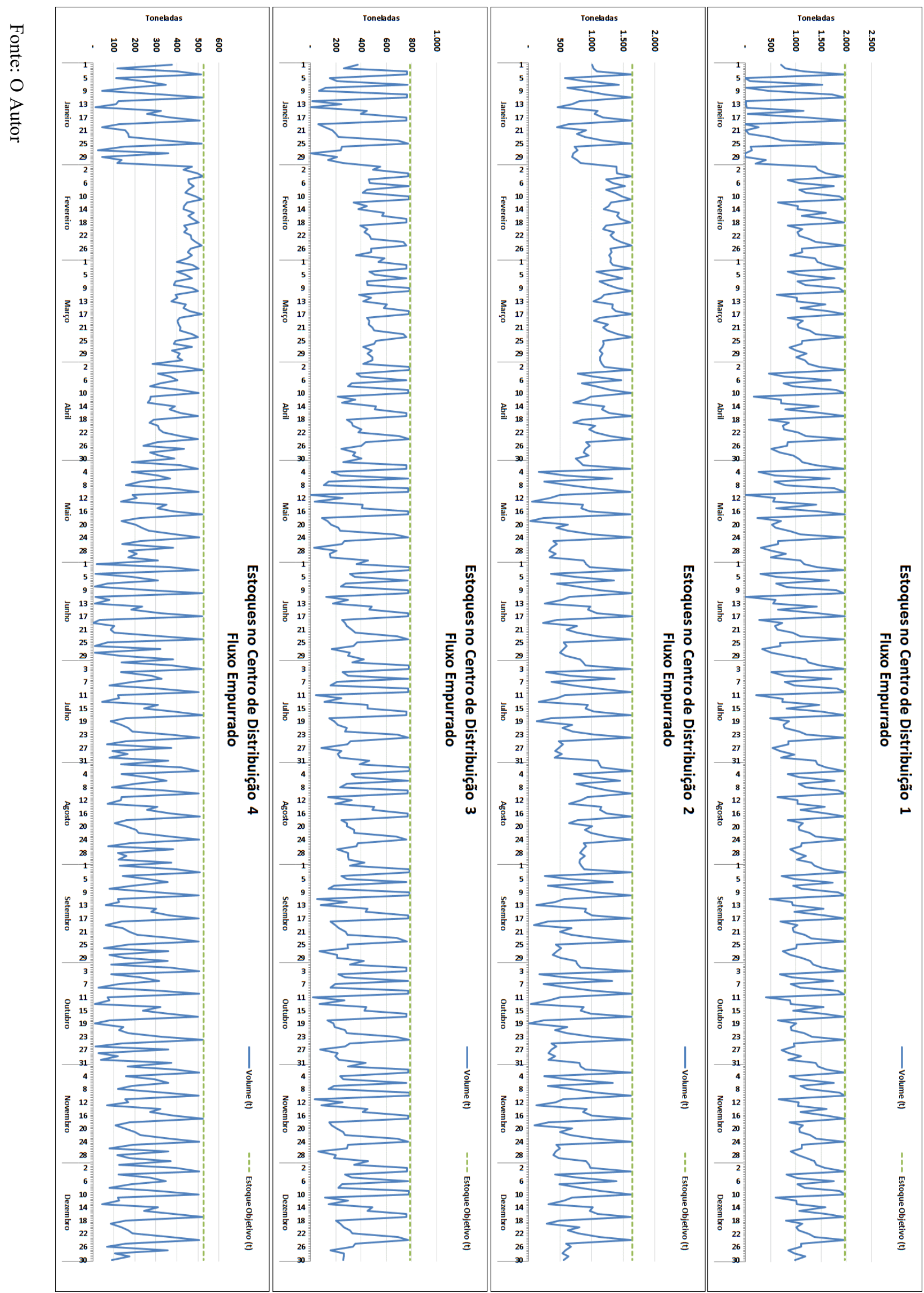

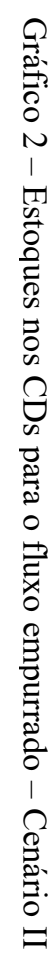




\subsection{CENÁRIO III}

Este cenário foi simulado considerando um baixo risco da demanda, alto risco de fornecimento e uma estratégia logística puxada. Os níveis de ruptura de estoques foram de 0,14 mil tons/ano e o lucro líquido atingido com esta operação foi de $\mathrm{R} \$ 111,03$ Milhões/ano. $\mathrm{O}$ gráfico 3 mostra a evolução dos estoques no período. A estratégia de operação simulada apresenta ser adequada ao cenário analisado, a alta variabilidade no abastecimento dos CDs teve pouco impacto nos resultados.

\begin{tabular}{|c|c|c|}
\hline \multicolumn{3}{|c|}{ DRE - Demonstrativo do Resultado do Exercício (Valores Anuais) } \\
\hline \multirow{2}{*}{ CONTAS - Valores em Millhões RS } & \multicolumn{2}{|c|}{ Cenário III } \\
\hline & \multicolumn{2}{|c|}{ Fluxo Puxado } \\
\hline 1 - Receita Bruta & $\mathbf{R} \mathbf{S}$ & 810,00 \\
\hline (-) Impostos sobre venda & $\mathrm{R} \$$ & 231,66 \\
\hline (=) Receita Líquida (1a) & $\mathbf{R} \boldsymbol{\$}$ & 578,34 \\
\hline 2 - Custo dos produtos vendidos & $\mathbf{R} \mathbf{S}$ & 271,31 \\
\hline 3 - Lucro Bruto (3 = 1a - 2 ) & RS & 307,03 \\
\hline 4 - Despesas Operacionais & $\mathbf{R} \mathbf{S}$ & 138,81 \\
\hline (-) Despesas administrativas & $\mathrm{R} \$$ & 9,04 \\
\hline (-) Fretes & $\mathrm{R} \$$ & 89,77 \\
\hline (-) Depreciação (4a) & $\mathrm{R} \$$ & 40,00 \\
\hline 5 - Lucro / Prejuízo antes do Imposto $(5=3-4)$ & $\mathbf{R} \mathbf{S}$ & 168,22 \\
\hline 6 - Tributos Federais (IR e CSLL) & $\mathbf{R} \mathbf{S}$ & 57,19 \\
\hline 7 - Resultado Líquido & $\mathbf{R} \mathbf{S}$ & 111,03 \\
\hline RESULTADO / RECEITA BRUTA & & $13,7 \%$ \\
\hline RESULTADO / RECEITA LÍQUIDA & & $19,2 \%$ \\
\hline 8 - Geração de Caixa - EBITDA (3 - $4+4 a)$ & $\mathbf{R} \mathbf{S}$ & 208,22 \\
\hline 9 - Margem EBITDA (8 / 1a) & & $36,0 \%$ \\
\hline
\end{tabular}

Tabela 9 - Indicadores de desempenho - Cenário III

\begin{tabular}{|c|c|}
\hline \multicolumn{2}{|c|}{ Indicadores de Desempenho (Valores Anuais) } \\
\hline Cenário & Cenário III \\
\hline Fluxo Logístico & Puxado \\
\hline Risco Demanda (Var. Demanda) & Baixo \\
\hline Risco Fornecimento (Var. Lead time) & Alto \\
\hline Lucro Líquido da cadeia de suprimento (MM R\$) & $\mathrm{R} \$ 111,03$ \\
\hline Ruptura (Mil tons) & 0,14 \\
\hline
\end{tabular}

Fonte: O Autor 


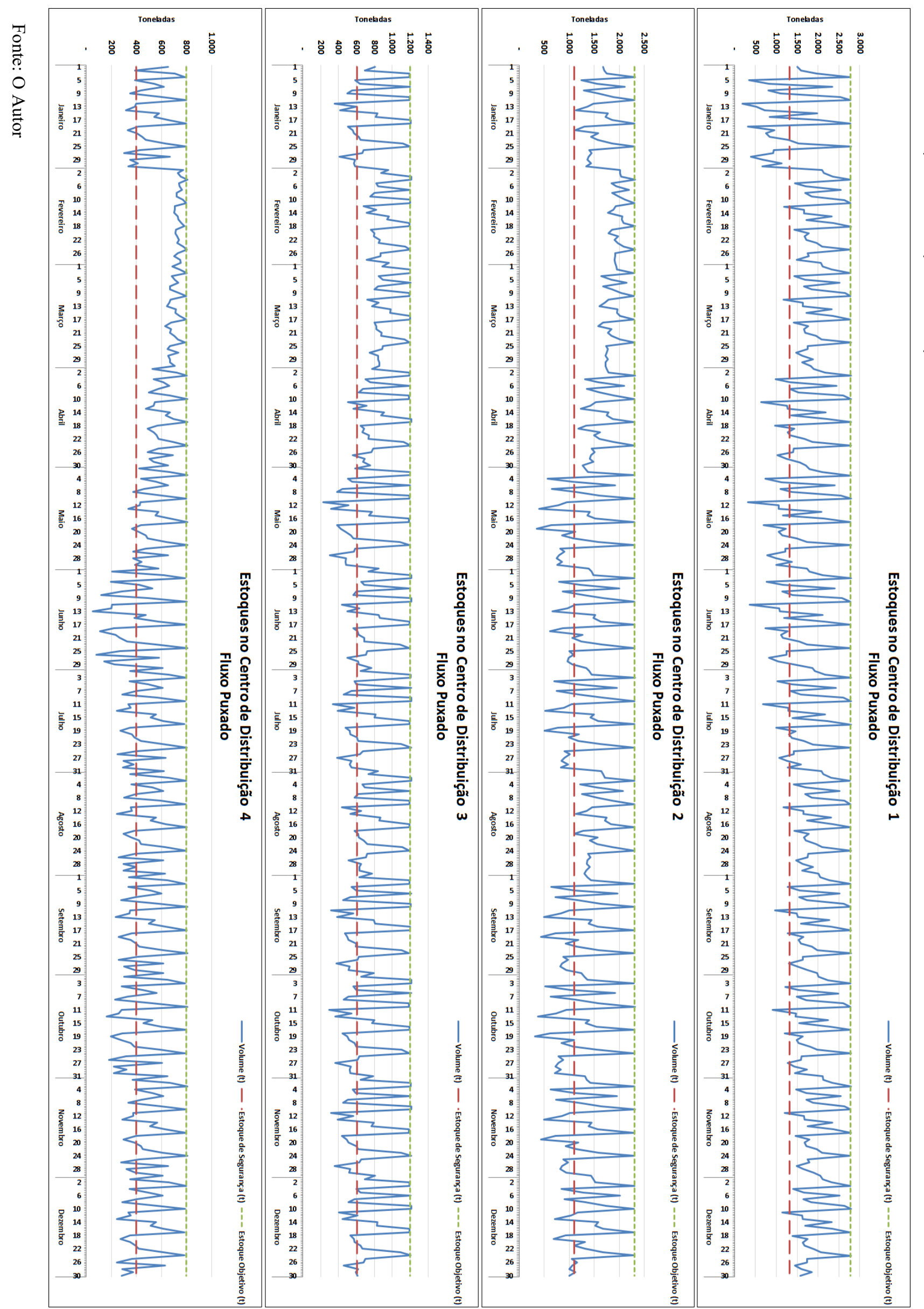




\subsection{CENÁRIO IV}

Este cenário foi simulado considerando um baixo risco da demanda, alto risco de fornecimento e uma estratégia logística empurrada. Os níveis de ruptura de estoques foram de 12,58 mil tons/ano e o lucro líquido atingido com esta operação foi de R \$106,85 Milhões/ano. O gráfico 4 mostra a evolução dos estoques no período. A estratégia de operação simulada apresenta ser adequada ao cenário analisado.

Tabela 10 - DRE Cenário IV

\begin{tabular}{|c|c|c|}
\hline \multirow{3}{*}{$\begin{array}{l}\text { CONTAS - Valores em Millhões RS } \\
\text { 1- Receita Bruta }\end{array}$} & \multirow{2}{*}{\multicolumn{2}{|c|}{$\begin{array}{c}\text { Cenário IV } \\
\text { Fluzo Empurrado }\end{array}$}} \\
\hline & & \\
\hline & $\mathrm{R} \$$ & 797,34 \\
\hline (-) Impostos sobre venda & $R \$$ & 228,04 \\
\hline (=) Receita Líquida (1a) & $\mathrm{R} S$ & 569,30 \\
\hline 2 - Custo dos produtos vendidos & $\mathrm{R} S$ & 269,45 \\
\hline 3 - Lucro Bruto $(3=1 a-2)$ & $\mathrm{R} S$ & 299,85 \\
\hline 4 - Despesas Operacionais & $\mathbf{R} \$$ & 137,96 \\
\hline (-) Despesas administrativas & RS & 8,98 \\
\hline$(-)$ Fretes & $R S$ & 88,98 \\
\hline (-) Depreciação (4a) & $\mathrm{R} \$$ & 40,00 \\
\hline 5 - Lucro / Prejuizo antes do Imposto $(5=3-4)$ & $\mathbf{R S}$ & 161,89 \\
\hline 6 - Tributos Federais (IR e CSLL) & $\mathbf{R S}$ & 55,04 \\
\hline 7 - Resultado Líquido & $\mathbf{R} \$$ & 106,85 \\
\hline RESULTADO / RECEITA BRUTA & & $13,4 \%$ \\
\hline RESULTADO / RECEITA LÍQUIDA & & $18,8 \%$ \\
\hline 8 - Geração de Caixa - EBITDA ( 3 - $4+4 a)$ & $\mathrm{RS}$ & 201,89 \\
\hline 9 - Margem EBITDA (8 / 1a) & & $35,5 \%$ \\
\hline
\end{tabular}

Fonte: O Autor

Tabela 11 - Indicadores de desempenho - Cenário IV

\begin{tabular}{|c|c|}
\hline \multicolumn{2}{|c|}{ Indicadores de Desempenho (Valores Anuais) } \\
\hline Cenário & Cenário IV \\
\hline Fluxo Logístico & Empurrado \\
\hline Risco Demanda (Var. Demanda) & Baixo \\
\hline Risco Fornecimento (Var. Lead time) & Alto \\
\hline Lucro Líquido da cadeia de suprimento (MM R\$) & $\mathbf{R} \mathbf{1 0 6 , 8 5}$ \\
\hline Ruptura (Mil tons) & $\mathbf{1 2 , 5 8}$ \\
\hline
\end{tabular}

Fonte: O Autor 


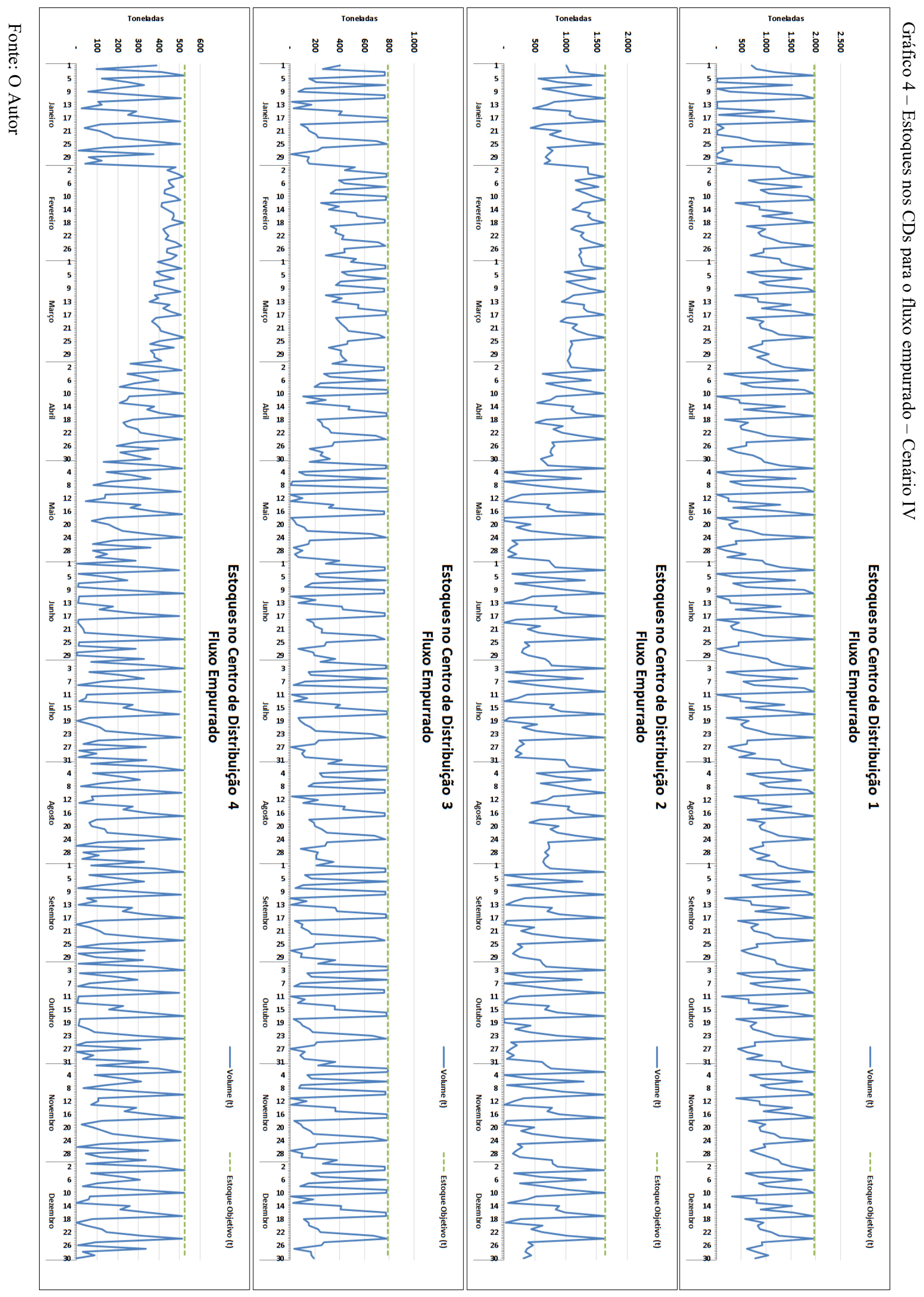




\subsection{CENÁRIO V}

Este cenário foi simulado considerando um alto risco da demanda, baixo risco de fornecimento e uma estratégia logística puxada. Os níveis de ruptura de estoques foram de 19,33 mil tons/ano e o lucro líquido atingido com esta operação foi de R \$111,29 Milhões/ano. O gráfico 5 mostra a evolução dos estoques no período. A estratégia de operação simulada apresenta ser adequada ao cenário analisado.

\begin{tabular}{|c|c|c|}
\hline \multicolumn{3}{|c|}{ DRE - Demonstrativo do Resultado do Exercício (Valores Anuais) } \\
\hline \multirow{2}{*}{ CONTAS - Valores em Millhões R\$ } & \multicolumn{2}{|c|}{ Cenário V } \\
\hline & \multicolumn{2}{|c|}{ Fluxo Puxado } \\
\hline 1 - Receita Bruta & $\mathbf{R} \mathbf{S}$ & 803,36 \\
\hline (-) Impostos sobre venda & $\mathrm{R} \$$ & 229,76 \\
\hline (=) Receita Líquida (1a) & $\mathbf{R} \mathbf{S}$ & 573,60 \\
\hline 2 - Custo dos produtos vendidos & $\mathbf{R} \mathbf{S}$ & 267,79 \\
\hline 3 - Lucro Bruto $(3=1 a-2)$ & $\mathbf{R} \mathbf{S}$ & 305,81 \\
\hline 4 - Despesas Operacionais & $\mathbf{R} \mathbf{S}$ & 137,19 \\
\hline (-) Despesas administrativas & $\mathrm{R} \$$ & 8,93 \\
\hline (-) Fretes & $\mathrm{R} \$$ & 88,26 \\
\hline (-) Depreciação (4a) & $\mathrm{R} \$$ & 40,00 \\
\hline 5 - Lucro / Prejuízo antes do Imposto $(5=3-4)$ & $\mathbf{R} \mathbf{S}$ & 168,63 \\
\hline 6 - Tributos Federais (IR e CSLL) & $\mathbf{R} \mathbf{S}$ & 57,33 \\
\hline 7 - Resultado Líquido & $\mathbf{R} \mathbf{\$}$ & 111,29 \\
\hline RESULTADO / RECEITA BRUTA & & $13,9 \%$ \\
\hline RESULTADO / RECEITA LÍQUIDA & & $19,4 \%$ \\
\hline 8 - Geração de Caixa - EBITDA (3 - 4 + 4a) & $\mathbf{R} \mathbf{S}$ & 208,63 \\
\hline 9 - Margem EBITDA (8 / 1a) & & $36,4 \%$ \\
\hline
\end{tabular}

Tabela 13 - Indicadores de desempenho - Cenário V

\begin{tabular}{|c|c|}
\hline \multicolumn{2}{|c|}{ Indicadores de Desempenho (Valores Anuais) } \\
\hline Cenário & Cenário V \\
\hline Fluxo Logístico & Puxado \\
\hline Risco Demanda (Var. Demanda) & Alto \\
\hline Risco Fornecimento (Var. Lead time) & Baixo \\
\hline Lucro Líquido da cadeia de suprimento (MM R\$) & R\$ 111,29 \\
\hline Ruptura (Mil tons) & 19,33 \\
\hline
\end{tabular}

Fonte: O Autor 


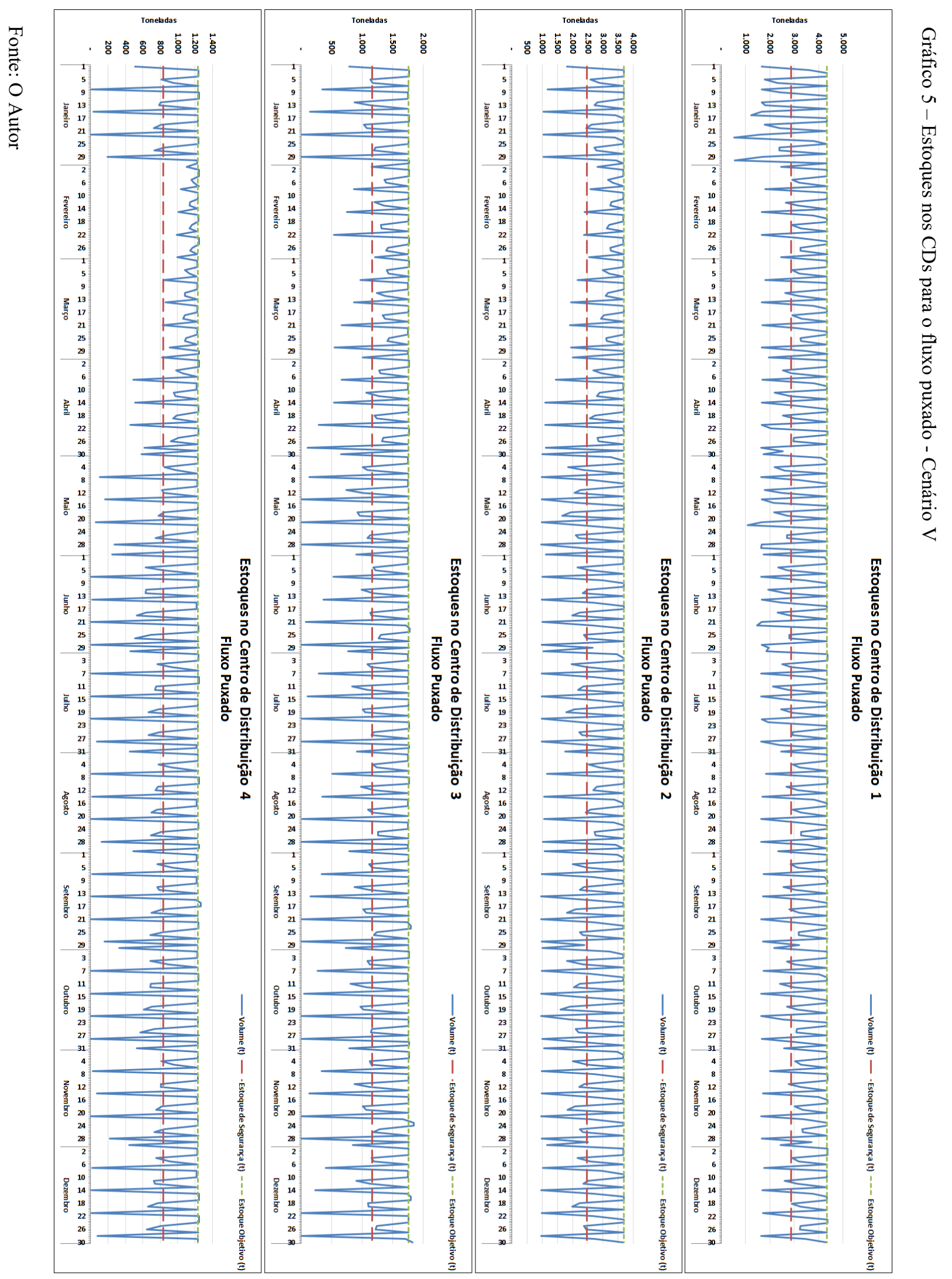




\subsection{CENÁRIO VI}

Este cenário foi simulado considerando um alto risco da demanda, baixo risco de fornecimento e uma estratégia logística empurrada. Os níveis de ruptura de estoques foram de 278,81 mil tons/ano e o lucro líquido atingido com esta operação foi de R\$92,89 Milhões/ano. O gráfico 6 mostra a evolução dos estoques no período. A estratégia de operação simulada não apresenta ser adequada ao cenário analisado.

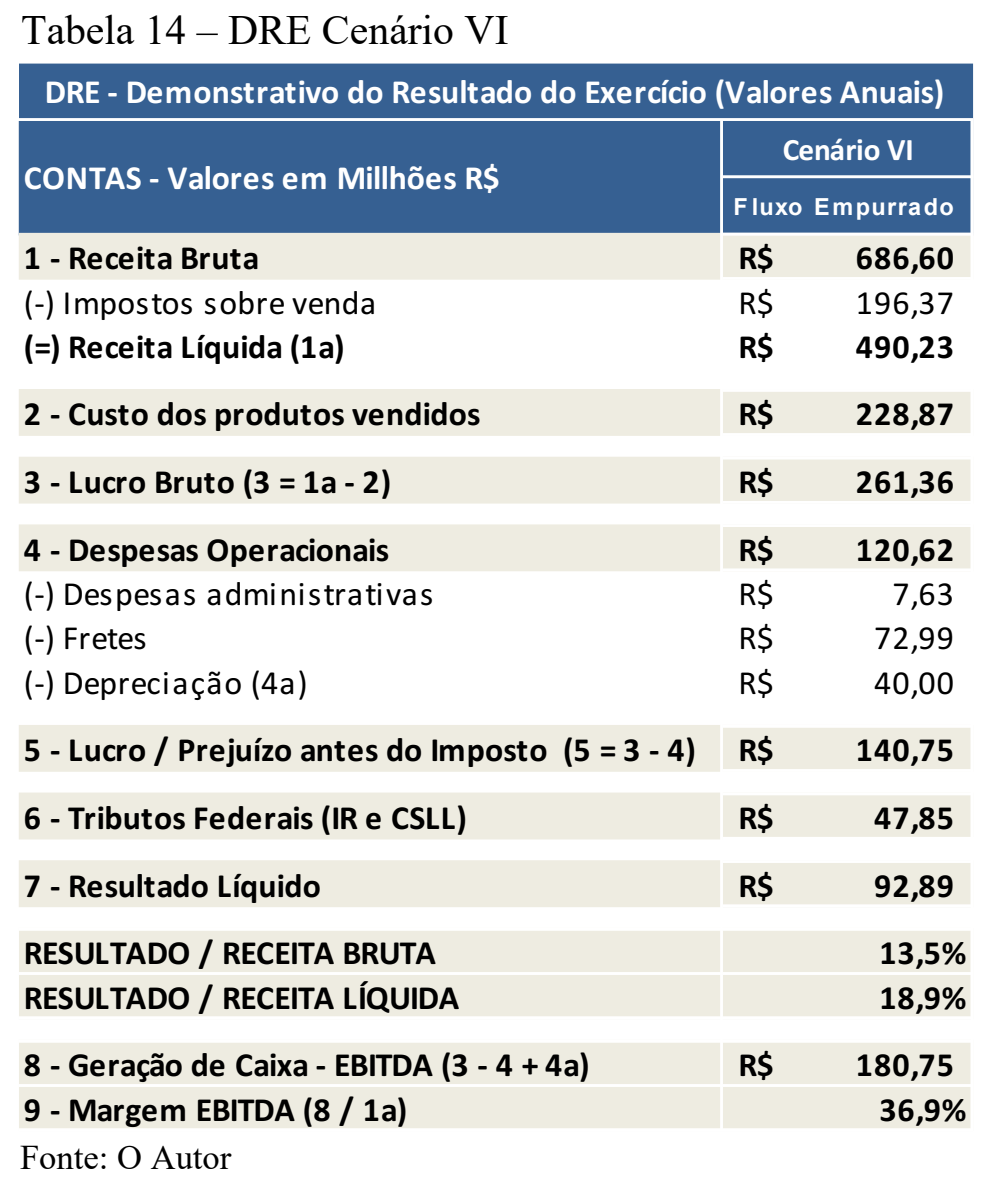

Tabela 15 - Indicadores de desempenho - Cenário VI

\begin{tabular}{|c|c|}
\hline \multicolumn{2}{|c|}{ Indicadores de Desempenho (Valores Anuais) } \\
\hline \multicolumn{1}{|c|}{ Cenário } & Cenário VI \\
\hline Fluxo Logístico & Empurrado \\
\hline Risco Demanda (Var. Demanda) & Alto \\
\hline Risco Fornecimento (Var. Lead time) & Baixo \\
\hline Lucro Líquido da cadeia de suprimento (MM R\$) & R\$ $\quad \mathbf{9 2 , 8 9}$ \\
\hline Ruptura (Mil tons) & $\mathbf{2 7 8 , 8 1}$ \\
\hline
\end{tabular}

Fonte: O Autor 


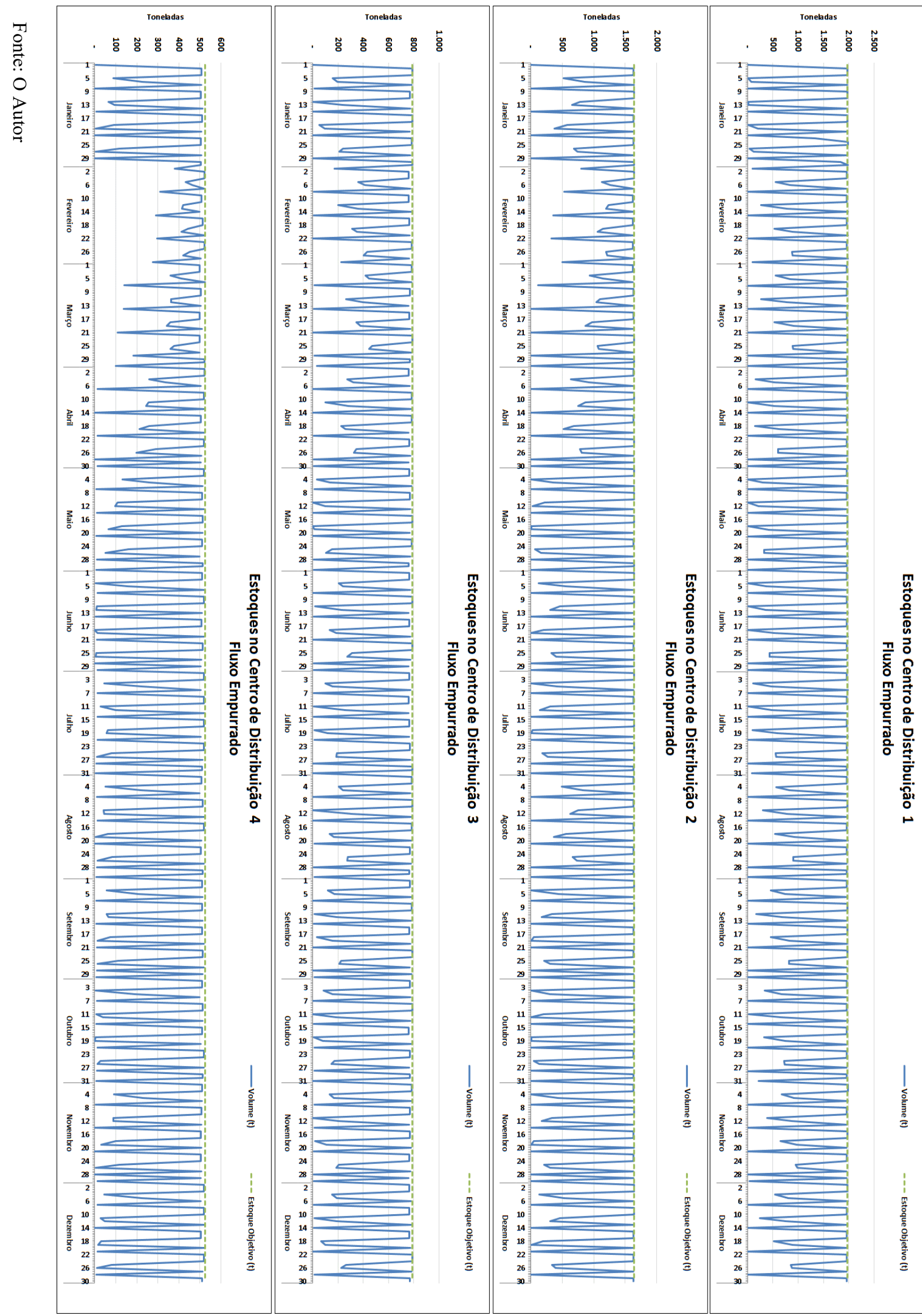




\subsection{CENÁRIO VII}

Este cenário foi simulado considerando um alto risco da demanda, alto risco de fornecimento e uma estratégia logística puxada. Os níveis de ruptura de estoques foram de 9,42 mil tons/ano e o lucro líquido atingido com esta operação foi de R\$112,11 Milhões/ano. O gráfico 7 mostra a evolução dos estoques no período. A estratégia de operação simulada apresenta ser adequada ao cenário analisado.

Tabela 16 - DRE Cenário VII.

\begin{tabular}{|c|c|c|}
\hline \multirow{3}{*}{$\begin{array}{l}\text { CONTAS - Valores em Millhões R\$̣ } \\
1 \text { - Receita Bruta }\end{array}$} & \multirow{2}{*}{\multicolumn{2}{|c|}{$\frac{\text { Cenário VII }}{\text { F luxo P uxado }}$}} \\
\hline & & \\
\hline & $\mathbf{R} \mathbf{S}$ & 807,83 \\
\hline (-) Impostos sobre venda & $\mathrm{R} \$$ & 231,04 \\
\hline (=) Receita Líquida (1a) & $\mathbf{R} \mathbf{S}$ & 576,79 \\
\hline 2 - Custo dos produtos vendidos & $\mathbf{R} \$$ & 269,28 \\
\hline 3 - Lucro Bruto (3 = 1a - 2) & $\mathbf{R} \mathbf{\$}$ & 307,51 \\
\hline 4 - Despesas Operacionais & $\mathbf{R} \mathbf{S}$ & 137,65 \\
\hline (-) Despesas administrativas & $\mathrm{R} \$$ & 8,98 \\
\hline (-) Fretes & $\mathrm{R} \$$ & 88,67 \\
\hline (-) Depreciação (4a) & $\mathrm{R} \$$ & 40,00 \\
\hline 5 - Lucro / Prejuízo antes do Imposto $(5=3-4)$ & $\mathbf{R} \mathbf{S}$ & 169,86 \\
\hline 6 - Tributos Federais (IR e CSLL) & $\mathbf{R} \mathbf{\$}$ & 57,75 \\
\hline 7 - Resultado Líquido & $\mathbf{R} \mathbf{S}$ & 112,11 \\
\hline RESULTADO / RECEITA BRUTA & & $13,9 \%$ \\
\hline RESULTADO / RECEITA LÍQUIDA & & $19,4 \%$ \\
\hline 8 - Geração de Caixa - EBITDA (3 - 4 + 4a) & $\mathbf{R} \mathbf{S}$ & 209,86 \\
\hline 9 - Margem EBITDA (8 / 1a) & & $36,4 \%$ \\
\hline
\end{tabular}

Fonte: O Autor

Tabela 17 - Indicadores de desempenho - Cenário VII

\begin{tabular}{|c|c|}
\hline \multicolumn{2}{|c|}{ Indicadores de Desempenho (Valores Anuais) } \\
\hline Cenário & Cenário VII \\
\hline Fluxo Logístico & Puxado \\
\hline Risco Demanda (Var. Demanda) & Alto \\
\hline Risco Fornecimento (Var. Lead time) & Alto \\
\hline Lucro Líquido da cadeia de suprimento (MM R\$) & $\mathbf{R} \$ \mathbf{1 1 2 , 1 1}$ \\
\hline Ruptura (Mil tons) & $\mathbf{9 , 4 2}$ \\
\hline
\end{tabular}

Fonte: O Autor 


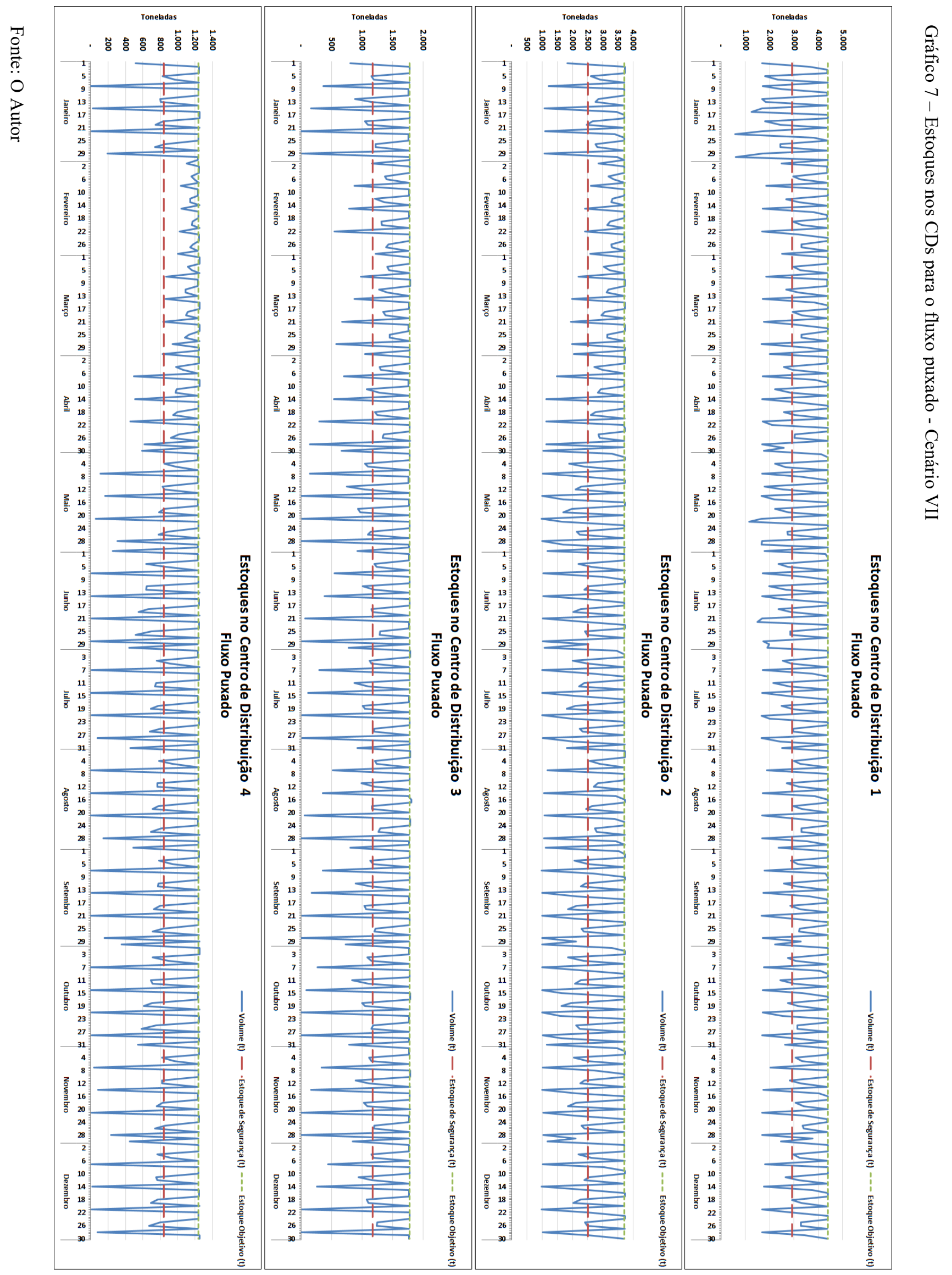




\subsection{CENÁRIO VIII}

Este cenário foi simulado considerando um alto risco da demanda, alto risco de fornecimento e uma estratégia logística empurrada. Os níveis de ruptura de estoques foram de 272,90 mil tons/ano e o lucro líquido atingido com esta operação foi de R \$93,3 Milhões/ano. O gráfico 8 mostra a evolução dos estoques no período. A estratégia de operação simulada não apresenta ser adequada ao cenário analisado;

\begin{tabular}{|c|c|c|}
\hline \multicolumn{3}{|c|}{ DRE - Demonstrativo do Resultado do Exercício (Valores Anuais) } \\
\hline \multirow{2}{*}{ CONTAS - Valores em Millhões RS } & \multicolumn{2}{|c|}{ Cenário VIII } \\
\hline & \multicolumn{2}{|c|}{ Fluxo Empurrado } \\
\hline 1 - Receita Bruta & $\mathrm{R} \$$ & 689,26 \\
\hline (-) Impostos sobre venda & $\mathrm{R} \$$ & 197,13 \\
\hline (=) Receita Líquida (1a) & RS & 492,13 \\
\hline 2 - Custo dos produtos vendidos & $\mathbf{R} \mathbf{S}$ & 229,75 \\
\hline 3 - Lucro Bruto $(3=1 a-2)$ & $\mathbf{R} \$$ & 262,38 \\
\hline 4 - Despesas Operacionais & $\mathbf{R} \mathbf{S}$ & 121,02 \\
\hline (-) Despesas administrativas & $\mathrm{R} \$$ & 7,66 \\
\hline (-) Fretes & $\mathrm{R} \$$ & 73,36 \\
\hline (-) Depreciação (4a) & $\mathrm{R} \$$ & 40,00 \\
\hline 5 - Lucro / Prejuízo antes do Imposto $(5=3-4)$ & $\mathbf{R} \$$ & 141,36 \\
\hline 6 - Tributos Federais (IR e CSLL) & $\mathbf{R} \mathbf{S}$ & 48,06 \\
\hline 7 - Resultado Líquido & $\mathbf{R} \$$ & 93,30 \\
\hline RESULTADO / RECEITA BRUTA & & $13,5 \%$ \\
\hline RESULTADO / RECEITA LÍQUIDA & & $19,0 \%$ \\
\hline 8 - Geração de Caixa - EBITDA (3 - 4 + 4a) & $\mathbf{R} \mathbf{S}$ & 181,36 \\
\hline 9 - Margem EBITDA (8 / 1a) & & $36,9 \%$ \\
\hline
\end{tabular}

Tabela 19 - Indicadores de desempenho - Cenário VIII

\begin{tabular}{|c|c|}
\hline \multicolumn{2}{|c|}{ Indicadores de Desempenho (Valores Anuais) } \\
\hline \multicolumn{1}{|c|}{ Cenário } & Cenário VIII \\
\hline \multicolumn{1}{|c|}{ Fluxo Logístico } & Empurrado \\
\hline Risco Demanda (Var. Demanda) & Alto \\
\hline Risco Fornecimento (Var. Lead time) & Alto \\
\hline Lucro Líquido da cadeia de suprimento (MM R\$) & $\mathbf{R} \mathbf{9 3 , 3 0}$ \\
\hline Ruptura (Mil tons) & $\mathbf{2 7 2 , 9 0}$ \\
\hline
\end{tabular}




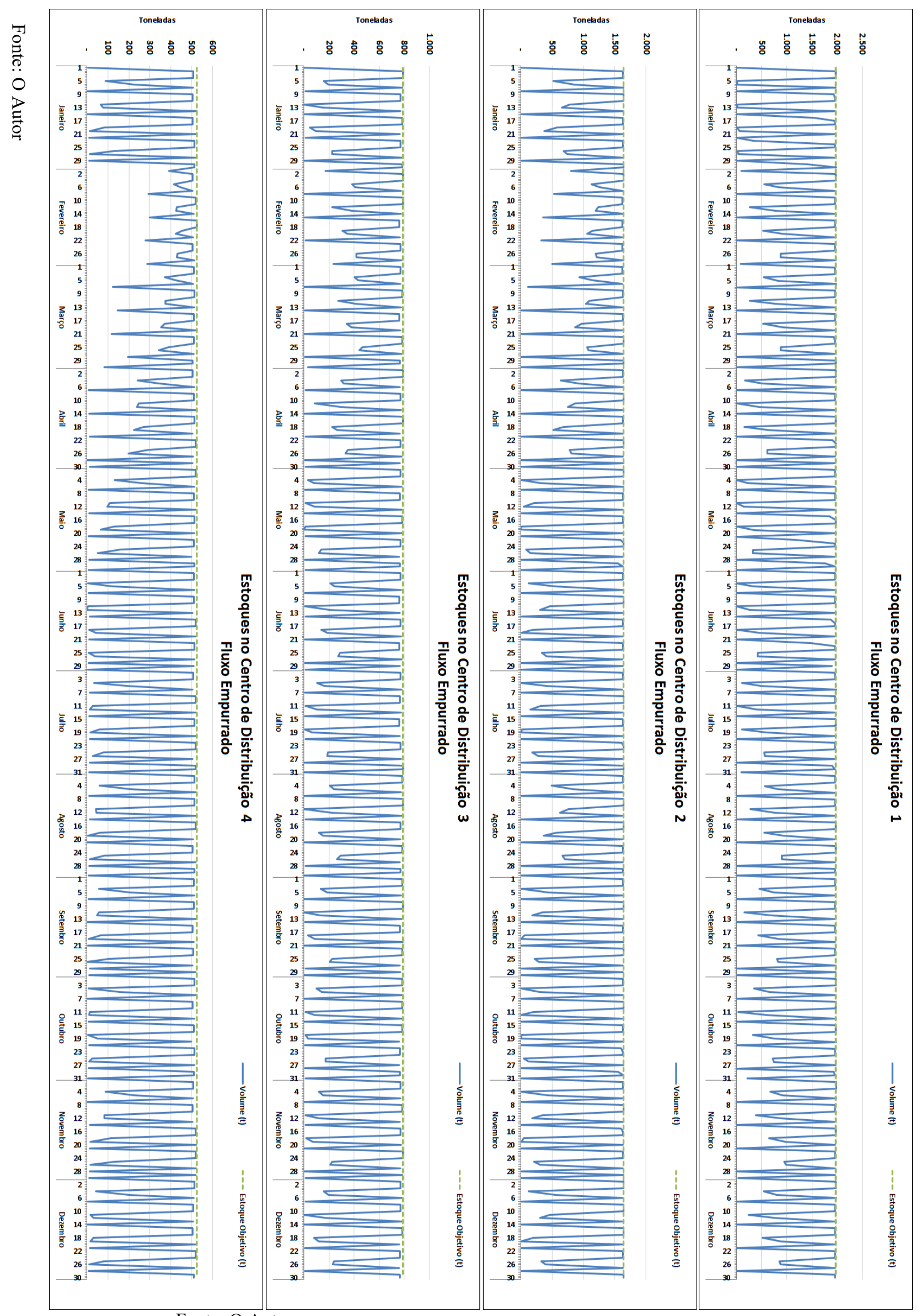


A tabela 20 resume os resultados dos indicadores obtidos com a simulação de cada cenário.

Tabela 20 - Resultados obtidos com a simulação

\begin{tabular}{|c|c|c|c|c|c|c|c|c|c|}
\hline \multicolumn{1}{|c|}{ Indicadores de Desempenho (Valores Anuais) } \\
\hline Cenários & Cenário I & Cenário II & Cenário III & Cenário IV & Cenário V & Cenário VI & Cenário VII & Cenário VIII \\
\hline Fluxo Logístico & Puxado & Empurrado & Puxado & Empurrado & Puxado & Empurrado & Puxado & Empurrado \\
\hline Risco Demanda (Var. Demanda) & Baixo & Baixo & Baixo & Baixo & Alto & Alto & Alto & Alto \\
\hline Risco Fornecimento (Var. Lead time) & Baixo & Baixo & Alto & Alto & Baixo & Baixo & Alto & Alto \\
\hline
\end{tabular}

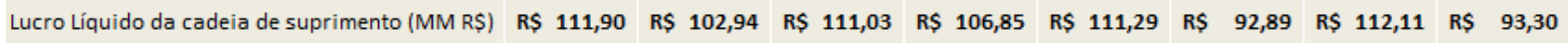

Ruptura (Mil tons)

$0,30 \quad 5,00 \quad 0,14$
$0,12,58$

19,33

278,81

9,42

272,90

Fonte: O Autor

Os indicadores de Ruptura e de Lucro Líquido são comparados e mostrados nos gráficos 9 e 10 respectivamente, para auxiliar as análises. A sigla RD significa Risco de Demanda e a sigla RF significa Risco de Fornecimento.

Gráfico 9 - Comparativo entre cenários - Ruptura (mil tons/ano)

\section{Ruptura (Mil Tons/ano)}

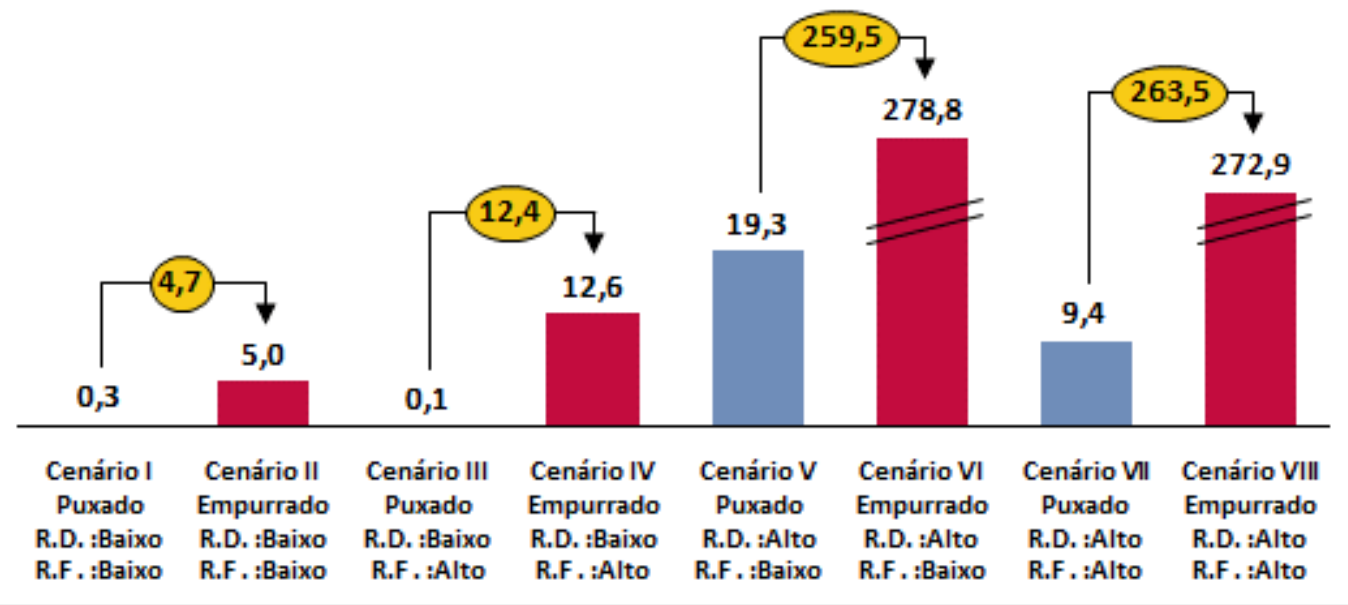

Fonte: O Autor

Gráfico 10 - Comparativo entre cenários - Lucro Líquido (MM R\$/ano) 


\section{Lucro Líquido (MM R\$̣)}

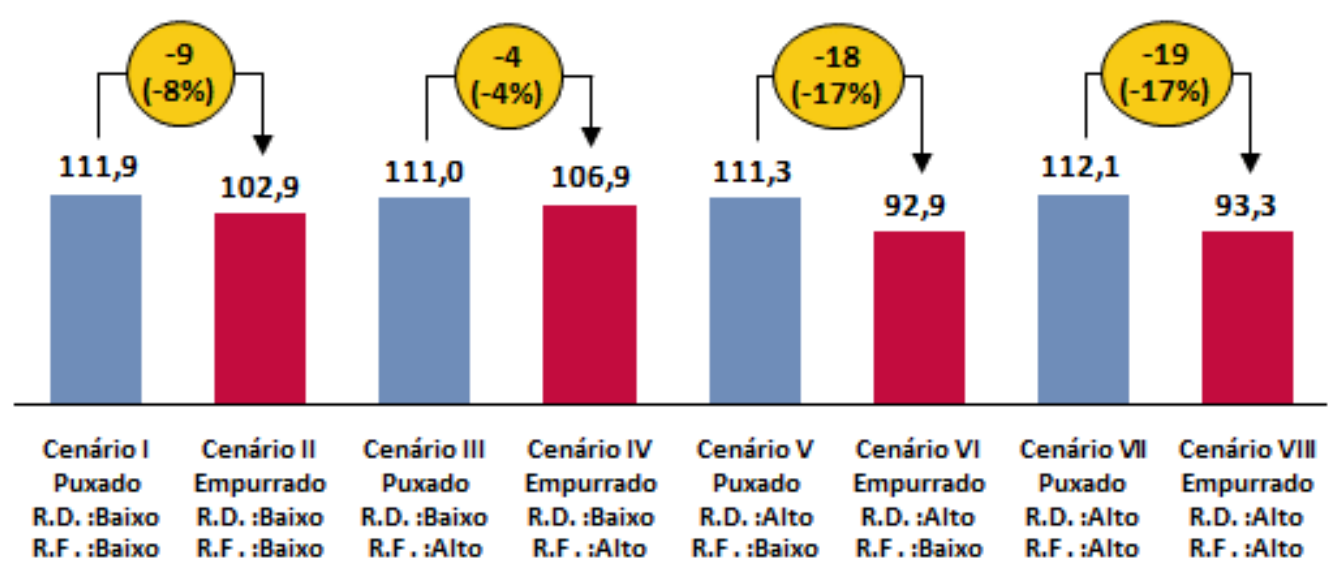

Fonte: O Autor

Com os dados obtidos em cada simulação pode-se responder as hipóteses propostas (Tabela 21).

Tabela 21 - Resultados das hipóteses propostas

\begin{tabular}{|c|l|c|}
\hline Hipótese & \multicolumn{1}{|c|}{ Descrição } & Resultado \\
\hline H1 & $\begin{array}{l}\text { Uma cadeia de suprimento de cimento com baixo risco de demanda e baixo risco de fornecimento } \\
\text { vai ter uma melhor lucratividade com a estratégia de cadeia de suprimento puxada do que com } \\
\text { cadeia de suprimento empurrada. }\end{array}$ & Verdadeira \\
\hline H2 & $\begin{array}{l}\text { Uma cadeia de suprimento de cimento com baixo risco de demanda e alto risco de fornecimento } \\
\text { vai ter uma melhor lucratividade com a estratégia de cadeia de suprimento puxada do que com } \\
\text { cadeia de suprimento empurrada. }\end{array}$ & Verdadeira \\
\hline H3 & $\begin{array}{l}\text { Uma cadeia de suprimento de cimento com alto risco de demanda e baixo risco de fornecimento } \\
\text { vai ter uma melhor lucratividade com a estratégia de cadeia de suprimento puxada do que com } \\
\text { cadeia de suprimento empurrada. }\end{array}$ & Verdadeira \\
\hline H4 & $\begin{array}{l}\text { Uma cadeia de suprimento de cimento com alto risco de demanda e alto risco de fornecimento vai } \\
\text { ter uma melhor lucratividade com a estratégia de cadeia de suprimento puxada do que com cadeia } \\
\text { de suprimento empurrada. }\end{array}$ & Verdadeira \\
\hline
\end{tabular}

Fonte: O Autor

As hipóteses propostas são verdadeiras. Em todos os cenários gerados houve maior lucratividade da empresa adotando-se a estratégia de cadeia de suprimentos puxada. 
Para efeito de análise, são comparados os resultados das simulações de cada fluxo operacional (puxado e empurrado) isoladamente a fim de se compreender os impactos dos riscos de demanda e de fornecimento em cada fluxo. São realizadas quatro comparações em cada grupo, alternando-se os níveis dos riscos de Fornecimento e de Demanda (alto e baixo).

A lucratividade da empresa não sofre impacto significativo (maior ou menor em 5\%) com a variação do fornecimento ou da demanda conforme pode-se observar nos respectivos gráficos 11 e 12. Pode-se afirmar que a lucratividade da empresa é mantida em todos os cenários de fluxo puxado simulados.

Gráfico 11 - Fluxo Puxado - Comparativo de Risco de Fornecimento

\section{Lucro Líquido (MM R\$̣/ano)}

Comparativo - Risco de Fornecimento Baixo / Alto

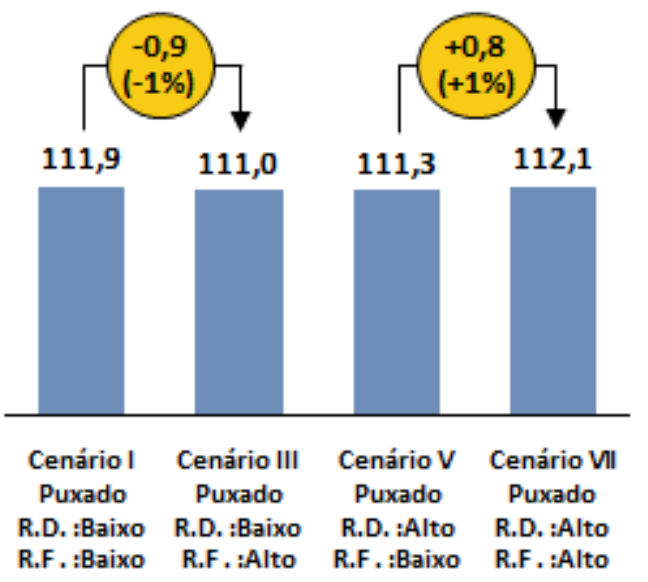

Fonte: O Autor 
Gráfico 12 - Fluxo Puxado - Comparativo de Risco de Demanda

\section{Lucro Líquido (MM R\$\$/ano)}

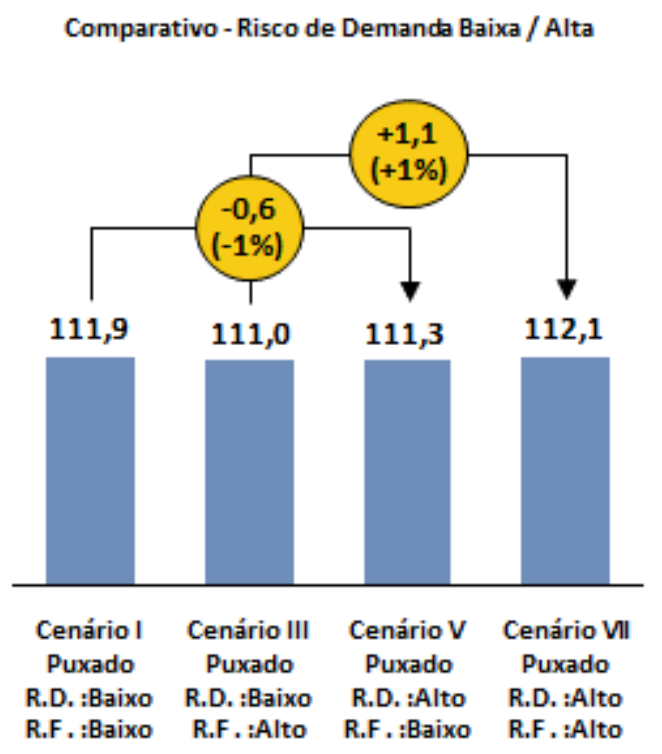

Fonte: O Autor

A lucratividade da empresa não sofre impacto significativo (maior ou menor em 5\%) com a variação do fornecimento no fluxo empurrado (Gráfico 13), para a empresa estudada as distâncias entre o CD Central e os CDs regionais são curtas (média de $150 \mathrm{Km}$ ) e, portanto, as variações no tempo de fornecimento que possam causar falta de produto são pequenas e cobertas pelo estoque do CD.

A lucratividade da empresa sofre impacto significativo quando existe variabilidade na demanda como pode ser observado no gráfico 14. O fluxo empurrado é sensível a este risco.

Pode-se afirmar que a lucratividade da empresa é mantida nos cenários de fluxo empurrado onde exista variação de lead time porém não é mantida caso ocorram variabilidade na demanda. 
Gráfico 13 - Fluxo Empurrado - Comparativo de Risco de Fornecimento

\section{Lucro Líquido (MM R\$̣/ano)}

Comparativo - Risco de Fornecimento Baixo / Alto

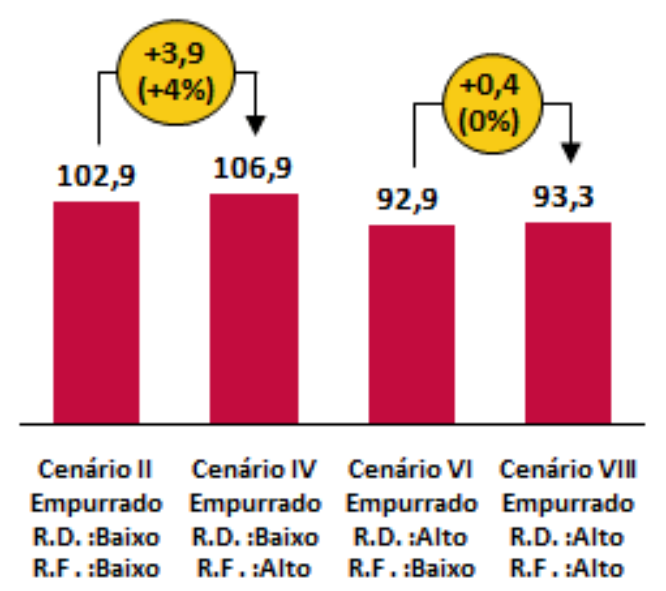

Fonte: O Autor

Gráfico 14 - Fluxo Empurrado - Comparativo de Risco de Demanda

\section{Lucro Líquido (MM R\$\$/ano)}

Comparativo - Risco de Demande Baixa / Alta

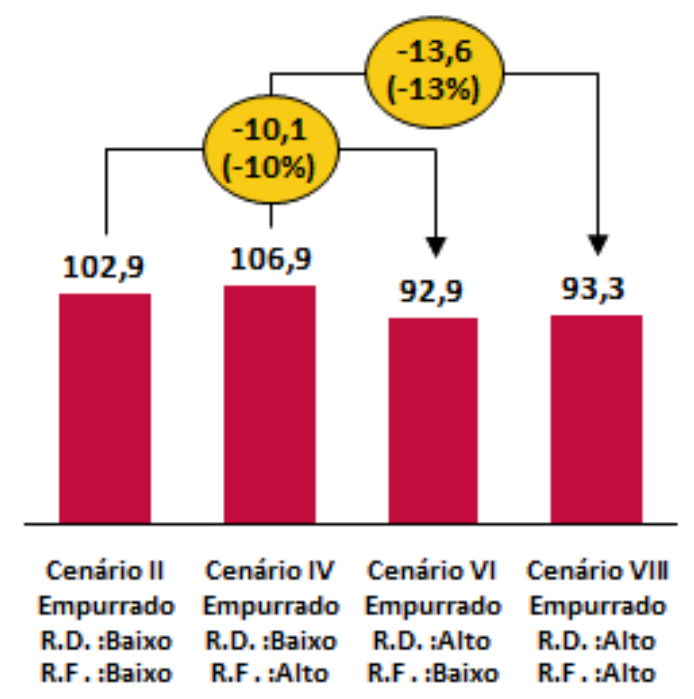

Fonte: O Autor 


\section{CONCLUSÕES}

A indústria do cimento tem como característica ser considerada uma atividade de capital intensivo devido ao grande investimento necessário para implantação de uma unidade e é desenhada para gerar economias de escala. A produção é um processo contínuo e altamente automatizado com o objetivo de atingir um plano de vendas. A produção é make-to-stock, o produto final é enviado para centros de distribuição, aguardando a venda.

Nota-se, porém, que em determinadas situações de incerteza de mercado onde exista oscilação na demanda, são registrados maiores níveis de ruptura de estoque, afetando a rentabilidade do negócio.

Como resultado da simulação, pode-se observar que a ruptura de estoque registrada é menor nos cenários de fluxos logísticos puxados, isto se reflete na disponibilidade do produto no ponto de venda, consequentemente gerando um maior faturamento para a empresa.

A ruptura dos estoques e consequentemente queda no faturamento é maior nos cenários de fluxos logísticos empurrados, quando afetado pela variabilidade da demanda.

Estes fatos podem ser comprovados analisando-se os indicadores de performance calculados em cada cenário.

Pode-se concluir que não é possível generalizar qual o melhor modelo de distribuição para a indústria de cimentos. Pode-se afirmar que a distribuição é sensível à influência da variação da demanda do produto, conforme demonstra a teoria de Simchi Levi, Kaminsky e Simchi Levi (2010).

As simulações realizadas demonstram que para garantir ganho de escala, desde que a demanda possua baixa variabilidade, o fluxo logístico ideal é o empurrado. Com a elevação do nível de variação da demanda, a ruptura dos estoques se eleva causando perda de vendas e, consequentemente, reduzindo o faturamento e a lucratividade da empresa. A partir de determinado nível de variabilidade na demanda, o fluxo logístico adotado deve ser o puxado.

Portanto os ganhos financeiros obtidos com a implementação do fluxo logístico puxado serão representativos caso exista grande variabilidade na demanda.

Foram realizadas buscas nos principais bancos de dados de periódicos como o Proquest, EBSCO, ScinceDirect e outros, com a finalidade de encontrar pesquisas sobre o tema estudado. Com foco em indústrias de cimentos foram encontrados poucos trabalhos tratando do tema com a mesma especificidade, portanto é possível considerar que esta pesquisa possua grande 
relevância para esta indústria.

O modelo computacional desenvolvido representa a realidade das operações logísticas da empresa analisada, é confiável para analisar os benefícios dos fluxos puxados e empurrados, bem como quaisquer processos logísticos que se deseje operar virtualmente.

A adoção do modelo puxado de distribuição em determinadas situações é benéfica para a empresa, porém depende de um grande esforço no desenvolvimento de controles e projeções de demanda precisos, possivelmente com auxílio de softwares específicos e práticas de S\&OP.

Conclui-se que o comportamento da demanda exerce influência na cadeia de suprimentos da indústria analisada e pode determinar a maneira de se controlar o fluxo de distribuição (puxado ou empurrado) dependendo do nível de variabilidade que possua.

Com a evolução do trabalho, foram surgindo sugestões que podem ser aplicadas em futuras pesquisas, como o desenvolvimento de um modelo que avalie o impacto de abertura de centros de distribuição mais distantes para atingir novos mercados e o impacto de trabalhar com multiproduto. Cada opção deve ser analisada a luz da teoria existente e servem como propostas para o desenvolvimento de novos trabalhos voltados à indústria cimenteira. 


\section{REFERÊNCIAS}

Associação Brasileira de Cimento Portland, (ABCP).2015. Disponível em $<$ http://www.abcp.org.br>. Acesso em: Abr. 2015.

CHOPRA, Sunil; MEINDL, Peter. Gerenciamento da Cadeia de Suprimentos: Estratégia, Planejamento, e Operação. In: Gerenciamento da Cadeia de Suprimentos: Estratégia, Planejamento, e Operação. Pearson Prentice Hall, 2003.

CHRISTOPHER, Martin. Logística e gerenciamento da cadeia de suprimentos. Cengage Learning, 2011.

CHWIF, Leonardo; MEDINA, Afonso Celso. Modelagem e simulação de eventos discretos. Afonso C. Medina, 2010.

COOPER, M. Bixby; BOWERSOX, D.; CLOSS, D. Gestão da Cadeia de Suprimentos e Logística. 2007.

CORRÊA, Henrique Luiz. Gestão de redes de suprimento: integrando cadeias de suprimento no mundo globalizado. São Paulo: Atlas, 2010.

GAlHARDO, Pedro Gutierrez. Estudo da Produção de Cimento com Ênfase no Classe G. 2014. Tese de Doutorado. Universidade Federal do Rio de Janeiro.

GIL, Antonio Carlos. Como elaborar projetos de pesquisa. São Paulo: Atlas, 2002.

GOMES, Roger; MENTZER, John T. The influence of just-in-time systems on distribution channel performance in the presence of environmental uncertainty. Transportation journal, p. 36-48, 1991.

HARRELL, Charles R.; PRICE, Rochelle N. Promodel: simulation modeling using promodel technology. In: Proceedings of the 34th conference on Winter simulation: exploring new frontiers. Winter Simulation Conference, 2002. p. 192-198.

LAKATOS, E. M.; MARCONI, M. de A., Metodologia do trabalho científico. São Paulo: Atlas, 1991.

LEAL, F.; ALMEIDA, D.A. de \& MONTEVECHI, J.A.B. Uma Proposta de Técnica de Modelagem Conceitual para a Simulação através de elementos do IDEF. In: Anais do XL Simpósio Brasileiro de Pesquisa Operacional, João Pessoa, PB, 2008. 
LU, Ming; WONG, Lap-Chi. Comparing PROMODEL and SDESA in modeling construction operations. In: Simulation Conference, 2005 Proceedings of the Winter. IEEE, 2005. p. 9 pp.

MANUJ, Ila; MENTZER, John T.; BOWERS, Melissa R. Improving the rigor of discrete-event simulation in logistics and supply chain research. International Journal of Physical Distribution \& Logistics Management, v. 39, n. 3, p. 172-201, 2009.

MENTZER, John T.; GOMES, Roger. The strategic planning model: a pc-based dynamic, stochastic, simulation DSS generator for managerial planning. Journal of Business Logistics, v. 12, n. 2, p. 193, 1991.

MIGUEL, Paulo Augusto Cauchick. Metodologia de pesquisa em engenharia de produção e gestão de operações. Elsevier, 2010.

MONTEVECHI, José Arnaldo Barra et al. Conceptual modeling in simulation projects by mean adapted IDEF: an application in a Brazilian tech company. In: Proceedings of the Winter Simulation Conference. Winter Simulation Conference, 2010. p. 1624-1635.

PIDD, Michael. Systems Modelling Theory and Practice. John Wiley \& Sons, Ltd, 2004.

ROBINSON, Stewart. Simulation: the practice of model development and use. Chichester: John Wiley \& Sons, 2004.

SARGENT, R.G. Verification and validation of simulation models. In: Proceedings of the Winter Simulation Conference, Austin, USA, 2009.

SASTRY, G. G.; SAXENA, M.; UPADHAYA, Nitin. A Review On Pull Control Systems In Manufacturing. International Journal of Emerging Trends in Engeneering and Development. Issue 2, vol 7, 2012.

SHANNON, Robert E. Introduction to the art and science of simulation. In:Proceedings of the 30th conference on Winter simulation. IEEE Computer Society Press, 1998. p. 7-14.

SIMCHI-LEVI, David; KAMINSKY, Philip; SIMCHI-LEVI, Edith. Cadeia de suprimentos projeto e gestão: conceitos, estratégias e estudos de caso. Bookman, 2010.

Sindicato Nacional da Indústria do Cimento (SNIC). 2013. Relatório Anual, 2013. Disponível em: <http://www.snic.org.br/pdf/RelatorioAnual2013final.pdf >. Acesso em: dez. 2014.

TORGA, Bruno Lopes Mendes. Modelagem, simulação e otimização em sistemas puxados de manufatura. 2007. Tese de Doutorado. UNIVERSIDADE FEDERAL DE ITAJUBÁ. 
YIN, Robert K. Estudo de Caso. Planejamento e Métodos. $3^{\circ}$ Edição. Porto Alegre: Bookman, 2005.

WILSON, R. (2006), "17th annual state of logistics report”, Council of Supply Chain Management Professionals, Washington, DC, 2006, pp. 1-20. 